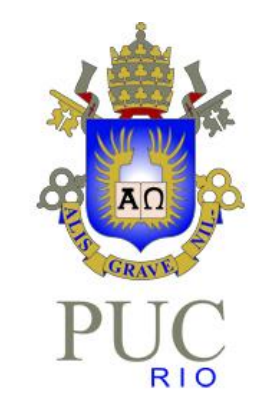

Rodrigo Almeida da Fonseca

Modelo de previsão de volatilidade de índice de ações utilizando fatores extraídos de variáveis de risco de crédito, taxa de juros, moedas e commodities

Dissertação de Mestrado

Dissertação apresentada como requisito parcial para obtenção do grau de Mestre pelo Programa de PósGraduação em Economia da PUC-Rio.

Orientador: Prof. Marcelo Cunha Medeiros 
Rodrigo Almeida da Fonseca

\title{
Modelo de previsão de volatilidade de índice de ações utilizando fatores extraídos de variáveis de risco de crédito, taxa de juros, moedas e commodities
}

\begin{abstract}
Dissertação apresentada como requisito parcial para obtenção do grau de Mestre pelo Programa de Pós-Graduação em Macroeconomia e Finanças do Departamento de Economia do Centro de Ciências Sociais da PUC-Rio. Aprovada pela Comissão Examinadora abaixo assinada.
\end{abstract}

Prof. Marcelo Cunha Medeiros Orientador

Departamento de Economia - PUC-Rio

Prof. Ruy Monteiro Ribeiro Departamento de Economia - PUC-Rio

Prof. Caio Ibsen de Almeida EPGE - FGV

Profa. Mônica Herz Coordenadora do Centro de Ciências Sociais - PUC-Rio 
Todos os direitos reservados. É proibida a reprodução total ou parcial do trabalho sem autorização da universidade, do autor e do orientador.

Rodrigo Almeida da Fonseca

Graduou-se em Engenharia Mecânica-Aeronáutica pelo Instituto Tecnológico de Aeronáutica (ITA - São José dos Campos, SP). Cursou o Mestrado Profissional em Macroeconomia e Finanças, com ênfase em Finanças, pelo Departamento de Economia da PUC-Rio.

Ficha Catalográfica

Fonseca, Rodrigo Almeida da
Modelo de previsão de volatilidade de índice de
ações utilizando fatores extraídos de variáveis de risco de
crédito, taxa de juros, moedas e commodities / Rodrigo
Almeida da Fonseca ; orientador: Marcelo Cunha
Medeiros. - 2017.
83 f. : il. color. ; 30 cm
Dissertação (mestrado)-Pontifícia Universidade
Católica do Rio de Janeiro, Departamento de Economia,
2017. $\quad$ Inclui bibliografia
1. Economia - Teses. 2. Modelo de precificação
por fatores. 3. Volatilidade. 4. Modelo GARCH. I. Medeiros,
Marcelo Cunha. II. Pontifícia Universidade Católica do Rio
de Janeiro. Departamento de Economia. III. Título.




\section{Agradecimentos}

Agradeço a todas as pessoas que me ajudaram durante essa trajetória no Mestrado e na construção desta Dissertação, em especial à minha noiva Vivian, minha família e amigos. Agradeço também ao meu orientador Prof. Dr. Marcelo Cunha Medeiros pelo conhecimento transmitido e por me guiar ao longo da confecção deste trabalho. Por fim, agradeço à PUC-Rio e ao Departamento de Economia pela estrutura e pelo curso que foram fundamentais para a minha formação pessoal e professional. 


\section{Resumo}

Almeida da Fonseca, Rodrigo; Cunha Medeiros, Marcelo. Modelo de previsão de volatilidade de índice de ações utilizando fatores extraídos de variáveis de risco de crédito, taxa de juros, moedas e commodities. Rio de Janeiro, 2017. 83p. Dissertação de Mestrado Departamento de Economia, Pontifícia Universidade Católica do Rio de Janeiro.

Esta Dissertação apresenta um modelo para extrair fatores capazes de prever a volatilidade do índice de ações IBOVESPA, representativo do mercado de ações brasileiro. Esta metodologia é diferenciada por utilizar fatores que não incluem ativos da classe de ações. São utilizados fatores extraídos de classes de ativos de crédito, taxas de juros, moedas e commodities para precificar a volatilidade de um índice de ações. Além disso, os fatores são extraídos de painéis de volatilidades filtradas por modelos do tipo $\mathrm{GARCH}$.

\section{Palavras-chave}

Modelo de precificação por fatores; Volatilidade; Modelo GARCH 


\section{Abstract}

Almeida da Fonseca, Rodrigo; Cunha Medeiros, Marcelo. Volatility Forecast Model for market index using factors extracted from Credit Risk, Interest Rates, Exchange Rates and Commodities panels. Rio de Janeiro, 2017. 83p. Dissertação de Mestrado - Departamento de Economia, Pontifícia Universidade Católica do Rio de Janeiro.

It will be presented a model that is able to extract factors capable of predicting the volatility of IBOVESPA market index, which is representative of Brazilian equity market. This methodology is different from others because it won't use any inputs from equity asset classes. It will be used factors extracted from credit risk, interest rates, exchange rates and commodities data for pricing the volatility of an equity index. Besides that, those factors will be extracted from panels of volatility filtered by GARCH models.

\section{Keywords}

Factor asset pricing models; Volatility; GARCH models 


\section{Sumário}

1 Introdução 1

2 Características dos Fatores e Estudo de Correlações 12

3 Estimação dos Fatores $\quad 20$

4 Índice de Volatilidade e Variance Premium 23

5 Resultados 25

5.1. Índice de Volatilidade 25

5.2. Variance Premium 32

6 Conclusões $\quad 37$

Referências Bibliográficas $\quad 40$

$\begin{array}{ll}\text { Anexo - } 1 & 41\end{array}$ 


\section{Introdução}

Esta Dissertação apresenta um modelo para extrair fatores que se mostram eficientes em prever a volatilidade do índice IBOVESPA, representativo do mercado de ações brasileiro. Em particular, será previsto um índice de volatilide do IBOVESPA e o "Variance Premium" extraído também do IBOVESPA. Ambos são construídos pela FEA-USP usando metodologias próprias. Este modelo se mostra diferenciado por: (i) não utilizar variáveis da classe de ativos de ações. A metodologia utiliza fatores extraídos de variáveis das classes de ativos de crédito, taxas de juros de curto-prazo, moedas e commodities; (ii) extrair fatores de painéis de volatilidades filtradas por modelo do tipo GARCH.

A metodologia se baseia no método desenvolvido por Andreou e Ghysels (2014) porém adaptado a variáveis brasileiras. O objetivo é mostrar empiricamente as mesmas relações do paper original, porém fazendo as adaptações nos fatores para utilizar aqueles que se relacionam melhor com o Brasil.

O modelo procura se diferenciar das metodologias usuais uma vez que não utiliza fatores extraídos das próprias classes de ações para prever uma volatilidade de índice de ações. Da mesma forma, não será utilizado nenhum fator que seja obtido através de ativos da classe de opções, como volatilidades implícitas. Essa metodologia baseada em volatilidades implícitas já foi amplamente explorada pela literatura atual como em Carr e Wu (2009), Egloff, Leippold, e Wu (2010), Zhou (2010), Bakshi, Panayotov e Skoulakis (2011) e portanto não será foco desta metodologia.

Todas as estimativas de volatilidade usadas para construir os fatores que serão a base da metodologia serão provenientes de filtros por modelos GARCH. Esses modelos também possuem ampla cobertura pela literatura atual e seus detalhes não serão alvo de ampla discussão nesta Dissertação. Os modelos do tipo GARCH foram escolhidos por proporcionarem boas estimativas de volatilidades para as séries com frequência diária ou semanais que compõem os painéis construídos para os modelos. Não optou-se por dados intra-diários ou mensais como outros artigos acadêmicos porque não seria possível obter-se 
dados suficientes para as amostras com esta frequência em todas as variáveis utilizadas.

É possível comparar o modelo desta Dissertação com outros modelos de extração de fatores e precificação por fatores. Existem na literatura diversos casos em que a precificação de ativos da classe de ações são realizados por fatores extraídos desta mesma classe. O modelo mais famoso deste tipo é o FamaFrench, cujos fatores são totalmente confinados na mesma classe de ativos. Também são conhecidos os trabalhos em que são extraídos o nível, a inclinação e a curvatura da estrutura a termo da taxa de juros como sendo os principais fatores para essa classe de ativos. Todos esses modelos demonstram as metodologias que buscam precificar determinados ativos com fatores extraídos dentro da sua própria classe de ativos.

A metodologia aqui apresentada, conforme descrito anteriormente, não será confinada dentro da mesma classe de ativos que busca prever. Serão construídos painéis distintos, cada um concentrado em alguma classe de ativos exclusivamente. Cada painel passa então por uma Análise de Componentes Principais (PCA) e o primeiro fator é extraído. Em seguida, este fator passa por um filtro $\mathrm{GARCH}$ e a volatilidade estimada é retirada. Dessa forma, cada fator utilizado pode ser interpretado como a volatilidade do fator principal de cada classe de ativos. O mesmo procedimento é feito em todos os demais painéis de forma que se obtenham todos os fatores usados na previsão. É possível, portanto, nomear os fatores extraídos de acordo com sua classe de ativos de onde foi extraído.

O modelo é focado em variáveis brasileiras, por isso todas as variáveis utilizadas para construir os fatores são, de alguma forma, relacionadas ao Brasil. As taxas de juros de curto prazo são vértices da estrutura a termo de taxa de juros brasileira, as variáveis de crédito são relacionadas ao yield de títulos emitidos por empresas brasileiras no exterior, as commodities são preços em dólar das principais commodities do mercado e as moedas são cotações das moedas mais representativas no mundo contra o Real (BRL). Serão explorados mais a frente os detalhes específicos de cada painel.

Nesse ponto temos uma diferença com relação ao modelo de Andreou e Ghysels (2014). Como a Dissertação tem foco em variáveis brasileiras, foi escolhido incluir um painel a mais para modelar o risco país somado aos demais já existentes. O painel adicional inclui, portanto, as variações cambiais de moedas representativas contra o Real e suas consequências e representatividade serão discutidas mais a frente. 
As séries a serem previstas, como já descrito anteriormente, serão os índices de volatilidade e o Variance Premium do IBOVESPA calculados pelo Nefin da FEA - USP. Estes dados são calculados a partir de dados de opções cujo ativo subjacente seja o IBOVESPA e utilizam metologias próprias com algumas semelhanças ao que é utilizado para cálculos semelhantes de variáveis como o VIX. Os dados obtidos para índice de volatilidade são com base diária e os dados obtidos para o Variance Premium são com base semanal. A construção destes índices não fazem parte do escopo deste trabalho, uma vez que já estão amplamente documentados no site da instituição.

Assim sendo, o foco deste trabalho se dará na construção dos modelos de previsão para estes índices, na discussão de seus resultados bem como de abordagens alternativas para a medição dessa volatilidade de outras formas, aproveitando os fatores do modelo. De uma forma geral, buscaremos demonstrar a relevância dos fatores construídos aqui para este tipo de modelo e suas interpretações.

O modelo de previsão a ser utlizado será uma regressão linear simples (Mínimos Quadrados Ordinários). A variável dependente será uma das duas séries de índices descrita anteriormente e as variáveis independentes serão os 4 fatores construídos nesta Dissertação. O modelo será feito com atrasos entre as variáveis independentes e a variável dependente de 1 dia, 5 dias, 21 dias e 63 dias no caso do Índice de Ações ou de 1 semana, 5 semanas, 21 semanas e 63 semanas no caso do Variance Premium. Além disso, o modelo será feito através de janelas rolantes, nas quais a regressão é feita usando os fatores com o respectivo atraso, em amostras de 300 dias ou 100 semanas para o Índice de Volatilidade e para o Variance Premium, respectivamente. Assim sendo, a cada regressão, o ponto imediatamente seguinte é previsto, e a janela anda um dia para frente. Assim sendo, teremos um modelo sempre construído out-of-sample, que mais se assemelha com um formato real fora do ambiente de back-test.

As equações que regem as regressões são listadas abaixo para cada atraso construído, onde cada fator é representado por $f_{i}$ e o erro por $\gamma$ :

Modelo 1 (atraso de 1 dia/semana):

$$
\text { Índice }_{\text {Ibov }_{t}}=a_{1} f_{1_{t-1}}+a_{2} f_{2_{t-1}}+a_{3} f_{3_{t-1}}+a_{4} f_{4 t-1}+\gamma
$$

Modelo 2 (atraso de 5 dias/semanas):

$$
\text { Índice }_{\text {Ibov }_{t}}=a_{1} f_{1_{t-5}}+a_{2} f_{2_{t-5}}+a_{3} f_{3_{t-5}}+a_{4} f_{4_{t-5}}+\gamma
$$


Modelo 3 (atraso de 21 dias/semanas):

$$
\text { Índice } \text { Ibov }_{t}=a_{1} f_{1_{t-21}}+a_{2} f_{t_{t-21}}+a_{3} f_{3_{t-21}}+a_{4} f_{4 t-21}+\gamma
$$

Modelo 4 (atraso de 63 dias/semanas):

$$
\text { Índice } \text { Ibov }_{t}=a_{1} f_{1_{t-63}}+a_{2} f_{2_{t-63}}+a_{3} f_{3_{t-63}}+a_{4} f_{t_{t-63}}+\gamma
$$

Ao final dos resultados descobre-se que há sim relevância dos fatores na previsão do Índice de Volatilidade e do Variance Premium. Dependendo do atraso utilizado podemos ter maior relevância de cada um dos dos fatores de forma diferente, porém de uma forma geral, os resultados são mais consistentes com atrasos menores. Entre todos eles, destaca-se o fator relativo à taxa de juros de curto prazo que possui a maior relevância em quase todos os casos. Estes resultados são consistentes com o observado no paper de Andreou e Ghysels (2014), no qual os resultados foram semelhantes.

Também visualisamos como a aderência é modificada dependendo do momento ao longo do tempo. Em momentos de menor stress a aderência dos fatores é maior do que nos períodos de maior stress. Como este trabalho utilizou amostras de um período amplo de tempo, durante momentos de maior incerteza política no Brasil, foi possível ver o modelo perder aderência nesses momentos. 


\section{Características dos Fatores e Estudo de Correlações}

Nesta seção serão exploradas as características dos fatores, como eles são construídos e qual o método de estimação. Como já apresentado anteriormente, os fatores são obtidos a partir da construção de painéis com séries de retornos de ativos de uma mesma classe. Nesse caso temos então 4 painéis representando as classes de taxas de juros de curto prazo, yields de bonds corporativos de empresas brasileiras emitidos em dólar, commodities incluindo metais, produtos agrícolas e energia, e taxas de câmbio das moedas mais representativas do mundo contra o Real.

Assim como foi introduzido anteriormente, cada série de cada painel passa por uma Análise de Componentes Principais (PCA) e, em seguida, a primeira componente de cada painel é retirada e passa por um filtro do tipo ARMA $(1,0)+$ GARCH $(1,1)$, onde a volatilidade dessas componentes é retirada. A seguir serão aprofundados os detalhes de cada painel.

Primeiramente, define-se que o período que será analisado começa no início de Julho de 2011 e termina no início de Março de 2016 para o Índice de Volatilidade e começa no final de Agosto de 2011 e termina no final de Julho de 2015 para o Variance Premium. O período foi assim escolhido de forma a ter uma janela suficientemente grande para que diversos cenários e momentos da economia fossem tratados e, ao mesmo, a janela não fosse tão ampliada de forma que todos os ativos utilizados existam durante a maior parte do tempo. Em especial, encontra-se uma dificuldade grande no caso dos títulos de dívida corporativos de empresas brasileiras uma vez que alguns possuem emissão muito recente e dessa forma não conseguem constituir a amostra desde 2011. Já nos casos dos painéis de taxas de juros de curto prazo, commodities e moedas, não há nenhuma limitação com relação aos prazos mais antigos uma vez que estes possuem séries muito longas disponíveis. Além disso, é importante garantir a existência dos próprios índices a serem previstos.

O primeiro painel possui 6 vértices curtos da estrutura a termo da taxa de juros brasileira. Os vértices são 1 mês, 3 meses, 6 meses, 8 meses, 12 meses e 24 meses. As séries contém as variações das taxas dia a dia extraídas a partir dos valores dos futuros de DI negociados na ambiente da BVM\&F. Esses 
produtos possuem vencimentos fixos e portanto é necessário realizar uma normalização para padronizar em uma curva com os vértices descritos aqui.

Naturalmente iremos visualizar uma correlação alta entre os vértices utilizados aqui e isso é importante para garantir a uniformidade que buscamos em cada bloco de forma que a primeira componente extraída do painel seja representativa desta classe de ativos. Para este painel, mais especificamente, a primeira componente possui significado já explorado pela literatura. Existem resultados consagrados que mostram que a primeira componente extraída de séries de variações nas taxas da estrutura a termo da curva de juros representam os movimentos paralelos da curva. Apesar de não serem utilizadas aqui, a segunda e terceira componentes também possuem interpretação sendo portanto os movimentos na inclinação e na curvatura da estrutura a termo.

No caso brasileiro também já há estudos que demonstram que a primeira componente em questão aqui explica a maior parte da volatilidade das variações dos vértices da curva de juros nominal. Não entraremos em mais detalhes sobre estes estudos uma vez que não fazem parte do escopo deste trabalho e também porque os resultados já foram amplamente explorados em outros trabalhos.

Uma parte importante, porém, que será explorada a seguir trata do estudo da unicidade do painel no sentido de garantir que eles podem constituir um único bloco e não devem ser separados como classes de ativos diferentes. Apesar de parecer óbvio neste caso em que todos são vértices da curva de juros nominal, a discussão é importante para entender quais vértices devem ou não entrar na seleção, dado que o objetivo é garantir que toda a parte de curto prazo seja coberta. Vértices muito longos começam a perder um pouco a correlação com vértices mais curtos e podem eventualmente não ser a melhor escolha para compor o painel.

Abaixo temos a matriz de correlação entre os vértices utilizando toda a amostra com dados diários de Julho 2011 a Março de 2016, como exemplo:

\begin{tabular}{|c|rrrrrr|}
\hline & \multicolumn{1}{|c}{1 Mês } & 3 Meses & 6 Meses & 8 Meses & 12 Meses & 24 Meses \\
\hline 1 Mês & 1 & & & & & \\
3 Meses & 0.567928 & 1 & & & & \\
6 Meses & 0.338738 & 0.800809 & 1 & & & \\
8 Meses & 0.245357 & 0.740873 & 0.962104 & 1 & & \\
12 Meses & 0.093243 & 0.618673 & 0.890670 & 0.946548 & 1 & 1 \\
24 Meses & 0.075156 & 0.513616 & 0.774273 & 0.842598 & 0.919537 & 1 \\
\hline
\end{tabular}

Tabela 1: Correlação entre os vértices do primeiro painel. 
Analisando a tabela acima, percebe-se que todos os vértices possuem correlações altas entre si, apesar do vértice de 1 mês possuir correlação mais baixa com relação aos demais. Isso ocorre porque o vértice de 1 mês pode ou não sofrer os efeitos das modificações na taxa básica de juros através das mudanças na política monetária após cada reunião do COPOM (Comitê de Política Monetária do Banco Central do Brasil), que ocorre a cada 40 dias. Ou seja, em determinados períodos a janela de 1 mês vai incluir uma reunião do COPOM e em outros a reunião não está incluída. Dessa forma, esse vértice possui pequenas variações a maior parte do tempo e se ajusta com um salto no momento em que há uma mudança na taxa básica de juros através de uma reunião do COPOM. Nos demais vértices não temos variações tão bruscas porque a periodicidade das reuniões do COPOM é menor do que o prazo destes vértices.

Assim sendo, há uma forte evidência de que há significativa unicidade nesse painel. Como será visto nas seções seguintes ao longo dos resultados, este será um painel muito importante nas previsões dos Índices deste trabalho. Parte dessa importância pode ser resultado do painel possuir esta grande unicidade levando portanto a ter a primeira componente com significado relevante para a volatilidade do IBOVESPA.

Analisaremos agora o segundo painel, composto pelos títulos de dívida de empresas brasileiras emitidos em Dólar (USD). São 7 ativos com vencimentos em 2019, 2020, 2022 e perpétuos (títulos de dívida sem prazo de vencimento determinado). São todos portanto mais longos do que o vencimento mais longo presente no painel explorado anteriormente. Esta não é porém a única diferença entre os painéis: além de mais longos, estes títulos são capazes de capturar 0 risco Brasil, entendido como a percepção de crédito externa do Brasil e de suas empresas por consequência. Por fim, estes títulos também apresentam características individuais de crédito de cada empresa, porém, como a volatilidade dos títulos passará por uma decomposição em componentes principais e somente a primeira componente será aproveitada, este fator individual não deverá ter impacto.

O objetivo deste painel portanto será justamente acrescentar um fator que modele variáveis de crédito e de taxa de juros de longo prazo. Este complementa o painel anterior que por sua vez modela as taxas de juros básicas da economia brasileira e portanto as taxas de financimento de curto prazo.

Como foi mencionado anteriormente na Introdução, este painel é o mais difícil de ser construído porque não existem muitos títulos que existem durante todo o período de 2011 a 2016 como será utilizado neste trabalho. Além disso, os 
títulos precisam ser de empresas relevantes para a economia brasileira de forma que a componente gerada possa modelar a volatilidade do índice de ações mais representativo no Brasil. Para poder enquadrar os títulos nessas categorias, foram escolhidos títulos das seguintes empresas: Embraer, Vale, Petrobrás, BR Malls, BR Properties, Banco ABC Brasil e Banco Pan. Algumas destas empresas não possuem títulos existentes desde 2011 e portanto foi preciso completar somente para o período existente nestes casos.

Vamos analisar as correlações entre os ativos que compõem este painel assim como já feito com o anterior.

\begin{tabular}{|c|c|c|c|c|c|c|c|}
\hline & Banco Pan & Banco ABC Brasil & BR Properties & BR Malls & Petrobrás & Vale & Embraer \\
\hline Banco Pan & 1.00000 & & & & & & \\
\hline Banco ABC Brasil & 0.16676 & 1.00000 & & & & & \\
\hline BR Properties & 0.22846 & 0.07622 & 1.00000 & & & & \\
\hline BR Malls & 0.08773 & 0.20289 & 0.07797 & 1.00000 & & & \\
\hline Petrobrás & 0.08324 & 0.10830 & 0.06606 & -0.01890 & 1.00000 & & \\
\hline Vale & 0.09126 & 0.17003 & 0.05728 & 0.19315 & 0.08793 & 1.00000 & \\
\hline Embraer & 0.09354 & 0.19827 & 0.08599 & 0.14997 & 0.03568 & 0.33792 & 1.00000 \\
\hline
\end{tabular}

Tabela 2: Correlação entre os ativos do segundo painel.

Em uma primeira análise, nota-se já que os valores das correlações entre os ativos são muito menores, apesar de existir uma clara tendência de correlação positiva entre eles. Esse efeito já era esperado uma vez que estes ativos são bastante diferentes dos expostos no painel anterior. Nesse caso, a correlação positiva mesmo que pequena entre eles pode representar o efeito do fator que procuramos modelar: as variáveis de risco de crédito e risco país. Por outro lado, essa dispersão entre os ativos pode se revelar um problema e o painel ter pouca representatividade e pouco poder preditivo justamente por isso.

Assim como no painel anterior, essa análise não é definitiva sobre a escolha final da composição do painel, sendo apenas um estudo inicial para conhecer e explorar as variáveis de entrada e ajudar na posterior conclusão final. Além disso, este estudo também pode sugerir novos testes a serem feitos buscando uma melhor aderência do modelo. Todos estes pontos serão abordados novamente na seção de resultados.

Passaremos agora para o terceiro bloco composto por commodities agrícolas, metais, minérios e energia. Este bloco deverá possuir em vários momentos um papel bastante importante no modelo de previsão que é o objetivo final deste trabalho. Isso ocorre porque estamos procurando a previsão da 
volatilidade do principal índice de ações brasileiro que, como se sabe, está diretamente ligado a resultados de commodities como estas que compõem este terceiro painel.

As séries que irão compor este painel estão listadas abaixo:

- Ouro;

- Platina;

- Prata;

- Cobre;

- Zinco;

- Alumínio;

- Níquel;

- Milho;

- Soja;

- Trigo;

- Café;

- Açúcar;

- Algodão;

- Petróleo WTI;

- Petróleo Brent;

Percebe-se, como anunciado anteriormente, que existem commodities ligados a diferentes categorias. No paper de Andreou e Ghysels (2014) que baseou esta Dissertação, apenas commodities de metais e energia são considerados, porém no caso brasileiro as agrícolas são muito representativas para esta economia e consequentemente para seu índice de ações. Dessa forma, escolheu-se criar um bloco que unificasse todas estas séries. Um ponto inicial que é preciso verificar é uma eventual perda de significância pelo fato de um único bloco concentrar commodities de diferentes setores. Isso poderá ser verificado tanto na análise inicial que será feita a seguir quanto nos resultados que serão apresentados mais a frente.

Ao contrário do bloco anterior, as commodities são bastante padronizadas e suas séries de retorno são completas durante todo o período a ser analisado. Isso é mais um fator que irá contribuir para a significância do bloco durante todo o período a ser testado. Além disso, será possível comparar a correlação das séries durante todo o período de forma correta sem muitos valores incompletos. Veremos a seguir esta matriz de correlação. 


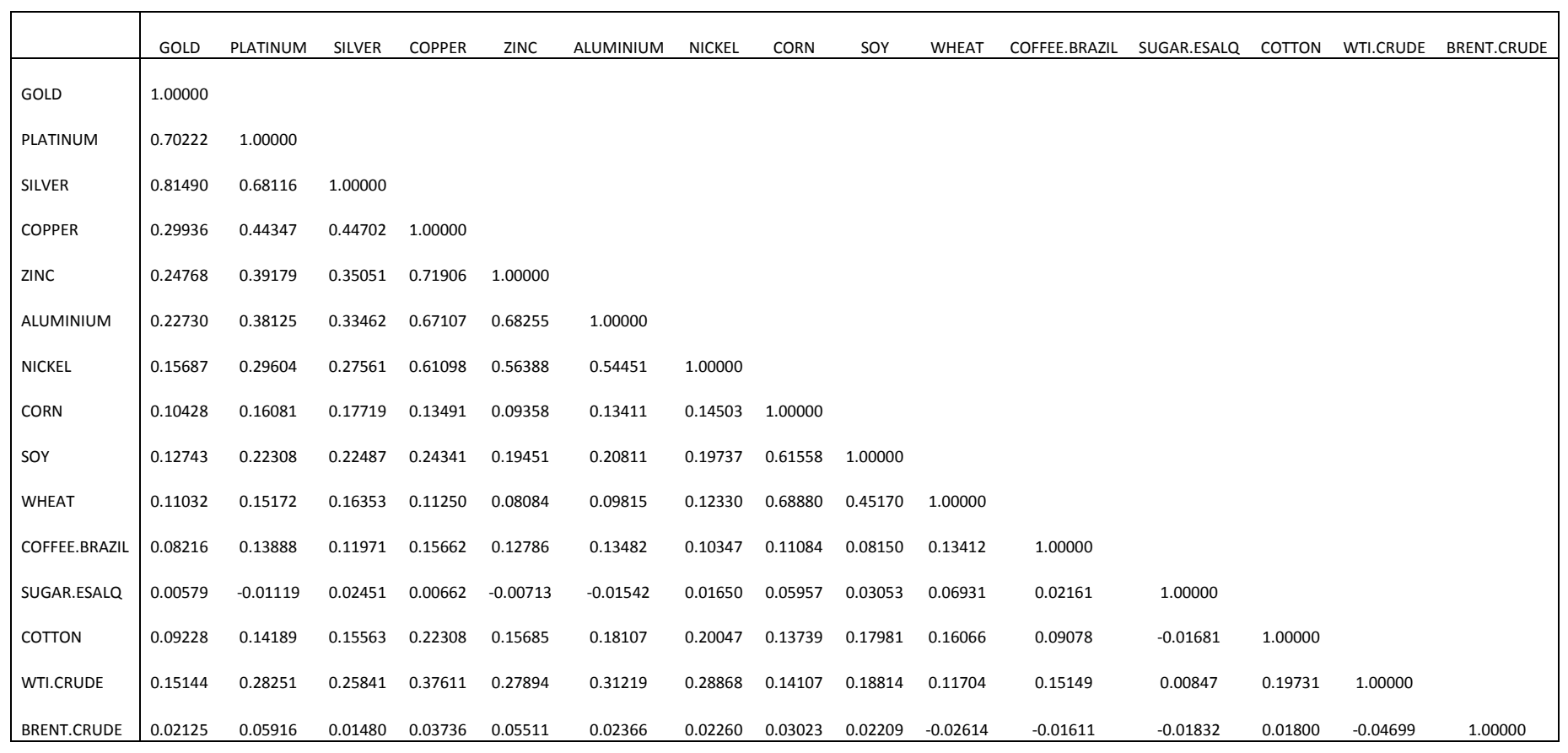

Tabela 3: Correlação entre os ativos do terceiro painel.

Ao analisar as correlações do painel, verificamos que os metais possuem uma correlação elevada entre eles. As commodities agrícolas, de uma forma mais geral, também possuem essa correlação elevada entre si. As commodities ligadas a petróleo possuem já um comportamento diferente: não possuem uma correlação relevante entre si, por outro lado, uma dessas séries possui correlação com todas as demais enquanto a outra não possui correlação com nenhuma outra de forma relevante. Já as correlações entre os sub-blocos possuem valores que oscilam entre baixos e medianos.

Esses resultados contribuem para reforçar a cautela que teremos ao analisar os resultados com esses painel. Apesar de alguns possuirem correlação baixa, mesmo assim ela é positiva e eventualmente até significativa. Assim, provavelmente a primeira componente da volatilidade a ser retirada aqui deve representar ainda assim o painel como um todo.

Em resumo, este bloco como um todo é ao mesmo tempo bastante relevante para nosso modelo, mesmo de uma forma qualitativa, e também heterogêneo uma vez que as diferentes commodities nem sempre são altamente correlacionadas. O que o modelo vai buscar provar empiricamente é como esse fator de heterogeneidade pode ser superado através da decomposição em componentes principais. Ou seja, o modelo pode se mostrar bastante robusto quanto aos dados que são inseridos como entrada.

Passando para o último painel, este será representado pelas variações nas cotações de diversas moedas relevantes mundialmente contra o Real brasileiro. 
Conforme descrito anteriormente, este quarto painel não está previsto no paper original de Andreou e Ghysels (2014), porém possui bastante importância para o modelo e deve representar um dos blocos mais homogêneos. Ao adaptar o modelo do paper citado ao Brasil, é necessário usar algumas modificações de forma a cobrir as peculiaridades do país. Ao modelar o principal índice da Bolsa brasileira, é natural que muitas variáveis que descrevem o risco do Brasil como um todo sejam importantes e relevantes.

Adicionalmente, o argumento a incluir esse tipo de painel se fortalece uma vez que já existem estudos presentes na literatura que mostram como as principais variáveis econômicas ou financeiras brasileiras possuem como fator principal basicamente um único fator comum. Ou seja, espera-se que o índice de ações deste trabalho tenha sua variância explicada majoritariamente por fatores comuns às variáveis que descrevam a economia brasileira, em especial, as taxas de câmbio do Real contra outras moedas.

Assim sendo, serão utilizadas as cotações do Real contra o Euro, Dólar Americano, Libra Britânica, Yen Japonês, Peso Mexicano, Peso Colombiano, Franco Suíço, Rand Sul-africano, Yuan Chinês, Peso Chileno, Dólar Australiano, Dólar Canadense, Won sul-coreano, Sol Peruano e Rublo Russo.

Iremos agora passar a análise das correlações deste bloco. Será analisada a correlação de todo o período assim como foi feito nos demais paineis.

\begin{tabular}{llllllllll} 
RL.EUR & BRL.USD & BRL.GBP & BRL.JPY & BRL.MXN & BRL.COP & BRL.CHF & BRL.ZAR & BRL.CNY & BRL.CLP \\
\hline
\end{tabular} 1.00000 J.83101 1.00000

BRL.GBF ̊o $J .885960 .889961 .00000$

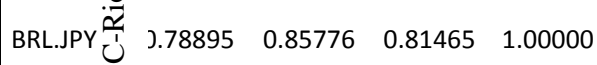

$\begin{array}{llllll}\text { BRL.MX: J.68620 } & 0.69392 & 0.71433 & 0.56906 & 1.00000\end{array}$

$\begin{array}{lllll}0.56164 & 0.59060 & 0.58362 & 0.51405 & 0.48885\end{array}$

$\begin{array}{lllllll}0.81096 & 0.73223 & 0.76330 & 0.73173 & 0.56157 & 0.48803 & 1.00000\end{array}$

$\begin{array}{llll}0.60856 & 0.52880 & 0.61212 & 0.49193\end{array}$

$0.73801 \quad 0.38592 \quad 0.49843 \quad 1.00000$

$\begin{array}{lllllll}0.67047 & 0.73166 & 0.71251 & 0.63859 & 0.68343 & 0.49\end{array}$

$\begin{array}{lllll}0.75853 & 0.72263 & 0.77972 & 0.68867 & 0.7\end{array}$

0.75756

$\begin{array}{llll}0.59146 & 0.73158 & 0.55382 & 1.00000\end{array}$

$\begin{array}{llllll}0.49285 & 0.57889 & 0.57911 & 0.73340 & 1.00000\end{array}$

Tabela 4: Correlação entre os ativos do quarto painel.

Como era esperado, a correlação é uma das mais altas entre todos os paineis desse trabalho. Esse bloco, portanto, além de ter muita relevância para o 
estudo também apresenta grande unicidade. É possível que tenha grande relevância ao prever a volatilidade do principal índice de ações brasileiro de forma consistente ao longo de todo o período deste trabalho.

Chegando ao fim da análise de todos os paineis, percebemos que existem alguns mais homogêneos do que outros. O trabalho procura estudar também o quanto as eventuais imperfeições nos blocos podem ser ou não relevantes para o modelo de previsão final. A expectativa é que a primeira componente principal seja suficiente para captar os efeitos desejados ao mesmo tempo que elimina eventuais imperfeições. Isso será demonstrado mais a frente juntamente com os resultados. 


\section{Estimação dos Fatores}

Após o estudo inicial das séries que irão compor cada painel, o próximo passo será seguir com o processo de construção de cada um. A primeira etapa será decompor em componentes principais (PCA) cada bloco e em seguida, a primeira componente será retirada e passará por um filtro $\operatorname{ARMA}(1,0)+\mathrm{GARCH}$ $(1,1)$. Para os resultados do modelo, todo esse processo será feito em janelas rolantes conforme descrito na introdução, porém para ilustrarmos melhor todo a amostra, desenvolveremos aqui o processo como todo o período de uma única vez.

Da mesma forma, durante os resultados, teremos a previsão do Índice de Volatilidade e do Variance Premium. Durante o primeiro serão usados dados com base diária enquanto para o segundo serão usados dados com base semanal. Os dados serão basicamente os mesmo, sendo que no segundo caso eles serão acumulados em semanas. Assim sendo, todo o processo descrito nessa seção seguirá sobre os dados diários já que a conclusão para os dados semanais é semelhante.

O início do processo de construção do primeiro fator pode ser visto na Figura 1 do Anexo 1. Primeiramente podemos analisar cada série em separado. No caso do painel de juros, as séries são normalizadas pelos dias até cada o vencimento de forma a termos dados comparáveis. Em todo caso pode-se ver que todas elas possuem comportamentos muito semelhantes uma vez que a correlação como foi visto anteriormente é bastante alta.

É possível destacar alguns momentos de maior volatilidade já na Figura 1. Em especial, nota-se momentos de volatilidade maior no segundo semestre de 2011, de 2013, de 2014 e, principalmente, de 2015.

Ao passarmos para a análise da Figura 2 no Anexo 1, verificamos que ela se assemelha à série mais longa do painel, representante do vértice de 24 meses. Isso é uma consequência natural uma vez que o vértice mais longo de uma curva juros já possui maior volatilidade e a análise de componentes principais (PCA) modela a componente de maior volatilidade do painel. Por isso verificam-se os mesmos picos de volatilidade na primeira componente. 
Após passar pelo filtro do ARMA $(1,0)+\operatorname{GARCH}(1,1)$, portanto, chegamos à Figura 3 do Anexo 1, que acaba por modelar exatamente os mesmos picos de volatilidade que identificamos desde a Figura 1. Assim, chegamos ao primeiro fator construído. É esperado que este fator seja portanto diretamente dependente dos momentos econômicos e políticos do Brasil, o que foi possível até agora já identificar pelo dados explorado aqui.

Passando ao segundo painel, analisamos as série que o compõem na Figura 4 do Anexo 1. Apesar deste painel ser muito mais heterogêneo do que o painel anterior, verificamos curiosamente os mesmos momentos de alta volatilidade. Os picos ocorrem no segundo semestre de 2011, de 2013, de 2014 e de 2015. Neste painel fica ainda mais evidente o momento de alta volatilidade ocorrido na economia brasileira em 2014 e 2015.

Mais uma vez as séries que possuem maior volatilidade em cada momento são vistas como dominantes na primeira componente na Figura 5 do Anexo 1. E por fim chegamos na Figura 6 do Anexo 1 com a segunda componente construída. Mais uma vez visualizamos muito claramente os momentos de maior volatilidade em momentos semelhantes ao painel anterior. Este painel, por sua vez, apesar de possuir séries relacionadas a dívidas de empresas bastante específicas, consegue apresentar um comportamente até de certa forma comparável ao anterior, uma vez que suas séries também possuem em parte interpretação de movimentos da curva de juros.

Já no terceiro painel, percebe-se que há um número muito maior de séries dessa vez. Todas as séries podem ser vistas na Figura 7 do Anexo 1. Neste caso há uma dispersão maior dos momentos de mais alta volatilidade entre as séries, não sendo possível identificar momentos claros de concentração de picos.

Assim sendo, como esperado, a Figura 8 do Anexo 1, que representa a primeira componente retirada desse painel é bastante dispersa apesar de já ser possível detectar momentos de maior stress no início e no final do período analisado. Por fim então, a Figura 9 do Anexo 1 confirma esses momentos de maior volatilidade entre o início e o fim da amostra. Isso provavelmente é devido ao fato das commodities não necessariamente estarem relacionadas a algum momento específico da economia brasileira, já que são preços internacionais que são determinados por diversos fatores. O mais provável é que algumas destas séries apenas possuam mais influência na economia brasileira do que outras.

Passando ao quarto e último painel, também nota-se que há um número elevado de séries que o compõem, porém desta vez já é possível identificar movimentos conjuntos entre elas, ao contrário do painel anterior. Isso pode ser 
visto na Figura 10 do Anexo 1. Como todas as séries são taxas de câmbio de moedas de diversos países contra o Real brasileiro, é natural que esse tipo de comportamento seja visível.

Assim sendo, na Figura 11 do Anexo 1, é possível ver que a primeira componente já possui uma tendência clara de aumento de volatilidade a partir do segundo semestre de 2014. Isso ocorreu a partir, portanto, das eleições ocorridas naquele período e a posterior crise política e econômica no país. Dessa forma, este será um painel que terá grande peso desse tipo de influência, destacando-se entre os demais. Por fim, na Figura 12 do Anexo 1, é confirmado esse comportamento e esse aumento de volatilidade após a estimação pelo ARMA $(1,0)+\operatorname{GARCH}(1,1)$.

Ao fim da construção e análise destes fatores, percebe-se que eles modelam diferentes aspectos que intuitivamente deveriam ser relevantes para o principal Índice de Ações brasileiro já que muitas dessas variáveis impactam diretamente o comportamento das empresas que compõem o IBOVESPA. Ao passarmos à seção de resultados será possível entender o quanto de fato estes fatores são relevantes para a volatilidade do mesmo.

Agora, em seguida, analisaremos uma pouco mais sobre as séries que desejamos prever do Índice de Volatilidade e do Variance Premium. 


\section{4 Índice de Volatilidade e Variance Premium}

Conforme mencionado anteriormente, os dados foram obtidos a partir de um trabalho realizado pela USP que criou um índice de volatilidade para o Brasil, semelhante ao VIX, que se refere ao IBOVESPA, principal índice de ações do país. O paper que deu origem à criação deste índice pode ser verificado em Astorino, Chague, Giovanetti e Silva (2015).

Para esta criação, portanto, foram levados em considerração os mais atuais métodos presentes na literatura. Mais especificamente, foram utilizadas opções do próprio IBOVESPA com algumas correções já que este mercado ainda é muito ilíquido (cerca de USD 20 milhões por dia) e possui poucos strikes negociados incluindo tanto Calls e Puts.

Para maiores detalhes sobre o método e a correção, além do próprio paper mencionado aqui, recomenda-se a leitura de Carr e Wu (2009) no qual é proposta a criação do novo VIX.

O processso de estimação do índice e todos os demais testes que compõem o seu estudo mais aprofundado não serão alvo de estudo neste trabalho uma vez que já são explorados na literatura aqui citada. De uma forma geral, utiliza-se os dois primeiros vencimentos negociados para a criação de um dado ponto. Como os vencimentos das opções ocorrem em meses pares para o IBOVESPA, se estivermos em Janeiro, por exemplo, serão utilizados os vencimentos de Fevereiro e Abril. Assim, após calcular as volatilidades implícitas ajustadas, é calculada uma média ponderada entre os dois vencimentos considerados.

Assim, pela forma como este é determinado, através de vencimentos futuros de opções, o índice de volatilidade carrega também informação sobre a volatilidade futura, como é demonstrado no paper. Esta informação é importante para levarmos em consideração uma vez que temos painéis que possuem características distintas quanto a informação futura. Mais especificamente, é esperado que os fatores do nosso modelo que estão ligados às estruturas de taxas de juros futuras tenham algum papel relevante para modelar isso.

É importante ressaltar também que apesar do fato de serem considerados apenas os pontos em que há negociação com um número limitado de strikes, o paper demonstra que não há viés na estimação ao utlizar os smiles das 
volatilidades para interpolar um número maior de pontos e verificar que não houve mudança nos resultados.

Por fim, os resultados do índice de volatilidade ao quadrado conseguem ser separados em duas partes: (i) a variância esperada dos retornos das ações e (ii) o Variance Premium, que nada mais é do que a diferença entre o índice de volatilidade e a variância esperada. Assim sendo, o Variance Premium pode ser entendido como uma medida de aversão ao risco do mercado brasileiro. Neste trabalho iremos utilizar tanto o índice de volatilidade quanto o Variance Premium como variáveis a serem previstas. Assim, teremos uma melhor informação sobre os fatores mais primitivos que podem compor cada uma das duas séries.

Ambas as séries podem ser visualizadas nas Figuras 13 e 14 do Anexo 1. Em primeiro lugar é importante verificar que o índice de volatilidade possui dados com frequência diária, enquanto que o Variance Premium possui dados semanais. É interessante também visualizar que todos os diferentes momentos de maiores oscilações por motivos econômicos ou políticos podem ser notados em ambos os gráficos. Mais especificamente temos um momento de maior stress em 2011 devido à crise na zona do Euro, depois em 2012 com o caso das ações da empresa OGX, depois os protestos de 2013, as eleições em 2014 e a crise que se seguiu em 2015 e 2016, quando termina a amostra.

Em seguida, serão apresentados os resultados obtidos através dos testes realizados ao longo deste trabalho. 


\section{Resultados}

Como já foi descrito na Introdução, os testes basicamente serão divididos em duas partes: (i) regressões por MQO em janelas rolantes de 300 dias cada uma do índice de volatilidade do IBOVESPA com dados diários nos fatores contruídos neste trabalho e; (ii) regressões por MQO em janelas de 100 semanas cada uma do Variance Premium relativo ao índice de volatilidade com dados semanais nos fatores construídos neste trabalho.

Da mesma forma, reapresentamos nesta seção as equações utilizadas no modelo:

Modelo 1 (atraso de 1 dia/semana):

$$
\text { Índice }_{\text {Ibov } t}=a_{1} f_{1_{t-1}}+a_{2} f_{2_{t-1}}+a_{3} f_{3_{t-1}}+a_{4} f_{4 t-1}+\gamma
$$

Modelo 2 (atraso de 5 dias/semanas):

$$
\text { Índice }_{\text {Ibov }}=a_{1} f_{1_{t-5}}+a_{2} f_{2_{t-5}}+a_{3} f_{3_{t-5}}+a_{4} f_{4_{t-5}}+\gamma
$$

Modelo 3 (atraso de 21 dias/semanas):

$$
\text { Índice }_{\text {Ibov }}=a_{1} f_{1_{t-21}}+a_{2} f_{2_{t-21}}+a_{3} f_{3_{t-21}}+a_{4} f_{4_{t-21}}+\gamma
$$

Modelo 4 (atraso de 63 dias/semanas):

$$
\text { Índice }_{\text {Ibov }}=a_{1} f_{1_{t-63}}+a_{2} f_{2_{t-63}}+a_{3} f_{3_{t-63}}+a_{4} f_{4_{t-63}}+\gamma
$$

Neste caso, os atrasos são em dias para os casos do índice de volatilidade e em semanas para os casos do Variance Premium. Assim sendo, iremos passar pelos 4 modelos com diferentes atrasos para as duas variáveis que serão testadas, num total de 8 resultados a serem explorados.

\section{1. Índice de Volatilidade}

Em primeiro lugar, vamos analisar o índice de ações como função dos 4 fatores com atraso de um dia. Analisando a Figura 15 do Anexo 1, verificamos que visualmente a regressão obtida possui comportamento semelhante ao índice durante boa parte do tempo. Porém, seu comportamento em momentos de maiores variações da volatilidade é diferente de momentos com menos saltos. Basta ver que na primeira metade temos um comportamento distinto da segunda metade. Em especial, a partir da metade de 2014 o comportamento entre as duas curvas começa a se distanciar visivelmente. É interessante notar que a partir 
deste ponto o Brasil começa a passar por um momento de incertezas políticas na eleição de 2014 e em seguida pela crise na Petrobrás e na economia do país em 2015, chegando até o momento que antecedeu o impeachment em 2016.

Ao analisarmos os erros desse primeiro modelo, já na Figura 16 do Anexo 1, esta mudança fica ainda mais evidente. Nota-se claramente uma mudança no comportamento dos erros ainda no segundo semestre de 2014. Antes desse período é possível observar que os erros são de magnitude controlada e até possivelmente aleatórios. Colocando em números esta constatação, podemos verificar na tabela abaixo como mudança se torna significativa a partir do ponto mencionado.

\begin{tabular}{|lcr|}
\hline & Erro (\%) & Erro Absoluto (\%) \\
\hline Total & $-13.58 \%$ & $17.41 \%$ \\
Até 31/Jul/2014 & $-10.74 \%$ & $13.66 \%$ \\
Após 31/Jul/2014 & $-17.11 \%$ & $22.08 \%$ \\
\hline
\end{tabular}

Tabela 5: Erros do modelo para índice de volatilidade com atraso de 1 dia

Entrando mais a fundo neste primeiro modelo, podemos observar os $P$ Values de cada um dos elementos da regressão. As figuras 17, 18, 19, 20 e 21 do Anexo 1 demonstram respectivamente a constante e os fatores de 1 a 4 presentes no Modelo 1 para índice de volatilidade do índice de ações.

A constante, na Figura 17, oscila bastante, mas não é o principal alvo da nossa discussão. Por outro lado, ao analisar a Figura 18, percebe-se que o fator de Juros de curto prazo possui alta relevância durante a maior parte do período. Isso significa que este é um fator muito relevante para a previsão e a explicação do índice de volatilidade do lbovespa. Cabe ressaltar que até mesmo no paper de Andreou e Ghysels (2014) este é o fator mais relevante, ou seja, o resultado obtido aqui está de acordo com o obersavado na literatura existente.

Já o painel de Corporate Bonds na Figura 19 volta a ter uma oscilação entre momentos de maior ou menor relevância, sendo a maior parte do tempo pouco relevante. Mais uma vez temos um resultado comparável ao paper de Andreou e Ghysels (2014) e esta explicação pode passar pelo fato desses títulos serem muito pouco líquidos o que faz com que a volatilidade possa não ser antecipada e até possa ser postergada por simplemente não haver negociação suficiente no mercado.

O Painel de Commodities, por outro lado, na Figura 20, já possui diversos momentos de alta relevância, apesar de não ser da mesma forma do Painel de 
Juros. Os momentos ocorrem somente durante um período intermediário da amostra, lembrando que cada ponto no gráfico representa uma regressão da janela rolante. É esperado que as Commodities tenham alguma relevância uma vez que a economia brasileira é bastante dependente destes ativos. Assim sendo, as empresas que compõem o lbovespa podem ser bastante afetadas por escilações nestes preços e consequentemente receber essa volatilidade recebida através das Commodities. Em todo caso, é possível que ao aumentar o atraso dos fatores esta relevância seja reduzida e isto será verificado mais adiante.

Por fim, o painel de moedas na Figura 21 volta a possuir poucos momentos de alta relevância. Este resultado é, até certo ponto, não esperado, uma vez que além de não estar presente no paper de Andreou e Ghysels (2014), era possível entender que as moedas possuiriam papel relevante dentro da economia brasileira. Uma possível explicação para isso pode ser a eventual correlação que este painel tenha com os demais e que isso pode diminuir sua relevância.

Apesar de possuir fatores com alta relevância na regressão, como demonstrado anteriormente, a Figura 22 revela que o $R^{2}$ não ultrapassa os $25 \%$, aproximadamente, em nenhum momento. Ou seja, os fatores em tese não explicariam mais de $25 \%$ do índice de volatilidade do IBOVESPA. Mais uma vez, o resultado obtido aqui é de certa forma surpreendente uma vez que fora observados fatores com alta relevância e erros relativamente baixos e controlados durante boa parte do teste. Para obter mais uma métrica para este modelo, na Figura 23 do Anexo 1, é demonstrado o P-Value da própria regressão ao longo das simulação em cada janela rolante. Nesse gráfico, por sua vez, é possível notar que a regressão em si é muito relevante durante praticamente toda a extensão da amostra. Ou seja, é possível sim admitir que o índice de volatilidade é de certa forma função dos 4 fatores deste trabalho, apesar do mesmo não ser completamente explicado por isso.

Passaremos agora para o Modelo 2, no qual o índice de volatilidade será previsto com uma semana de antecedência pelos fatores. Em uma primeira análise, na Figura 24 do Anexo 1, percebe-se ainda bastante semelhança com o modelo anterior com 1 dia de atraso. Porém, aparentemente, as falhas de previsão são maiores na segunda metade da amostra. É interessante já aí perceber que há alguma persistência no poder preditivo dos fatores, porém, em todo caso, analisaremos as demais métricas assim como no modelo anterior. $\mathrm{Na}$ tabela abaixo visualizaremos os erros médios do modelo: 


\begin{tabular}{|lrr|}
\hline & Erro (\%) & Erro Absoluto (\%) \\
\hline Total & $-14.56 \%$ & $18.10 \%$ \\
Até 31/Jul/2014 & $-9.66 \%$ & $13.41 \%$ \\
Após 31/Jul/2014 & $-20.65 \%$ & $23.92 \%$ \\
\hline
\end{tabular}

Tabela 6: Erros do modelo para índice de volatilidade com atraso de 5 dias

Assim sendo, comparando esta tabela com a tabela de erros médios do Modelo 1, visualizamos um pequeno aumento para a amostra total, nas duas colunas. Porém, ao dividirmos novamente em períodos de antes e depois de 31/Jul/2014, verificamos que na realidade a primeira parte apresenta uma pequena diminuição em relação ao modelo anterior. Portanto o aumento no valor médio dos erros é devido à segunda parte da amostra onde temos maiores variações na volatilidade com as crises política e econômica que se iniciaram.

Isso pode indicar que de fato, durante as crises que ocorreram, outros fatores que não estão presentes nas variáveis que foram utilizadas ou que não são as primeiras componentes principais estão presentes atuando na volatilidade do índice de ações. Ao analisar os próximos modelos com atrasos maiores, poderemos constatar se esse aumento nos erros permanece.

Por outro lado, na Figura 25 do Anexo 1, é possível perceber que, apesar do primeiro período até Julho/2014 possuir erros com portamento melhor do que o segundo, a magnitude destes erros se torna por vezes maior do que no Modelo de 1 dia de atraso anteriormente apresentado.

Já na análise do P-value entre as variáveis, nas Figuras de 26 a 30 do Anexo 1, há períodos distintos em que alguns fatores são relevantes ou não. Tomando o fator de taxa de juros, na Figura 27, este continua sendo o fator que possui durante a maior parte do tempo relevância para a regressão, assim como já era visto no Modelo 1 anterior. Por outro lado, o painel de Corporate Bonds já passa a apresentar maiores períodos de relevância, enquanto as Commodities apresentam períodos mais curtos, todos em comparação com o modelo de atraso de 1 dia.

Vale lembrar que os Corporate Bonds em geral possuem algum atraso em repassar a volatilidade para seus preços justamente pela liquidez dos ativos. Isto pode influir nos resultados ao compararmos diferentes atrasos nos fatores Por outro lado, no caso das Commodities estas provavelmente já possuem a maior parte da volatilidade apresentada simultaneamente ao lbovespa e portanto com o 
aumento do atraso esta passe a ser menos significante, via de regra. Por fim, o painel de moedas segue sendo como aquele que possui o menor número de períodos com relevância para a previsão do índice de volatilidade.

Já no gráfico da Figura 31, visulizamos um comportamento semelhante ao do modelo anterior, porém com uma leve diminuição no valor máximo atingido pelo $R^{2}$ ao longo das regressões. Neste provelmente, o principal efeito seja realmente o atraso maior que faz com que no geral os fatores apresentem poder explicativo menor. Na Figura 32, por sua vez, ainda verificamos que o P-Value das regressões continua a maior parte do tempo com valores muito baixos, mantendo o que foi visto no modelo anterior e indicando que as regressões continuam sendo significativas.

A Figura 33 do Anexo 1, por sua vez, demonstra o Modelo 3 em comparação com o índice de volatilidade. Neste caso, com um atraso de 21 dias já é possível perceber que o modelo possui uma capacidade preditiva muito menor nos momentos de maior stress. A partir de Julho de 2014 o modelo subestima quase que continuamente o nível do índice, apesar de no período anterior a esta data ainda possuir boa aderência no gráfico. Colocando a performance do modelo em número, chegamos à tabela abaixo:

\begin{tabular}{|lcr|}
\hline & Erro (\%) & Erro Absoluto (\%) \\
\hline Total & $-17.07 \%$ & $19.63 \%$ \\
Até 31/Jul/2014 & $-10.27 \%$ & $14.00 \%$ \\
Após 31/Jul/2014 & $-25.51 \%$ & $26.63 \%$ \\
\hline
\end{tabular}

Tabela 7: Erros do modelo para índice de volatilidade com atraso de 21 dias

Em comparação ao modelo com atraso de 5 dias, nota-se que até Julho de 2014 os erros médios possuem valores semelhantes, porém, a partir desse ponto a performance é ainda mais reduzida. Como o momento de stress nesse segundo período foi resultado de eleições, crise política e crise na Petrobrás, muitos dos eventos que ocorreram eram muito difíceis de serem antecipados, em especial pelos fatores que apresentamos neste trabalho. É razóavel pressupor que a estrutura a termo de taxas de juros de curto prazo, os corporate bonds, as commodities e as taxas de câmbio não carreguem informações que possam antecipar tais eventos, ainda mais com 21 dias de antecedência. Isso explica muito do porque da quebra entre antes e depois de Julho de 2014. 
A Figura 34, portanto, confirma o que foi dito deste modelo até aqui: existe um comportamento dos erros que é modificado no segundo momento e há um viés de subestimação na segunda metade da amostra.

Nas Figuras 35 a 39 do Anexo 1, analisamos os P-Values das regressões em relação aos fatores. Como foi dito até aqui, os fatores neste ponto com atraso de 21 dias úteis já carregam pouca informação sobre a volatilidade do Ibovespa. Assim sendo, a Constante da regressão passa a assumir papel mais relevante em relação às demais variáveis. Mesmo o painel referente aos juros de curto prazo que nos modelos anteriores possuia muita relevância, agora já apresenta poucos momentos com relevância e apenas a série de Commodities apresenta breves momentos com maior relevância.

Estas conclusões também se refletem na Figura 40 , onde o $R^{2}$ máximo alcançado chega a até $17 \%$ nos momentos de pico, bem menor do que os modelos anteriores. Entretanto o P-value na Figura 41 ainda possui muitos momentos com valores próximos de zero, em especial na primeira metade do período analisado indicando que ainda há relevância nesta parte.

Por fim, passamos ao quarto e último modelo relativo ao índice de ações. Neste o atraso entre os fatores e a variável a ser prevista chega a 63 dias úteis. Analisando a Figura 42 do Anexo 1, em primeiro lugar notamos que apesar do atraso ser agora de 3 meses, ainda há uma aderência relevante na primeira metade da amostra, assim como nos modelos anteriores. Por outro lado, no momento seguinte, com maior stress e saltos no índice de volatilidade, voltamos a verificar que há uma tendência a subestimar o índice. Mais uma vez podemos inferir que há fatores não modelados a partir de meados de 2014 que entram em cena. Assim sendo, os fatores isoladamente levam a uma volatilidade menor do que a estimada recorrentemente, deixando esse "excesso de volatilidade" sem explicação. Os erros mpedios podem ser vistos na tabela abaixo:

\begin{tabular}{|lrr|}
\hline & Erro (\%) & Erro Absoluto (\%) \\
\hline Total & $-18.32 \%$ & $21.34 \%$ \\
Até 31/Jul/2014 & $-8.09 \%$ & $13.11 \%$ \\
Após 31/Jul/2014 & $-31.04 \%$ & $31.58 \%$ \\
\hline
\end{tabular}

Tabela 8: Erros do modelo para índice de volatilidade com atraso de 63 dias

O resultado visto na tabela é surpreendente uma vez que os erros médios até Julho de 2014 são os menores entre todos os modelos. Por outro lado, os erros daí em diante são os maiores entre todos os modelos. Ou seja, os fatores 
possuem uma certa persistência conforme o atraso aumenta em um momento de pouco stress, porém são incapazes de modelar corretamente cada vez mais os momentos de stress. O gráfico da Figura 43 então deixa isso bem claro, e mostra os dois momentos distintos antes e depois de meados de 2014 mais uma vez.

Os gráficos das Figuras 44 a 48 portanto irão demonstrar uma constante ainda mais relevante desta vez, mostrando que a média ainda é a parte mais relevante entre os fatores já que o conjunto informacional trazido pelos fatores já é pequeno. Entre os fatores, todos eles oscilam entre momentos de maior ou menor relevância, não tornando claro qual deles é definitivamente o significativo.

$\mathrm{Na}$ Figura 49, ao observar o $\mathrm{R}^{2}$, verificamos que os picos durante a primeira metade são semelahntes ao visto no modelo anterior, de até $17 \%$, porém, na segunda metade, há um pico de cerca de $27 \%$ repentino que vai diminuindo rapidamente em seguida. Não há como dizer, entretanto, que esse pico obtido é representativo do que foi visto ao longo de toda a amostra. Por outro lado, observa-se que na Figura 50 do Anexo 1 o P-Value da regressão possui na maior parte do tempo valores muito baixos, demonstrando que ainda tem-se uma regressão relevante.

Ao fim desta seção relativa ao índice de volatilidade, verificamos que com atraso menor de 1 ou de 5 dias entre os fatores e a variável a ser prevista, temos o painel de juros de curto prazo como sendo altamente relevante durante praticamente toda a amostra. Quanto aos demais fatores, temos o painel de Commodities com alguns momentos de relevância, em especial também com atrasos mais curtos, e os fatores de Corporate Bonds e Moedas, por sua vez, com momentos muito breves de relevância.

Com atrasos maiores de 21 e 63 dias quase todos os fatores possuem poucos momentos de relevância, até mesmo o fator de taxas de juros de curto prazo, e a média passa a ser mais relevante.

Por outro lado, é possível ver claramente uma mudança no comportamento do modelo antes e depois de Julho de 2014. Na primeira parte a aderência do modelo é mais relevante, seus erros médios são menores e com comportamento mais próximo de aleatórios. Nessa primeira metade da amostra também verficamos que os erros médios são mantidos conforme aumentamos o atraso dos fatores. Após Julho de 2014, em um momento de stress político e econômico brasileiro, os erros médios aumentam relevantemente e ainda mais conforme aumenta-se o atraso dos fatores. Também há um viés de subestimação no nível de volatilidade indicando que há algum fator não estimado responsável por este excesso de volatilidade. 


\subsection{Variance Premium}

Nesta segunda seção dos resultados, iremos usar o mesmo modelo de fatores para prever o Variance Premium, que nada mais é do que a diferença entre o próprio índice de volatilidade estudado na seção anterior e a variância prevista para o Ibovespa. Ou seja, este estudo focará no excesso de volatilidade acima daquela prevista por modelo de previsão de variância. Com isso, conseguiremos ter uma visão melhor se os fatores conseguem prever esse excesso de volatilidade. $\mathrm{Na}$ seção anterior foi possível verificar que havia uma subestimação em momentos de stress por parte do modelo, assim sendo, uma das conclusões que podem chegar nesta seção é que de fato os fatores não carregam informação sobre o excesso ou prêmio de volatilidade e por isso eles subestimam a volatilidade do índice em um momento de maior stress.

Como já foi dito anteriormente, nesta parte dos resultados estamos tratando de dados semanais, portanto o atraso entre os fatores e a variável a ser prevista também estará em semanas.

Analisaremos primeiramente a Figura 51 do Anexo 1. Nela é possível verificar que o modelo só se ajusta ao Variance Premium em momentos com poucos saltos, não sendo capaz de prever um aumento repentino de uma semana para a outra. A aderência, como pode ser observado, não é tão boa quanto a que foi vista na seção anterior para o índice de volatilidade, o que já pode ser um indicativo que os fatores não carregam informção para esse prêmio de volatilidade, como já era esperado.

Na Figura 52, vemos que a magnitude dos erros é muito maior agora do que era visto no índice do volatilidade, apesar de oscilar em torno do zero. Obviamente o fato de termos dados semanais piora a qualidade do modelo uma vez que é difícil agregar muitos dados sem ter um período muito longo e distinto a cada iteração da janela rolante. Em todo caso, pela magnitude dos erros é possível acreditar que a suspeita que foi levantada no início é verdadeira. Para visualizar melhor a magnitude dos erros, abaixo temos a tabela com os erros médios.

\begin{tabular}{|lrr|}
\hline & \multicolumn{1}{c|}{ Erro (\%) } & \multicolumn{1}{c|}{ Erro Absoluto (\%) } \\
\hline Total & $-62.48 \%$ & $200.02 \%$ \\
Até 31/Jul/2014 & $-7.29 \%$ & $141.07 \%$ \\
Após 31/Jul/2014 & $-119.88 \%$ & $261.34 \%$ \\
\hline
\end{tabular}

Tabela 9: Erros do modelo para Variance Premium com atraso de 1 semana 
Apesar de haver um valor baixo até Jul/2014 na tabela, ao analisarmos 0 erro absoluto podemos concluir que isso é apenas devido a erros em sentidos opostos que se cancelam na média. Mesmo assim, o erro é relevantemente alto, como já tínhamos demonstrado.

Nas Figuras 53 a 57 do Anexo 1, temos uma melhor visão agora fator a fator quanto às suas respectivas relevâncias para as previsões. Assim como foi observado na seção anterior para o índice de volatilidade, o fator ligado às taxas de juros de curto prazo ainda é o mais relevante durante a maior parte do tempo e os demais fatores oscilam entre momentos de maior e menor relevância.

Por outro lado, é curioso notar que o $\mathrm{R}^{2}$ na Figura 58 chega a atingir valores até expressivos de quase $40 \%$ em alguns momentos para as regressões que fazem parte desse processo de janelas rolantes. Esses valores são até mais altos do que observamos durante toda a seção anterior na previsão do índice de volatilidade. Em todo caso, já percebemos que essa métrica pode não ser a ideal para comparação entre os diferentes modelos aqui apresentados já que comprovamos pelos erros que o modelo aqui estudado possui pouco aderência.

Por fim, na Figura 59 notamos que ainda assim a regressão como um todo é relevante durante quase a totalidade do período da amostra. Ou seja, apesar de ter erros altos, tanto o $\mathrm{R}^{2}$ quanto o $\mathrm{P}$-value da regressão ainda indicam que as regressões das janelas rolantes são válidas. Veremos em seguida como esses valores são modificados ao se aumentar o atraso dos fatores.

$\mathrm{Na}$ Figura 60, portanto, verifica-se o modelo agora com atraso de 5 semanas. Mais uma vez o ajuste não se adapta muito bem a alguns dos saltos e momentos de maior stress, apesar de conseguir se ajustar ao nível da série a ser prevista. Como aqui estamos sempre tratando de semanas, o atraso aumenta de forma muito rápida ao passarmos de 1 para 5 semanas, portanto os resultados já podem possuir diferenças maiores rapidamente.

Na Figura 61 verificamos os erros das regressões. Nesse caso temos muita semelhança com o que foi visto no atraso de 1 semana, ou seja, valores que oscilam em torno do zero, mas que possuem valores muito altos em diversos momentos. O mesmo pode ser visto na tabela abaixo com os erros médios. 


\begin{tabular}{|lcr|}
\hline & Erro (\%) & Erro Absoluto (\%) \\
\hline Total & $-33.60 \%$ & $149.72 \%$ \\
Até 31/Jul/2014 & $-10.94 \%$ & $152.40 \%$ \\
Após 31/Jul/2014 & $-57.17 \%$ & $146.92 \%$ \\
\hline
\end{tabular}

Tabela 10: Erros do modelo para Variance Premium com atraso de 5 semanas

Assim sendo, a tabela nos dá uma informação também semelhante ao caso com 1 semana de atraso nos fatores: erros que aparentam ser pequenos até $\mathrm{Jul} / 2014$, mas que de forma absoluta possuem valores muito altos. Isso indica mais uma vez que temos um ajuste pouco ideal para as regressões que compõem as janelas rolantes do método.

Nas Figuras 62 a 66 do Anexo 1 é possível verificar que mesmo possuindo um nível de erros alto, existem fatores que possuem relevânca alta para as regressões. São os casos dos painéis de juros de curto prazo mais uma vez, como já visto no atraso de 1 semana e também na seção anterior. Porém nesse caso também há uma alta relevância do fator de Corporate Bonds durante um período relevante.

Além disso, na Figura 67, temos mais uma vez o $\mathrm{R}^{2}$ com valores que oscilam entre $20 \%$ e $30 \%$ durante grande parte das regressões. Isso se assemelha ao que foi visto também no atraso de 1 semana. E por fim chegamos à Figura 68 onde temos também uma relevância alta do P-Value das regressões durante um período bastante extenso. Ou seja, apesar de possuir erros muito elevados, continuamos visualizando alguns fatores repetidamente aparecerem como relevantes, um $\mathrm{R}^{2}$ que mantém uma faixa de valores semelhante até mesmo ao que foi visto na seção anterior e um P-Value da regressão que indica alta relevância.

Passando agora para uma atraso ainda maior de 21 semanas, visualizamos o resultado da previsão na Figura 69 do Anexo 1. O resultado, apesar do atraso maior, continua bastante semelhante ao que foi visto nos casos anteriores desta mesma seção. O modelo não consegue prever saltos repentinos mas se mantém em torno de um valor médio ao longo de quase toda o período coberto. Há, mais uma vez, um pico maior que não é bem modelado e onde o erro atinge seu máximo em módulo. Portanto na Figura 70 verificamos um mesmo padrão de erros oscilando ao redor de zero, porém com momento de pico nos quais os erros atingem valores muito altos. Quanto aos erros médios, eles podem ser vistos na tabela abaixo. 


\begin{tabular}{|lcr|}
\hline & Erro (\%) & Erro Absoluto (\%) \\
\hline Total & $-65.99 \%$ & $186.65 \%$ \\
Até 31/Jul/2014 & $-74.06 \%$ & $156.08 \%$ \\
Após 31/Jul/2014 & $-57.60 \%$ & $218.43 \%$ \\
\hline
\end{tabular}

Tabela 11: Erros do modelo para Variance Premium com atraso de 21 semanas

Nas Figuras 71 a 75 já é possível verificar que houve uma mudança de comportamento nos fatores. Desta vez, já há uma perda de significância dos mesmos, até mesmo no fator de juros de curto prazo que possui agora um período mais curto de relevância na regressão. Enquanto nos outros fatores os períodos de alta relevância se tornam pontuais.

$\mathrm{Na}$ Figura 76, por sua vez, visualiza-se o $\mathrm{R}^{2}$ que passa parte do período com valores baixos e parte do período com valores um pouco mas altos, chegando a atingir $35 \%$ no valor máximo. Interessante notar que os valores máximos ocorrem em momentos de maiores valores de erros, justamente nos momentos de stress. Assim sendo, como já foi comentado em outros momentos, não necessariamente o $\mathrm{R}^{2}$ pode ser a melhor métrica para analisar as regressões deste trabalho.

Por fim, na Figura 77 do Anexo 1, pode-se verificar a evolução do P-Value da regressão que já não é relevante durante a maior parte do período como foi visto em outros testes desse tipo anteriormente. Apenas por alguns breves momentos temos a regressão mais relevante.

Passando agora ao maior atraso para esta seção, temos os fatores com lag de 63 semanas com relação a variável a ser prevista. Na Figura 78, portanto, é possível ver a comparação das regressões com o próprio Variance Premium. O formato observado ainda continua semelhante ao que foi visto anteriormente com atrasos menores, apesar de possuir visivelmente momentos com erros relevantes. Colocando em números, podemos verificar os erros médios na tabela abaixo.

\begin{tabular}{|lrr|}
\hline & Erro (\%) & \multicolumn{1}{c|}{ Erro Absoluto (\%) } \\
\hline Total & $50.80 \%$ & $250.64 \%$ \\
Até 31/Jul/2014 & $-47.95 \%$ & $131.82 \%$ \\
Após 31/Jul/2014 & $153.51 \%$ & $374.21 \%$ \\
\hline
\end{tabular}

Tabela 12: Erros do modelo para Variance Premium com atraso de 63 semanas

Assim sendo, como já era esperado temos erros de valores muito altos independente do momento em que a regressão está localizada. Ou seja, apesar de termos um aumento na segunda parte da amostra, a primeira parte já é 
relevantemente alta. $\mathrm{O}$ mesmo pode ser visto também na Figura 79, em que o mesmo padrão se repete com oscilações nos valores do erros de magnitudes muito elevadas.

Nas Figuras 80 a 84 , percebe-se que com um atraso muito grande entre os fatores, este já perderam praticamente toda a relevância e capacidade preditiva com relação ao Variance Premium. Com poucas exceção, os gráficos mostram que durante a maior parte do período todas as séries são pouco relevantes para a regressão, inclusive o painel de juros de curto prazo que já apresentou alta relevância em outros momentos destes testes.

Já na Figura 85, curiosamente, observa-se que o $\mathrm{R}^{2}$ das regressões deste modelo em específico assume por vezes valores muito altos, chegando a $70 \% \mathrm{em}$ alguns breves momentos. Ou seja, apesar de possuir erros relevantes e ter por grande parte do tempo os fatores pouco relevantes, a regressão dá a entender que pode explicar bem os movimentos do Variance Premium. Essa informação acaba por não ser conclusiva, dadas as demais evidências que se encontra para esse mesmo modelo.

Por fim, na Figura 86, temos os valores de P-Value das regressões com os fatores atrasados de 63 semanas. Esses valores observados conversam em parte com os valores de $\mathrm{R}^{2}$ uma vez que indicam relevância nos mesmos momentos que o valor de $\mathrm{R}^{2}$ é alto. Mais uma vez é interessante notar que mesmo com um atraso grande entre os fatores e a variável a ser prevista e com erros por vezes muito relevantes, ainda há muita relevância e poder explicativo em certos momentos.

Assim sendo, após a análise de 4 diferentes atrasos para os fatores em relação ao Variance Premium, chegamos a resultados não muito conclusivos. Durante a maior parte dos testes feitos visualizamos erros por vezes de magnitudes muito elevadas. Além disso, o fator de Juros segue sendo o mais relevante, apesar de sua relevância ser diminuida conforme o atraso aumenta, enquanto os demais fatores oscilam entre momentos de maior e menor relevância. Por outro lado, existem algumas evidências através de medidas de $\mathrm{R}^{2}$ e de P-Value das regressões que existe alguma relevância. De uma forma geral, em comparação com o estudo semelhante feito na seção anterior para o índice de volatilidade, não é possível dizer que os fatores conseguem explicar de forma satisfatória esse "excesso de variância" presente no índice de volatilidade, apesar de algumas evidências positivas nesse sentido. 


\section{Conclusões}

Após o fim do estudo proposto, podemos resumir algumas conclusões. Primeiramente, foi possível verificar que os fatores podem ser construídos com diversas séries dentro de um mesmo grupo de ativos. O estudo de correlações para as séries que irão compor cada painel é importante, porém a decomposição em componentes principais (PCA) já realiza um trabalho de extraír o principal fator que determina a volatilidade do bloco. Na realidade mais relevante é verificar a presença de outliers após a construção do $\operatorname{ARMA}(1,0)+\operatorname{GARCH}(1,1)$ que por sua vez podem influenciar a primeira componente principal já que esta busca se alinhar à dimensão de maior volatilidade a ser explicada.

Ao analisar os modelos de previsão do índice de volatilidade, percebemos que há claramente uma quebra a partir da metade de 2014, quando o Brasil começa a passar por diversas crises políticas e econômicas. Na primeira metade da amostra então, o modelo se adapta bem e os fatores conseguem demonstrar uma boa capacidade preditiva, porém na segunda metade da amostra, com momentos de mudanças abruptas na volatilidade, os fatores passam a perder essa capacidade.

Além disso, é possível ver pelo estudo dos erros médios que na primeira metade há uma persistência no valor destes erros mesmo quando o atraso é aumentado entre 1 e 63 dias. Já na segunda metade há uma tendência clara de aumento no valor dos erros médios conforme o atraso entre os fatores e a variável a ser prevista aumenta.

Mais especificamente, durante todos estes testes, nos gráficos dos erros percebe-se que até Julho de 2014 os valores se aproximam mais de um comportamento aleatório, oscilando em torno do zero, apesar de possuir alguns valores mais altos em poucos momentos. Já após a metade de 2014 os erros passam a ter uma tendência clara de constantemente subestimar o nível de volatilidade observado no índice. Pode-se entender portanto que durante os momentos de crise política e econômica há fatores não modelados pelos 4 construídos nesse trabalho que causam um excesso de volatilidade ou prêmio entre o que era esperado e o que de fato se observa no índice de volatilidade. 
Assim sendo, conclui-se que durante momentos ordinários, a volatilidade do IBOVESPA pode de fato ser explicada e até prevista pelos 4 fatores construídos neste trabalho, porém durante momentos de incerteza outros fatores não controlados aqui passam a ter relevância e por isso passa a existir um prêmio relevante entre a volatilidade usual medida e o que de fato é cobrado pelos agentes de mercado refletido no índice de volatilidade. Também é importante levar em consideração que durante as crises enfrentadas pelo país desde 2014, vários saltos na volatilidade ocorreram por causa de eventos repentinos ocorridos às vezes em um único dia, que portanto são impossíveis de serem previstos por modelos desse tipo.

Ainda durante os testes para previsão do índice de volatilidade, pode-se notar que mesmo durante a primeira metade da amostra, existem crises que afetam a volatilidade o IBOVESPA, como as enfrentadas pela crise da zona do Euro em 2011, o evento das ações de OGX em 2012 e os protestos de 2013, mesmo assim para estas crises em específico, o modelo se adaptou bem. $O$ formato da crise enfrentada a partir de 2014 na realidade é o diferencial para o modelo perder parte relevante do seu poder preditivo.

Analisando os fatores, especificamente, nota-se claramente que o fator ligado a taxas de juros de curto prazo (até 2 anos) é o que durante a maior parte do tempo e em quase todos os testes possui maior relevância entre os demais. Em seguida pode-se destacar o fator ligado às commodities, seguido pelo painel de corporate bonds e por último o painel de moedas. $O$ fator de taxas de juros de curto prazo também se mostra muito relevante no paper de Andreou e Ghysels (2014) e isso é confirmado novamente para o caso brasileiro aqui. Por outro lado, o fator de moedas que foi introduzido aqui numa tentativa de melhor modelar as rápidas mudanças nas condições da economia do país acabou por ser um fator pouco relevante durante a mior parte do tempo. Como já foi citado anteriormente, esta surpresa pode ser talvez explicada pelo fator da informação trazida por este fator já estar presente nos demais e portanto este pode apresentar alta correlação com os demais.

$\mathrm{Na}$ análise do mesmo modelo aplicado ao Variance Premium, esperava-se confirmar ou não se estes fatores conseguem explicar o excesso de volatilidade citado anteriormente como presente principalmente em momentos de stress. Em primeiro lugar, nos modelos de previsão nota-se que há erros muito grandes em alguns momentos entre o valor previsto e o valor real assumido pela série em questão. É claro que o fato de passarmos a usar dados semanais pode explicar uma parte desse descasamento em alguns momentos e até mesmo as eventuais 
imperfeições na construção da própria série do Variance Premium. Porém é notável que os erros médios não são tão próximos de zero em qualquer valor de atraso utilizado. Da mesma forma, não há uma evidência persistente de que os fatores construídos aqui são melhores do que a média para explicar esse excesso de volatilidade. Isso pode ser visto pelos poucos momentos de relevância dos fatores em comparação com a constante da regressão.

Assim sendo, apesar de encontrarmos em alguns momentos valores um pouco mais elevados de $R^{2}$, pode-se dizer que não há evidência suficiente para concluir que os fatores conseguem explicar o Variance Premium, ou seja, o excesso de volatilidade entre os modelos convencionais e o realmente observado no mercado através do índice de volatilidade. Isso vai em linha com o que tínha sido concluído anteriormente, em que os fatores são bons para a previsão em momentos de pouco ou médio stress, mas não para momentos de mudanças repentinas de alto stress de forma generalizada na economia como foi visto a partir das eleições de 2014 no Brasil. Nestes momentos os agentes cobram um prêmio muito maior na volatilidade do IBOVESPA que só pode ser explicado e antecipado por fatores que não estão entre os 4 aqui propostos neste trabalho.

Assim sendo, foi possível compreender qual a utilidade dos fatores aqui construídos e também entender um pouco melhor sobre como os agentes cobram um prêmio por elevada incerteza em momentos de stress. Como evolução desse estudo, pode-se testar os fatores em momentos mais anteriores a estes utilizados aqui neste trabalho de forma a validar se sua capacidade de previsão se mantém conforme revisto em momentos de menor stress e também para entender melhor em que momento o excesso de volaitlidade não explicada pelos fatores volta a aparecer. Da mesma forma, pode-se continuar os testes com novos dados ao longo do tempo de forma a verificar se esse excesso de volatilidade diminui e os fatores passam a explicar a maior parte da volatilidade novamente. 


\section{Referências Bibliográficas}

[1] Andreou, E.; Ghysels, E.; "Predicting the VIX and the Volatility Risk Premium: What's Credit and Commodity Volatility Risk Got to Do with It?", disponível em SSRN: https://ssrn.com/abstract=2510196 ou http://dx.doi.org/10.2139/ssrn.2510196, 2014

[2] Carr, P.; Wu, L.; "Variance risk premiums", Review of Financial Studies, 22, 1311-1341, 2009

[3] Egloff, D.; Leippold, M.; Wu, L.; "The term structure of variance swap rates and optimal variance swap investments", Journal of Financial and Quantitative Analysis, 45, 1279-1310, 2010

[4] Zhou, H.; "Variance risk premia, asset predictability puzzles, and $\begin{array}{lcc}\text { macroeconomic uncertainty", } & \text { disponível } \\ \text { http://papers.ssrn.com/sol3/papers.cfm?abstract_id=1400049, } 2010\end{array}$ $\begin{array}{lcc}\text { macroeconomic uncertainty", } & \text { disponível } \\ \text { http://papers.ssrn.com/sol3/papers.cfm?abstract_id=1400049, } 2010\end{array}$

em

[5] Bakshi, G.; Panayotov, G.; Skoulakis, G.; "Improving the predictability of real economic activity and asset returns with forward variances inferred from option portfolios", Journal of Financial Economics, 100, 475-495, 2011

[6] Astorino, E.; Chague, F.; Giovannetti, B.; Silva, M.; "Variance Premium and Implied Volatility in a Low-Liquidity Option Market", disponível em SSRN: https://ssrn.com/abstract=2592650 ou http://dx.doi.org/10.2139/ssrn.2592650, 2015

[7] Carr, P.; Wu, L.; "Variance risk premiums", Review of Financial Studies 22 (3), 1311 - 1341, 2009 
Anexo-1

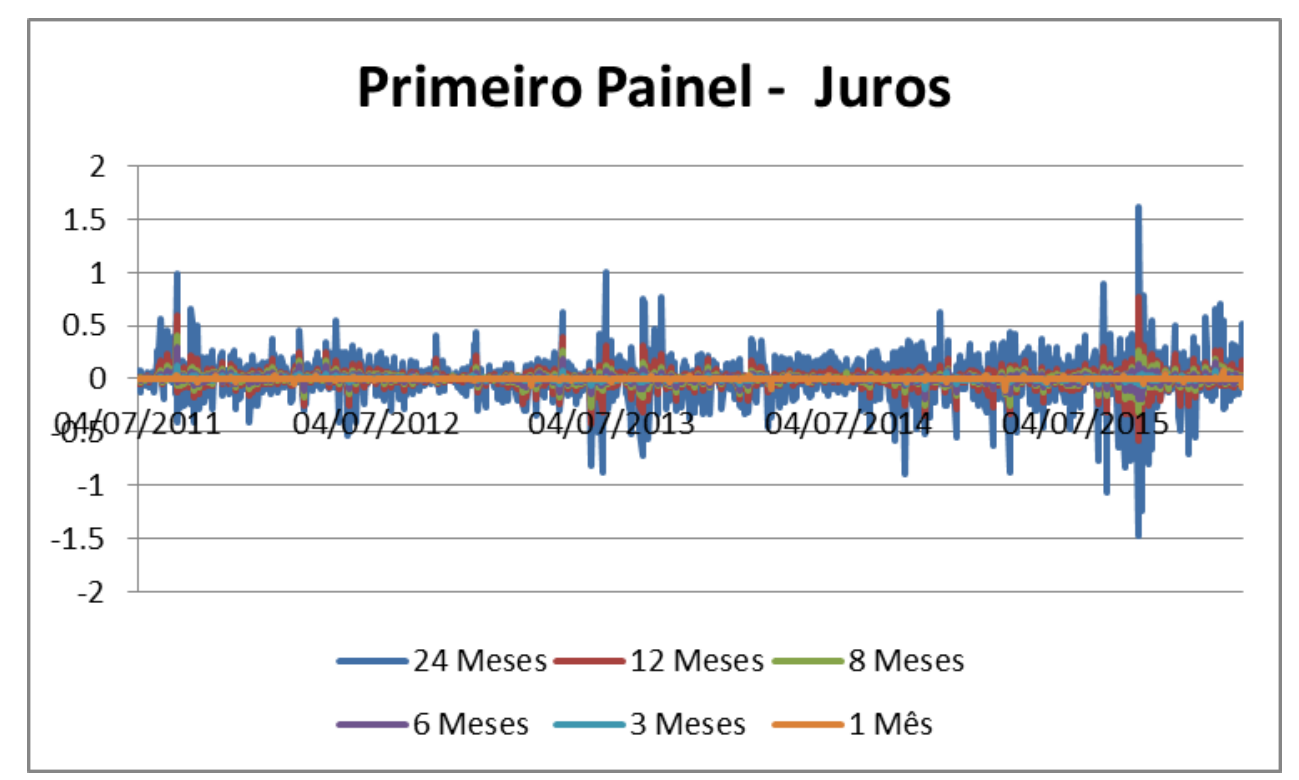

Figura 1: Séries do primeiro painel (Juros)

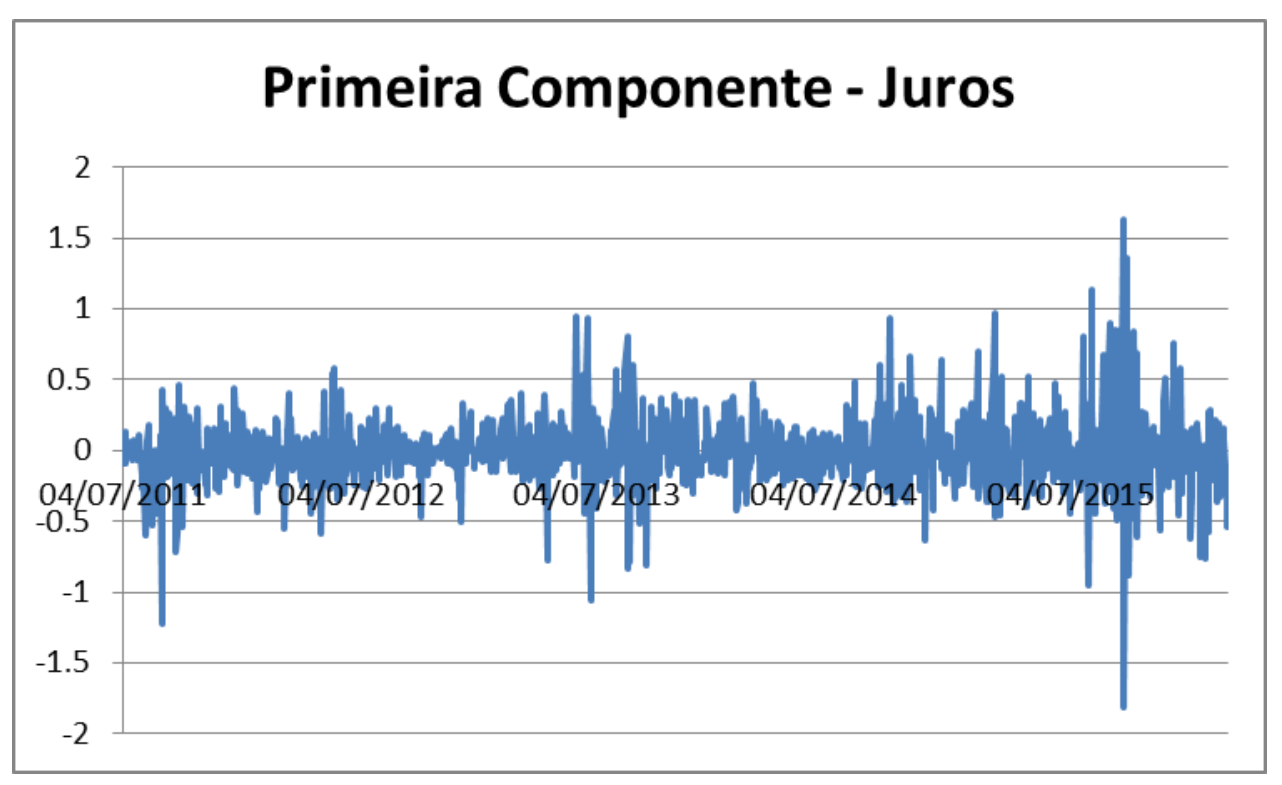

Figura 2: Primeira componente do primeiro painel (Juros) 


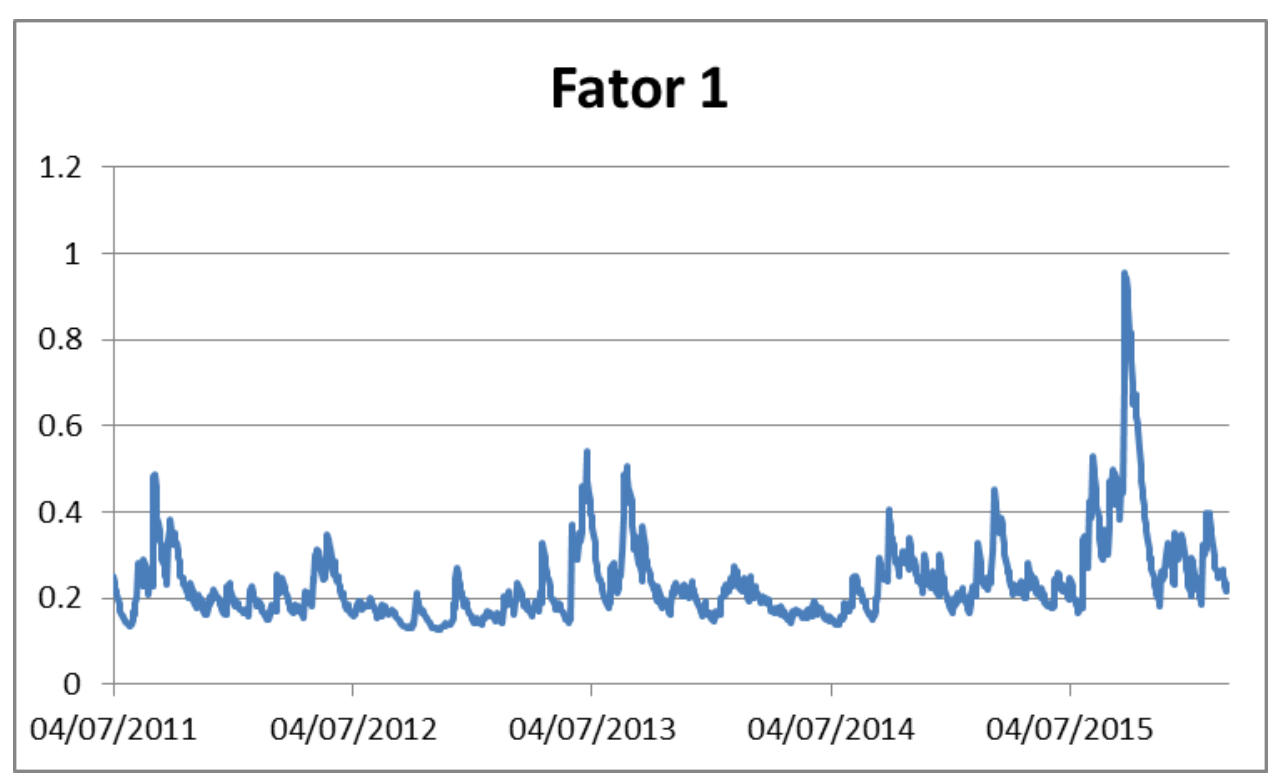

Figura 3: Primeiro fator (Painel de Juros)

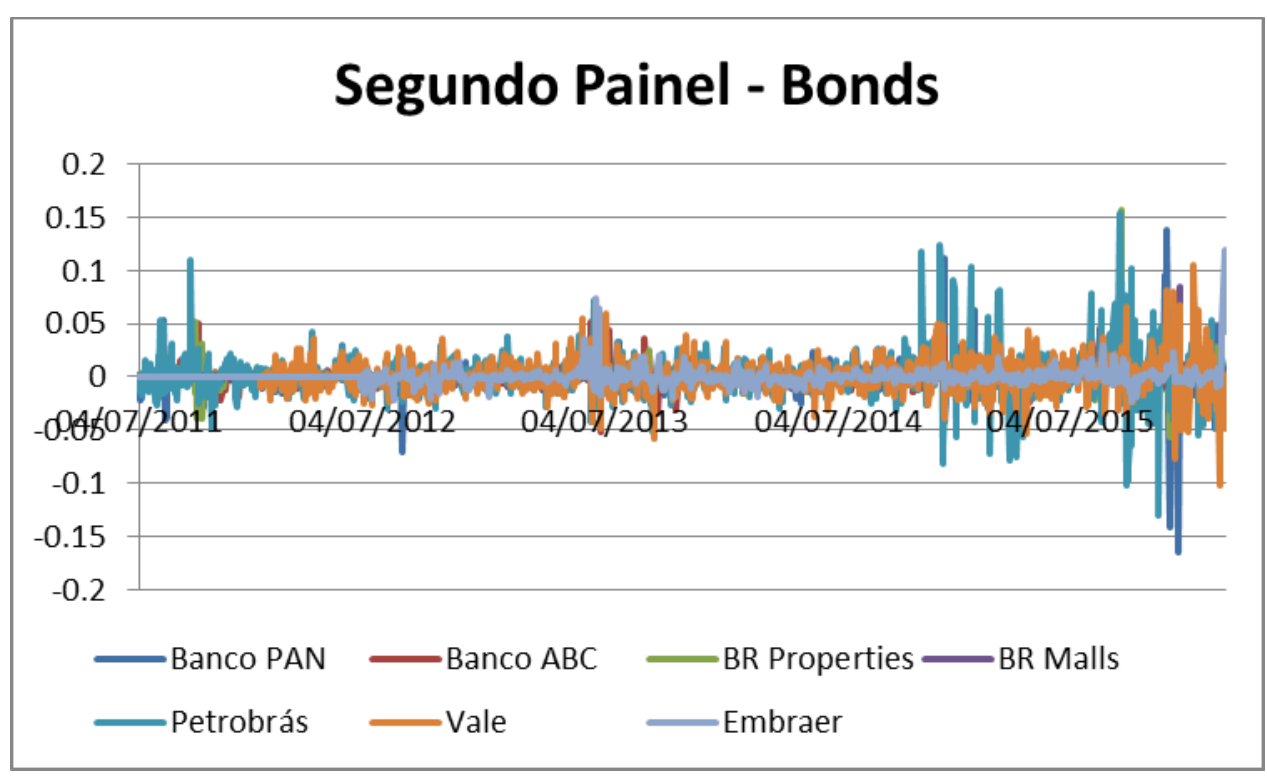

Figura 4: Séries do segundo painel (Bonds) 


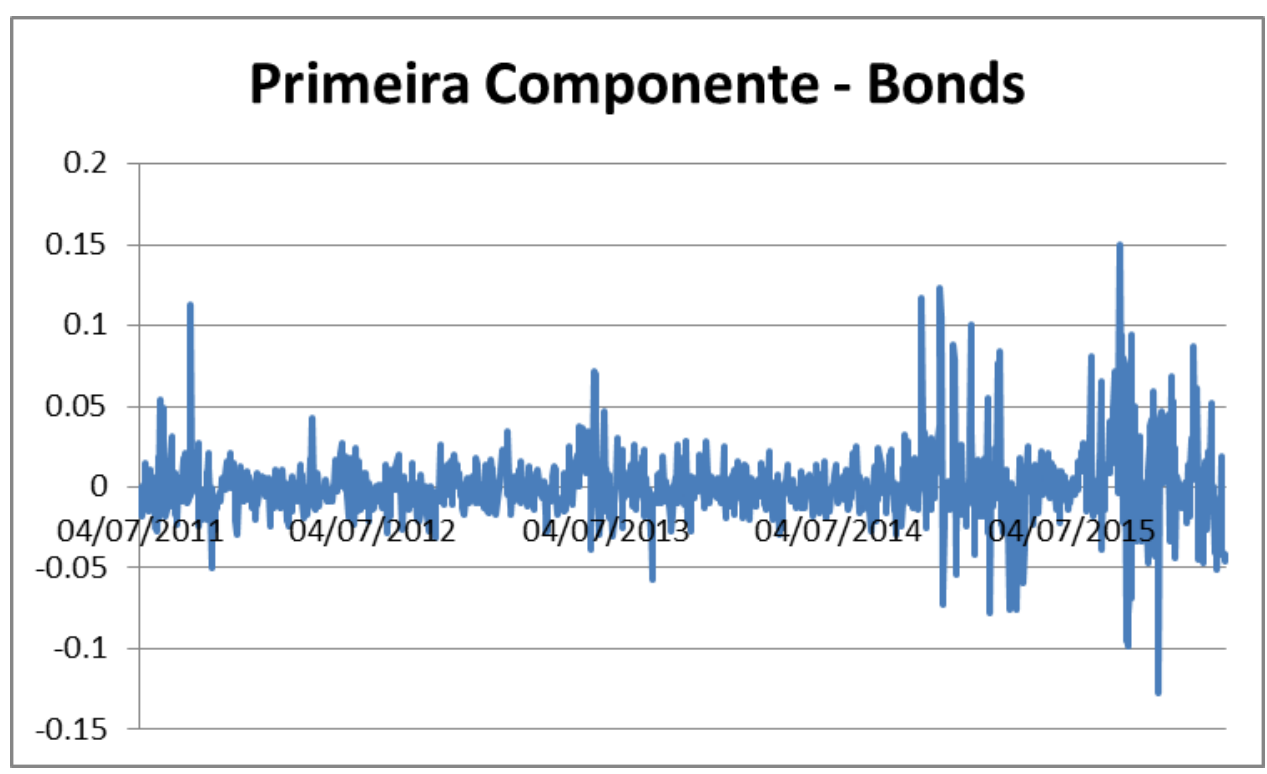

Figura 5: Primeira componente do segundo painel (Bonds)

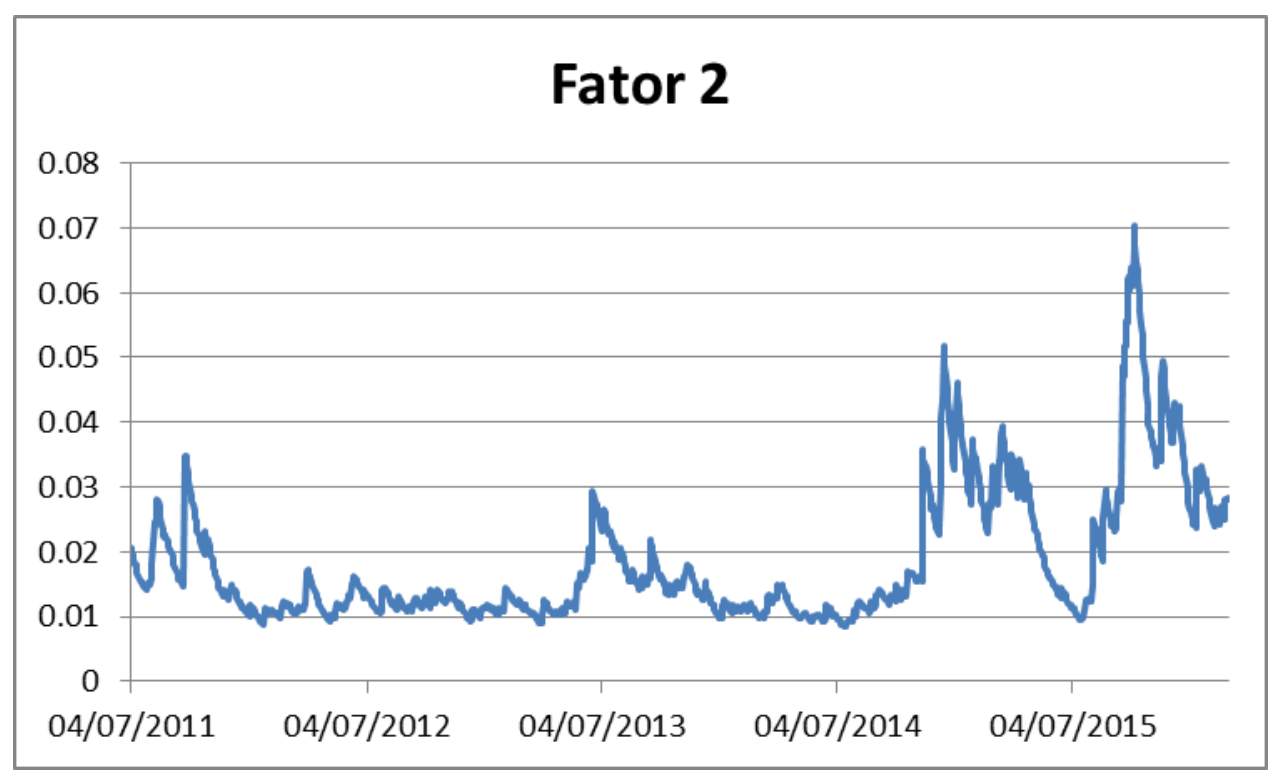

Figura 6: Segundo fator (Painel de Bonds) 


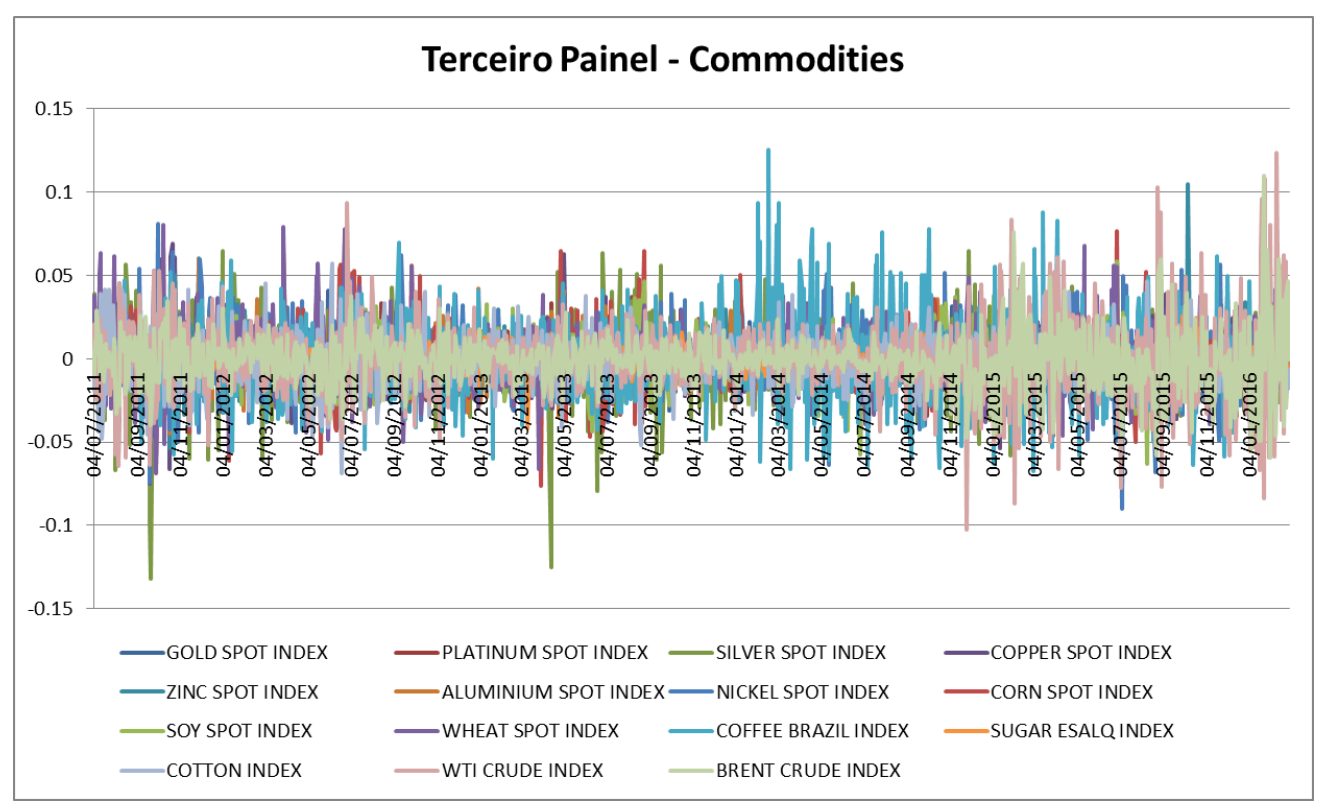

Figura 7: Séries do terceiro painel (Commodities)

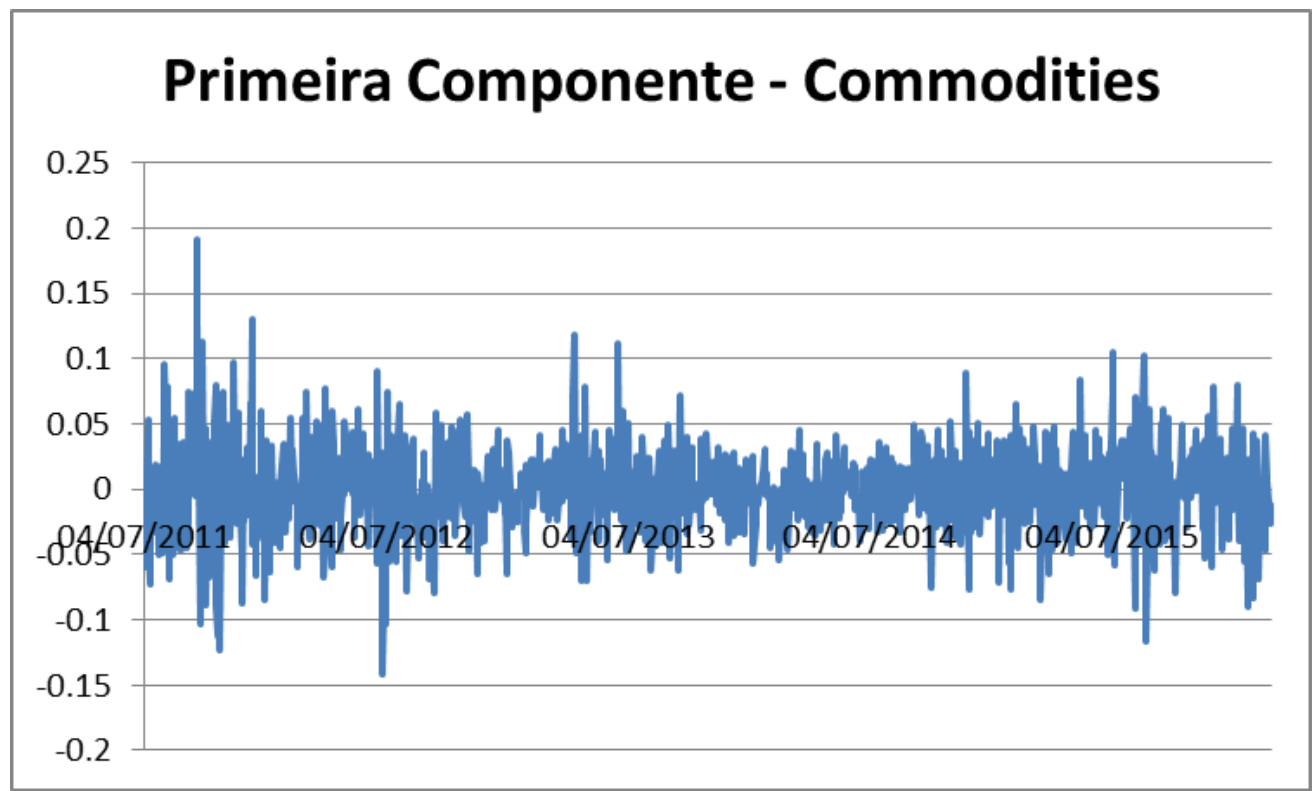

Figura 8: Primeira componente do terceiro painel (Commodities) 


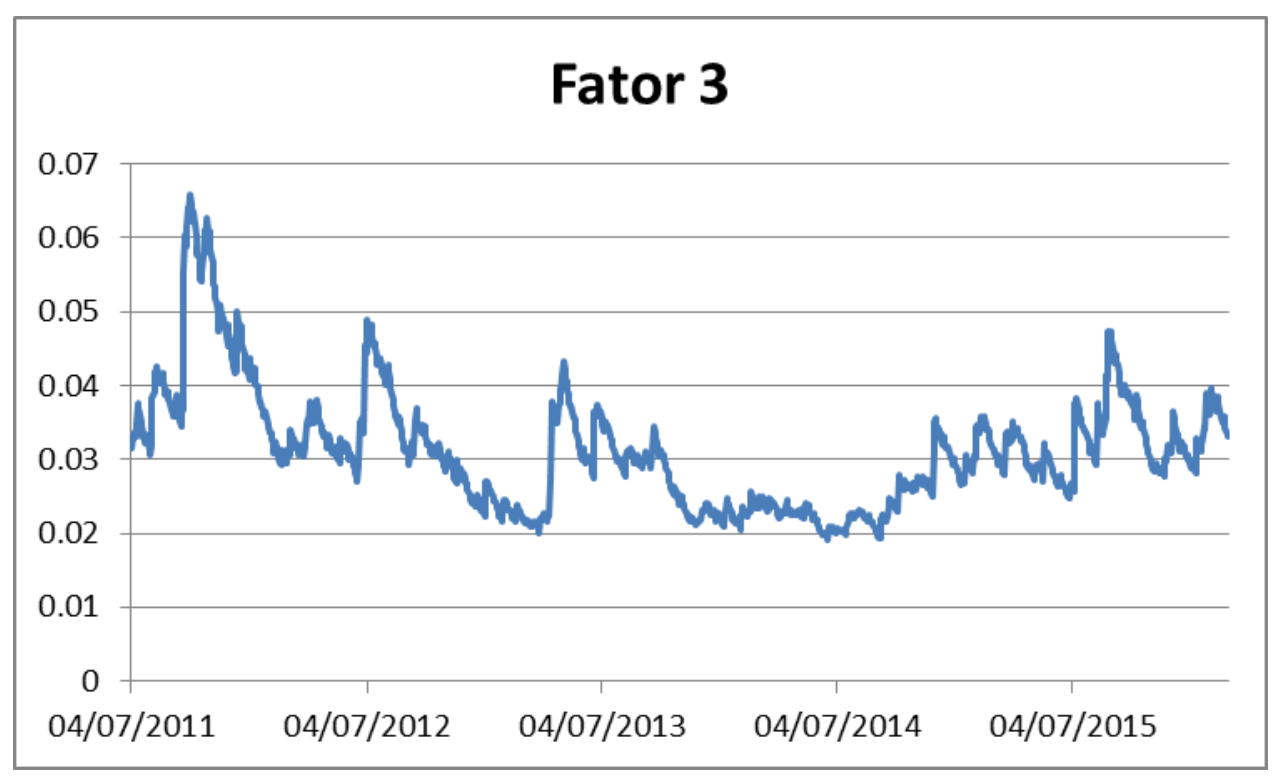

Figura 9: Terceiro fator (Painel de Commodities)

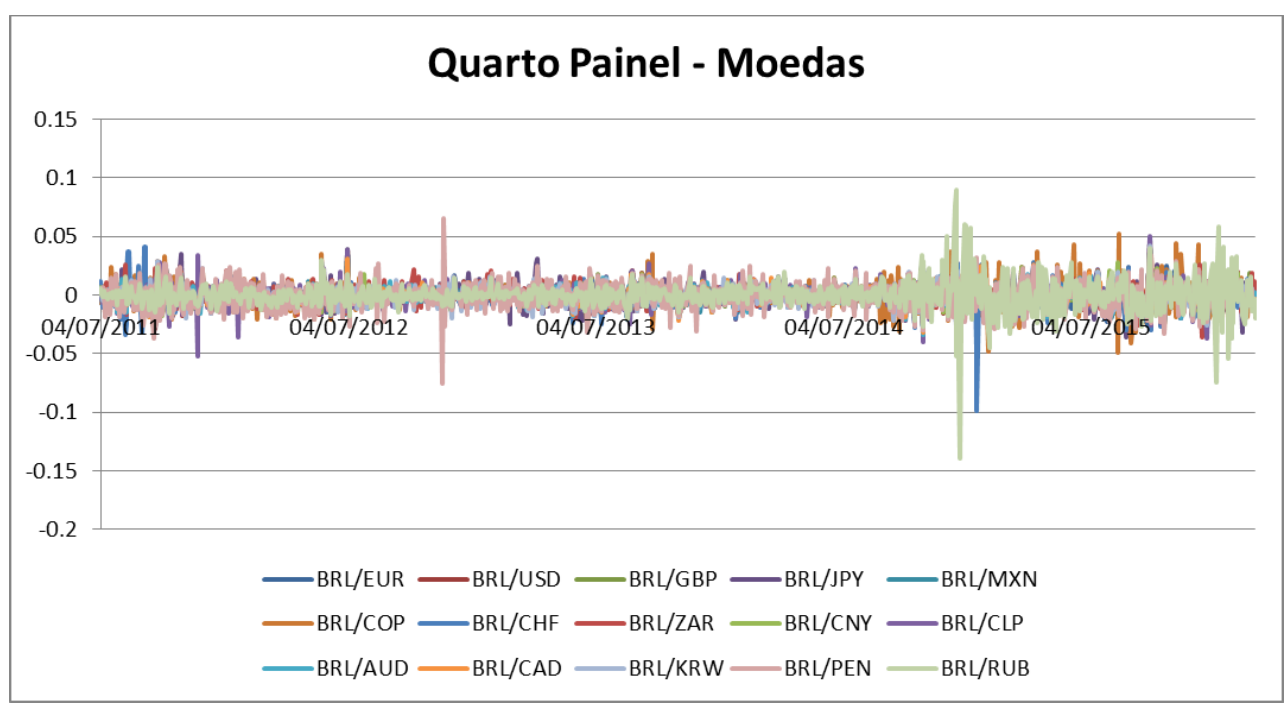

Figura 10: Séries do quarto painel (Moedas) 


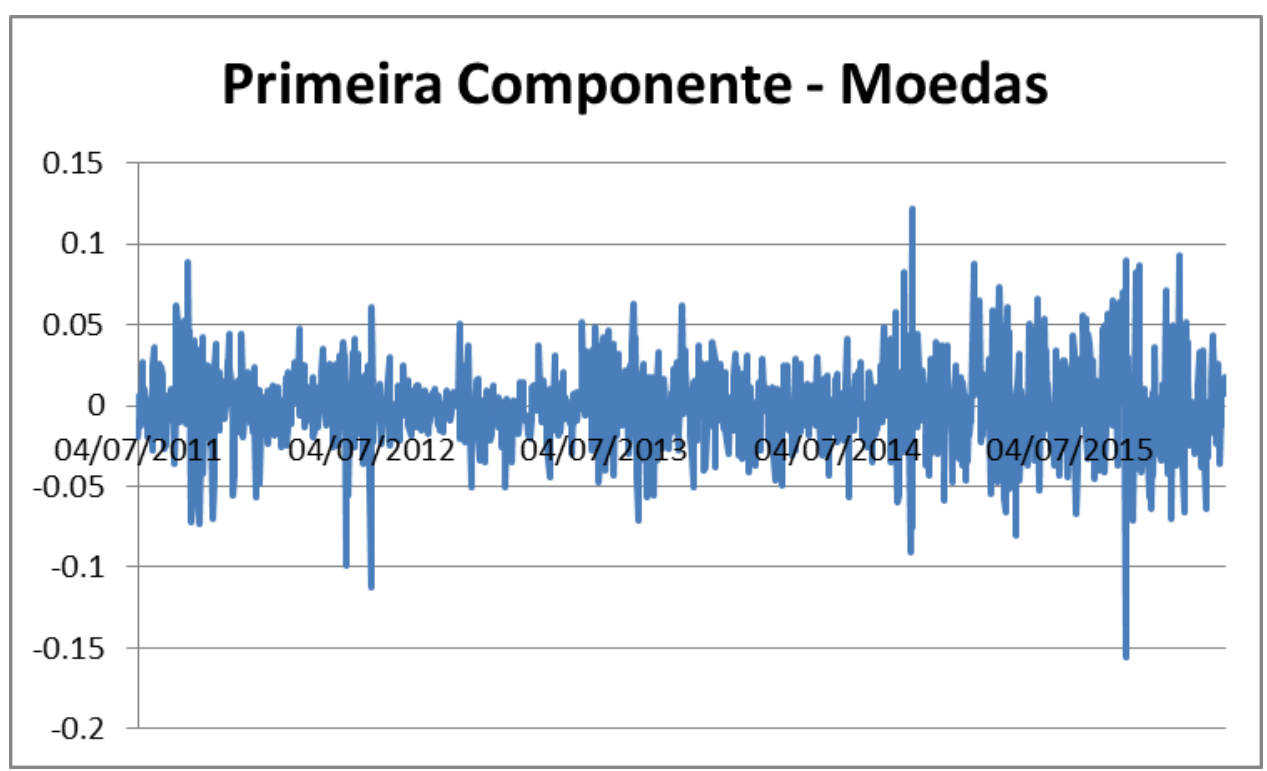

Figura 11: Primeira componente do quarto painel (Moedas)

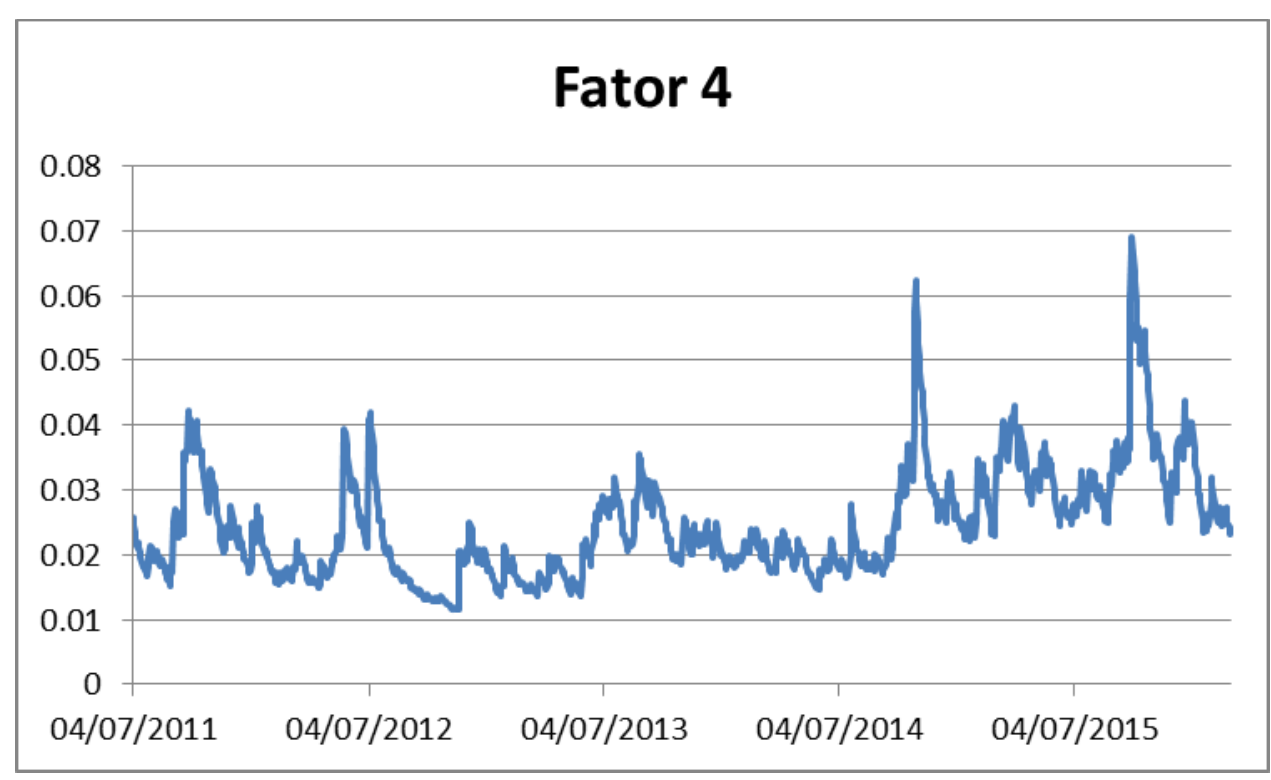

Figura 12: Quarto fator (Painel de Moedas) 


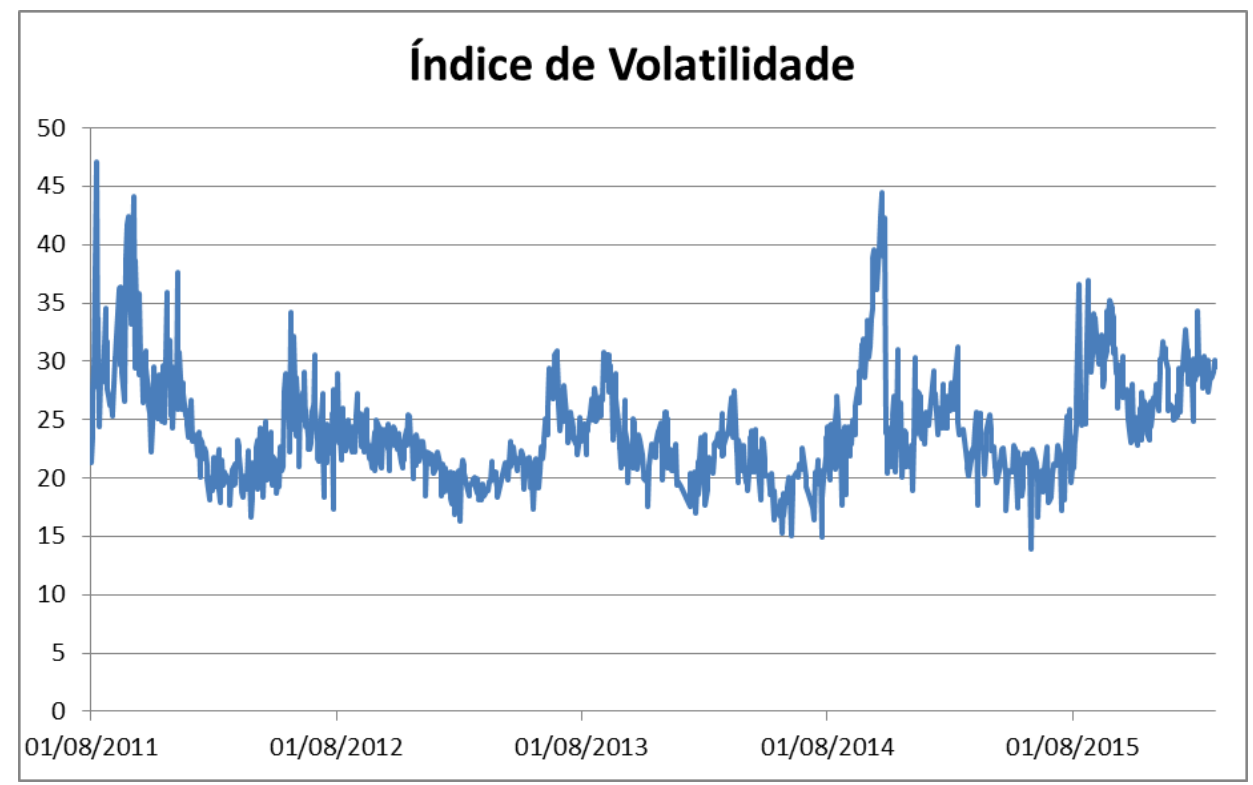

Figura 13:Série do Índice de Volatilidade

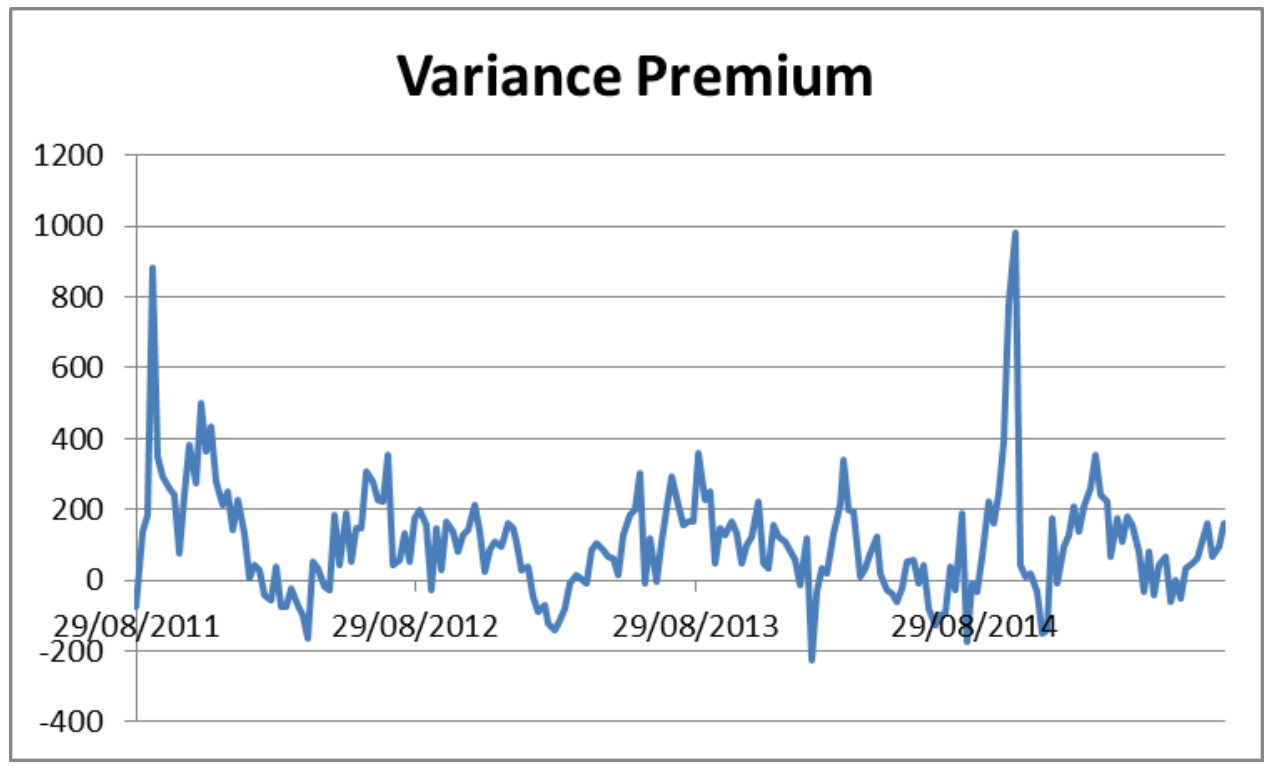

Figura 14: Série do Variance Premium. 


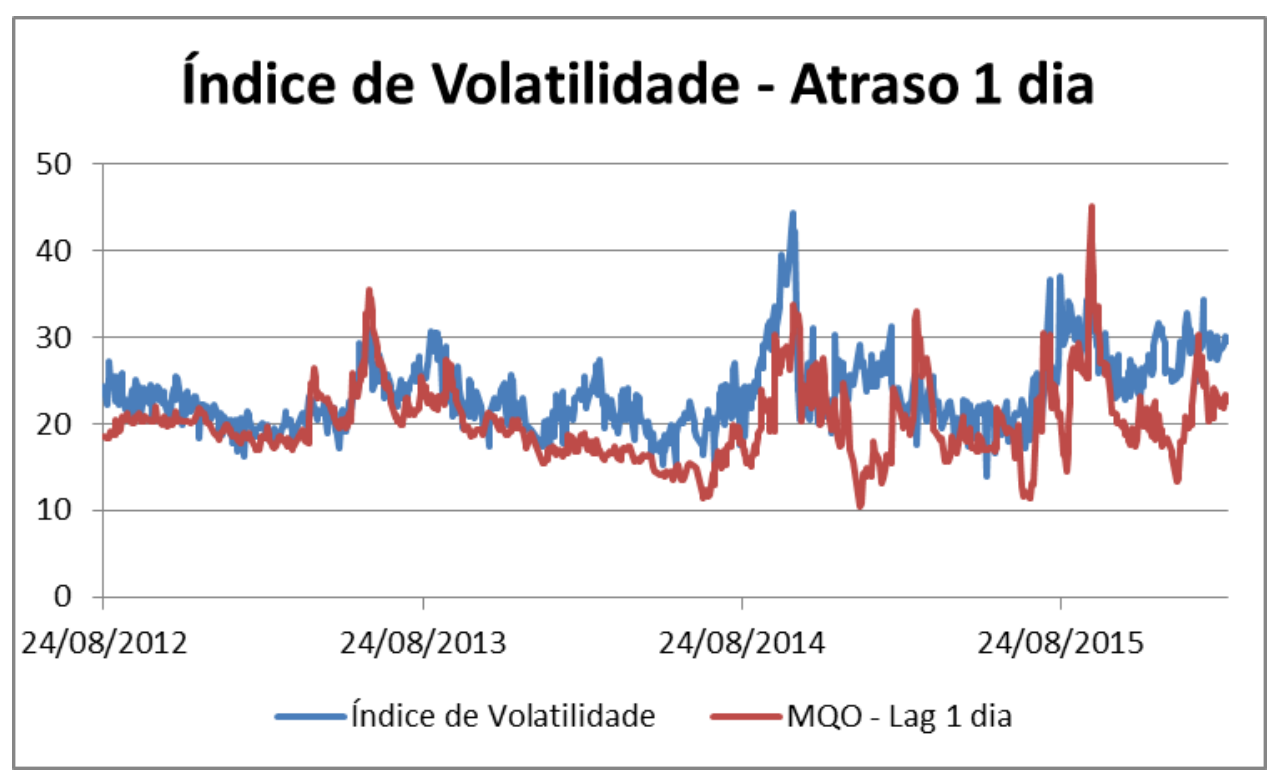

Figura 15: Regressão usando fatores com atraso de 1 dia

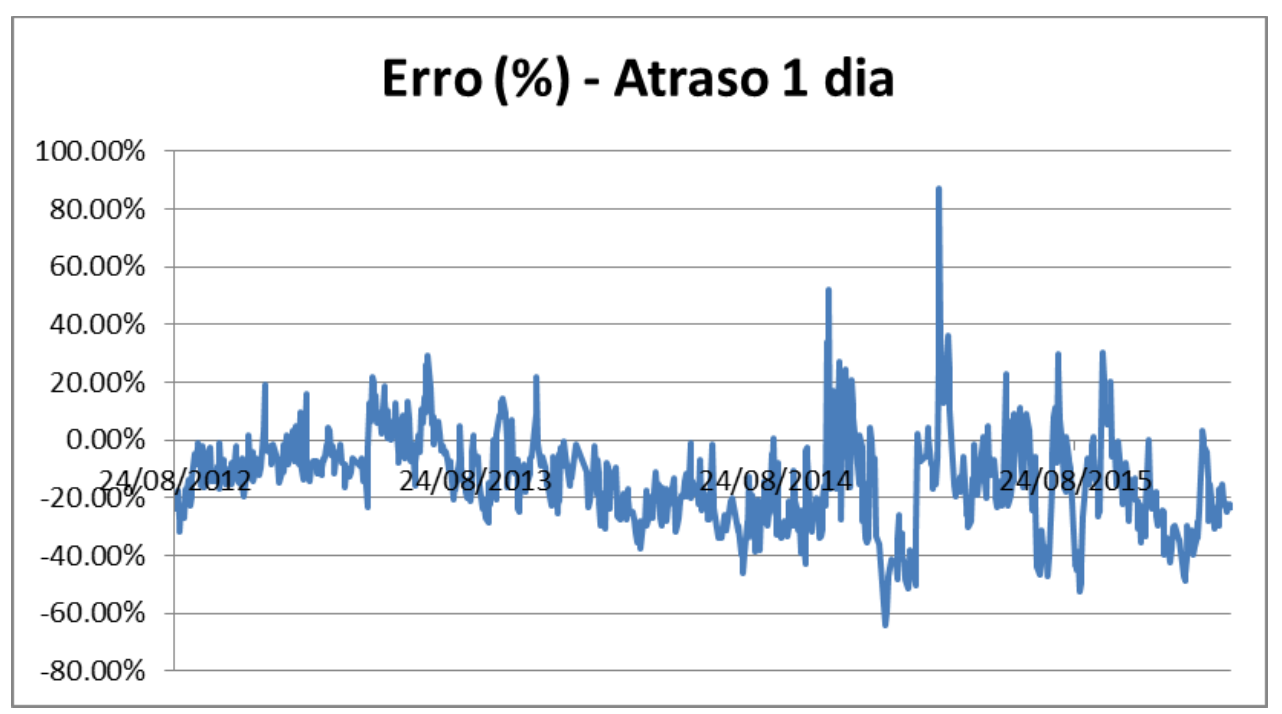

Figura 16: Erros da regressão do índice de ações - Lag 1 dia 


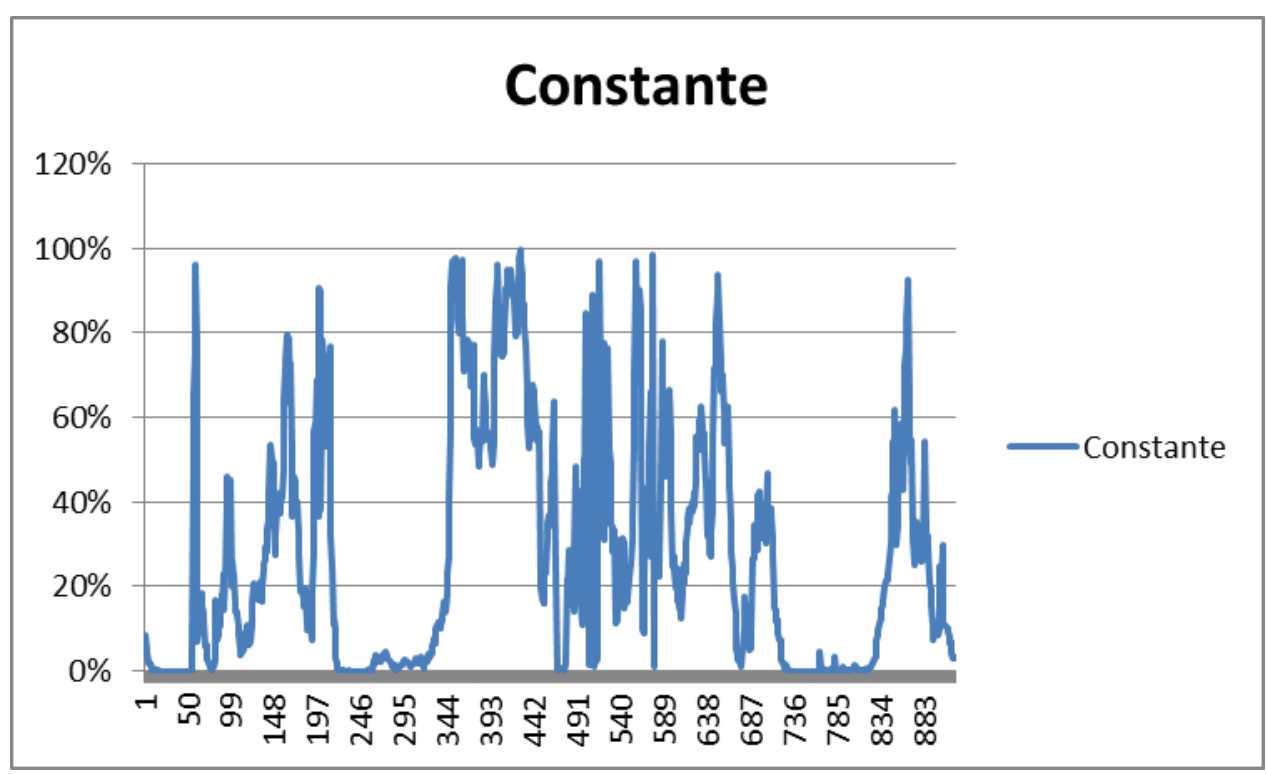

Figura 17: P-value da Constante na regressão com atraso de 1 dia

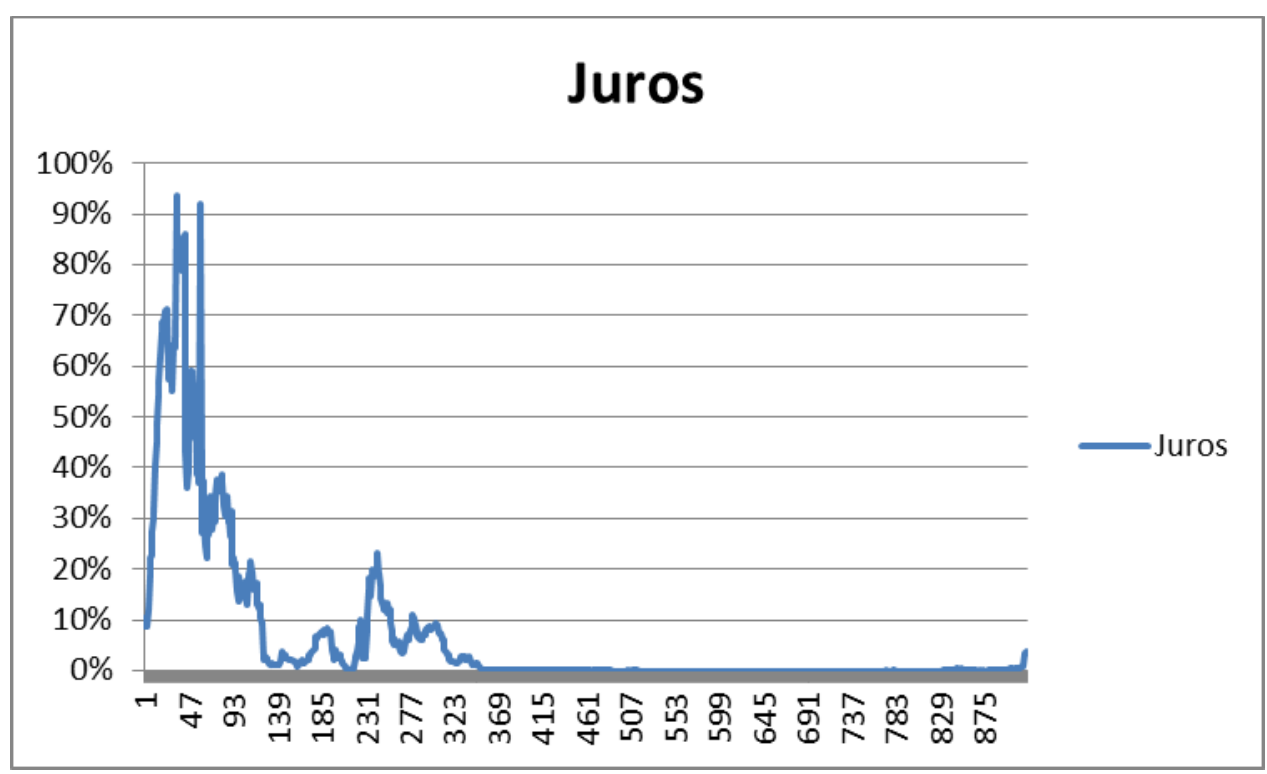

Figura 18: P-value do Fator de Juros na regressão com atraso de 1 dia 


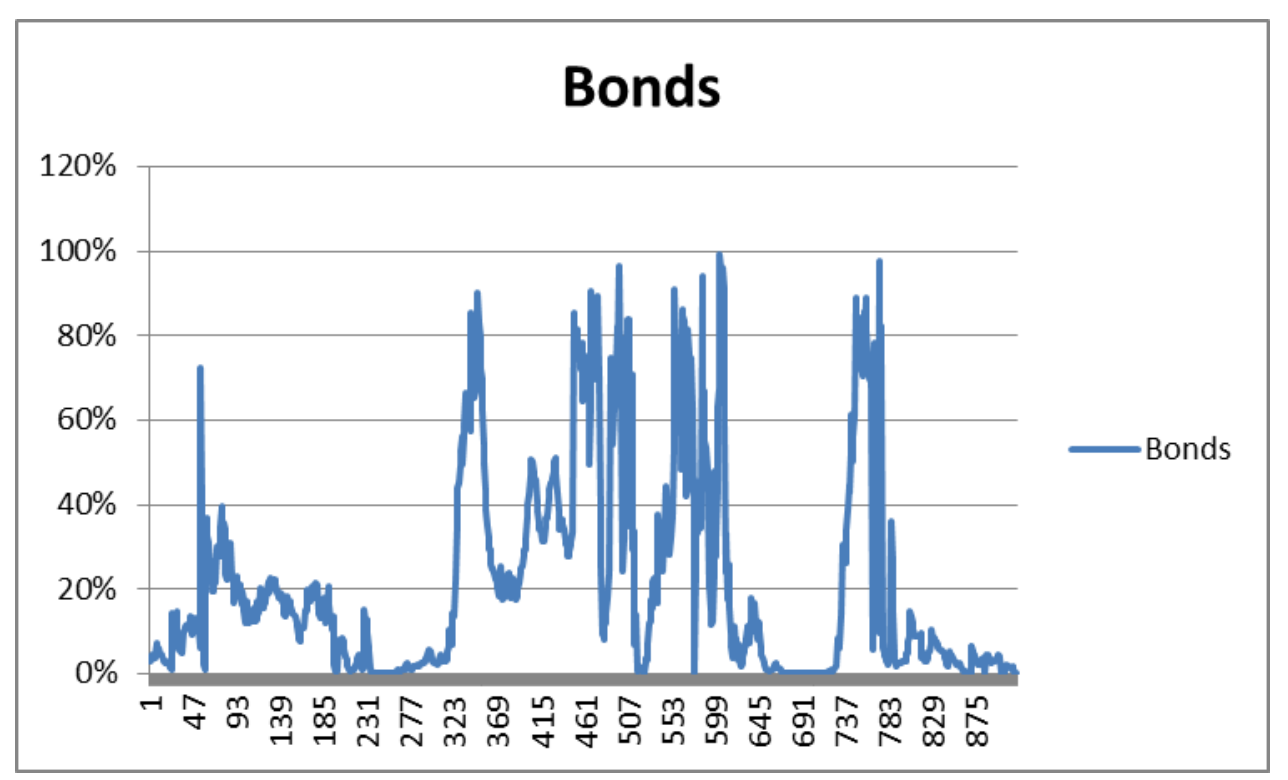

Figura 19: P-value do Fator de Bonds na regressão com atraso de 1 dia

\section{Commodities}

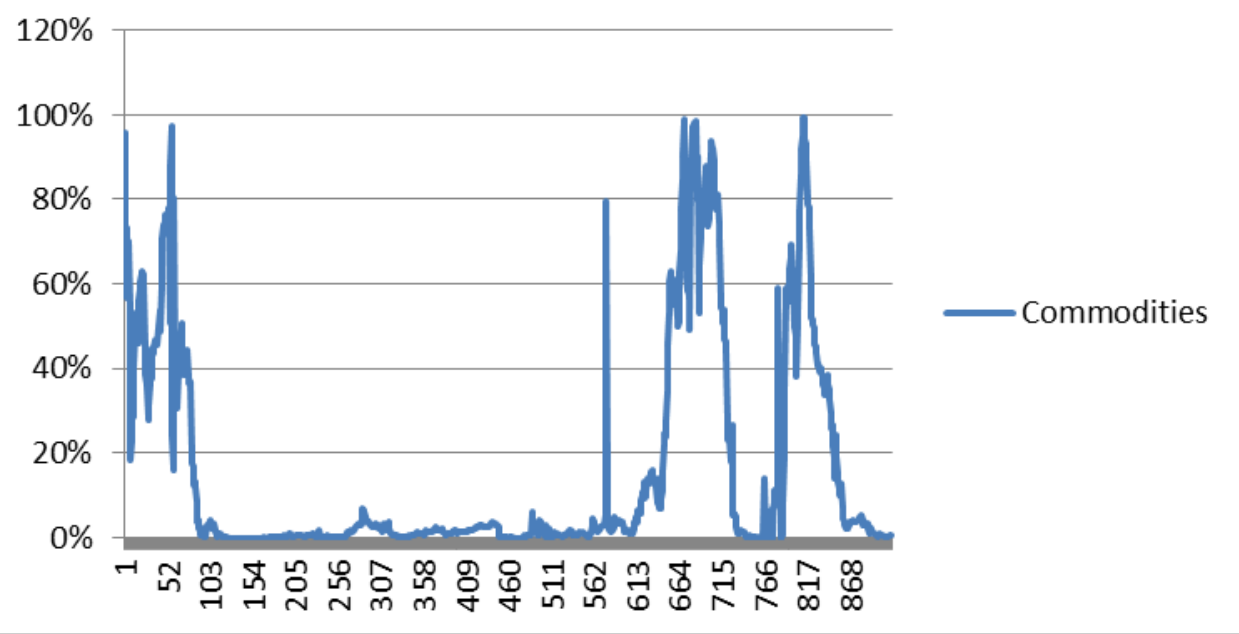

Figura 20: P-value do Fator de Commodities na regressão com atraso de 1 dia 


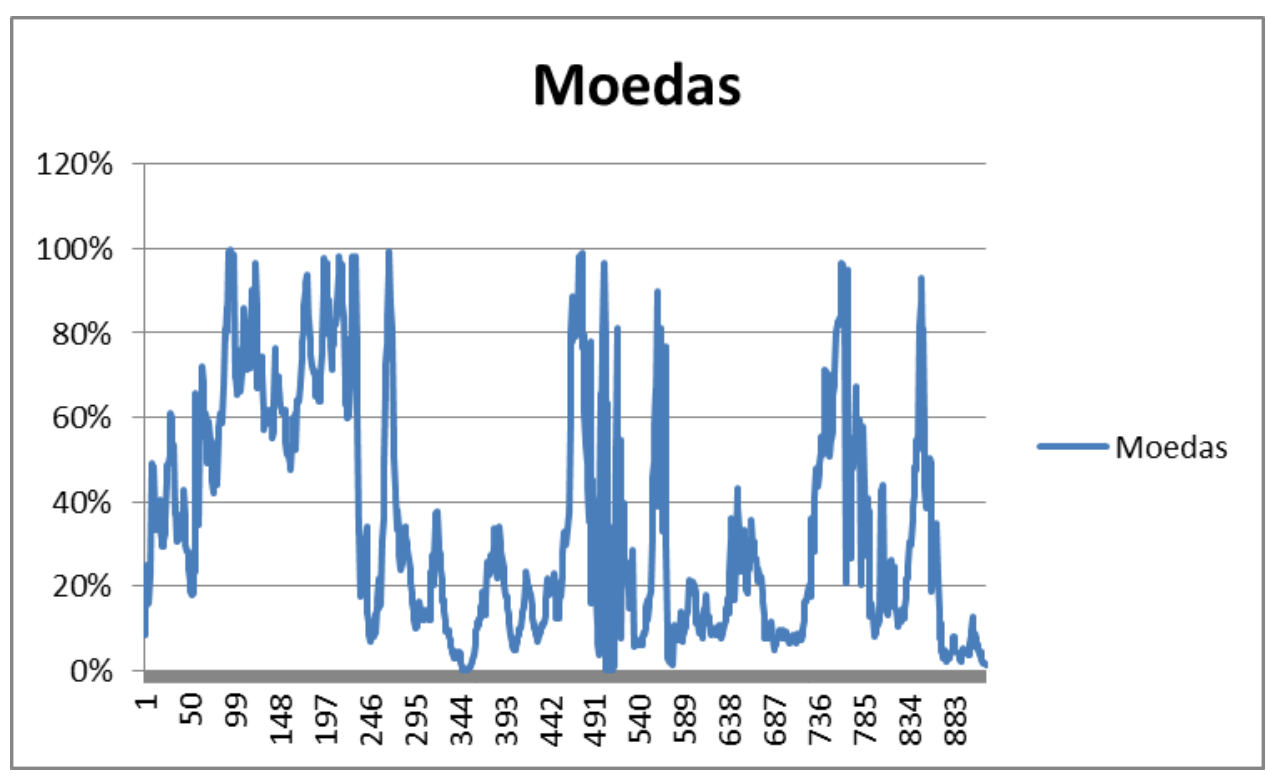

Figura 21: P-value do Fator de Moedas na regressão com atraso de 1 dia

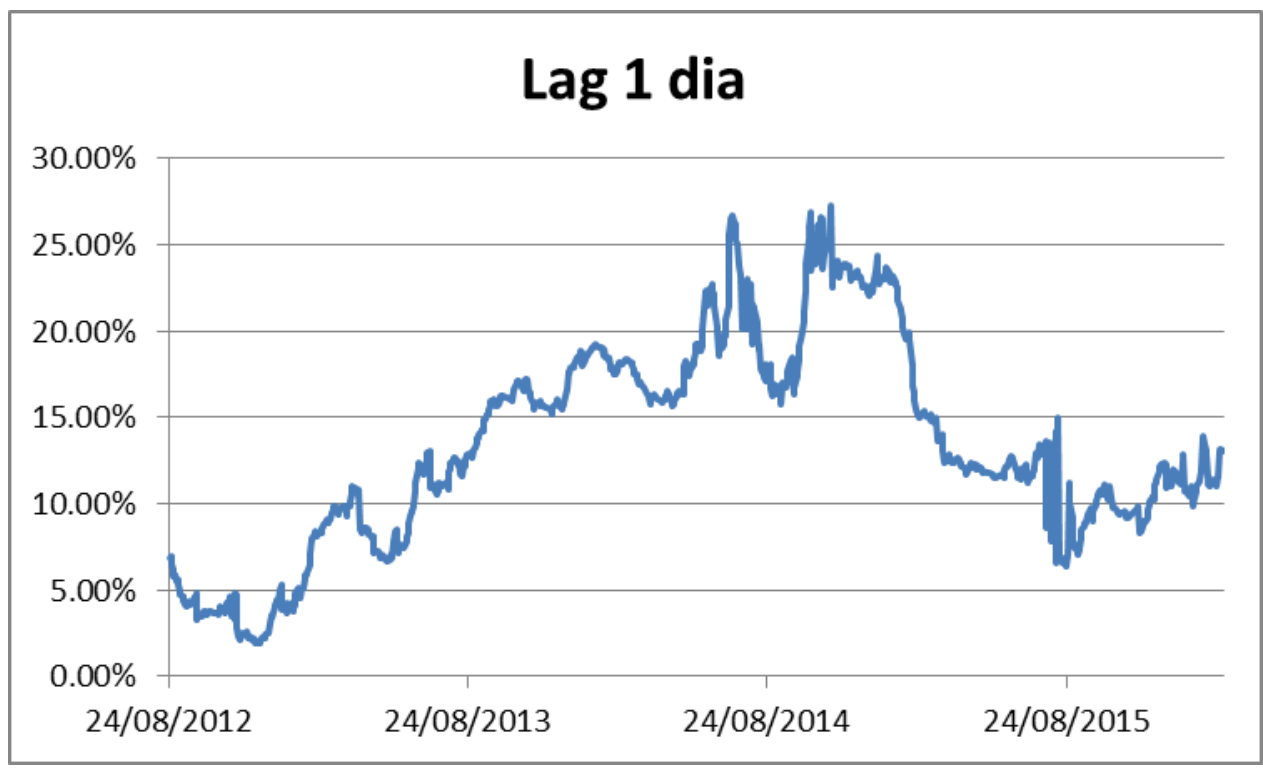

Figura 22: R Quadrado das regressões com atraso de 1 dia 


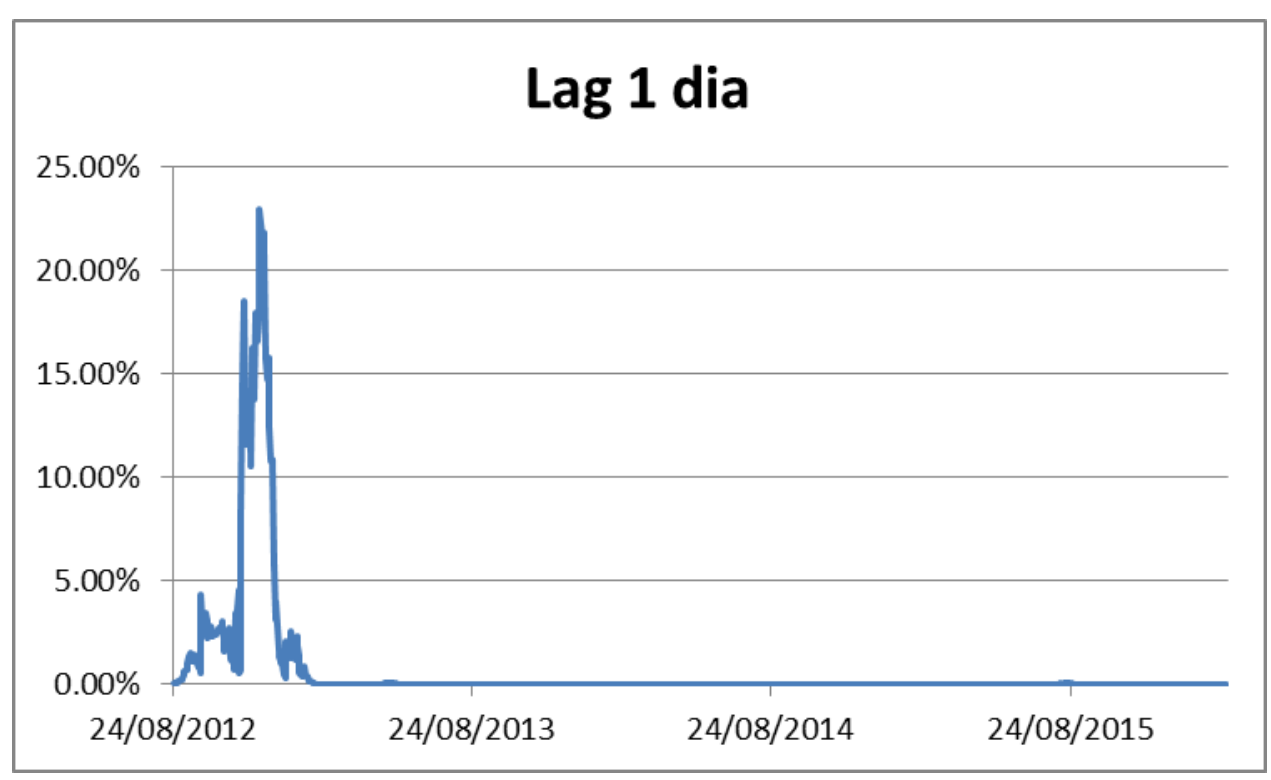

Figura 23: P-value das regressões com atraso de 1 dia

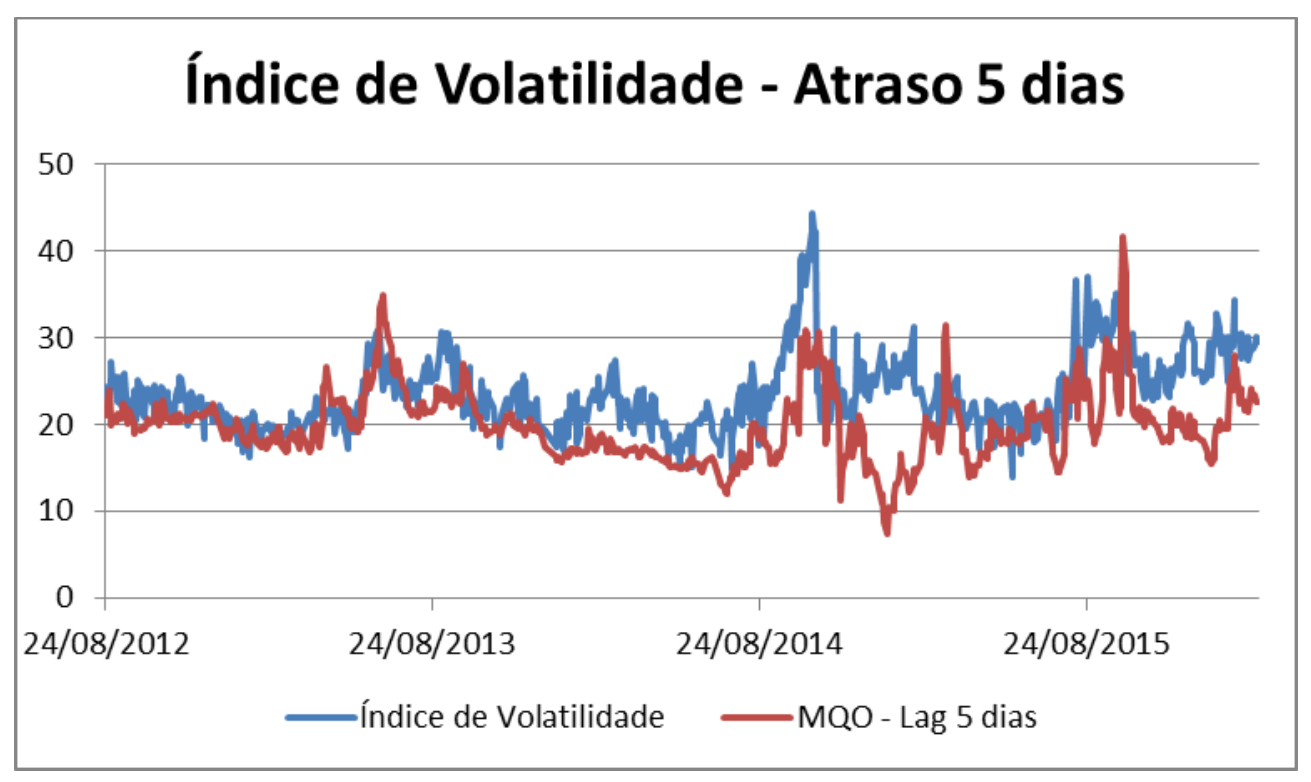

Figura 24: Regressão usando fatores com atraso de 5 dias 


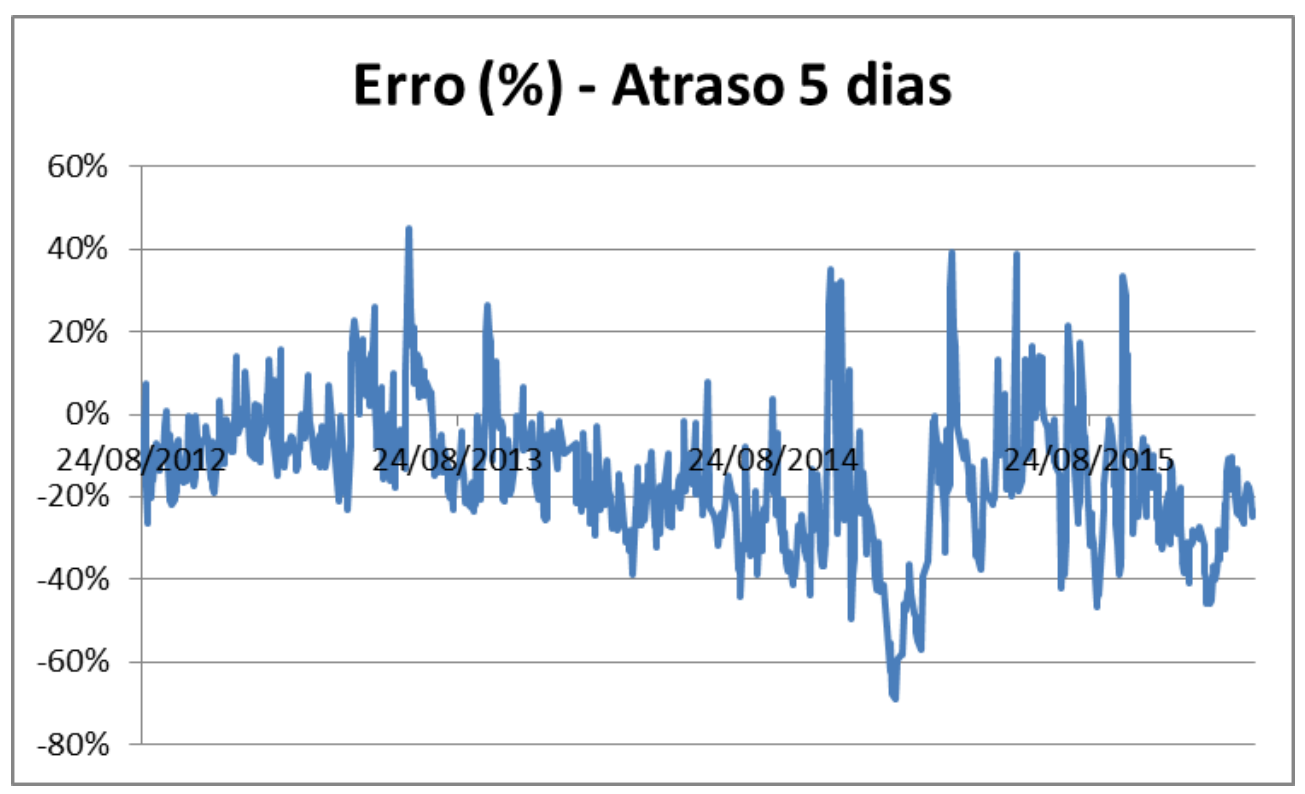

Figura 25: Erros da regressão do índice de ações - Lag 5 dias

\section{Constante}

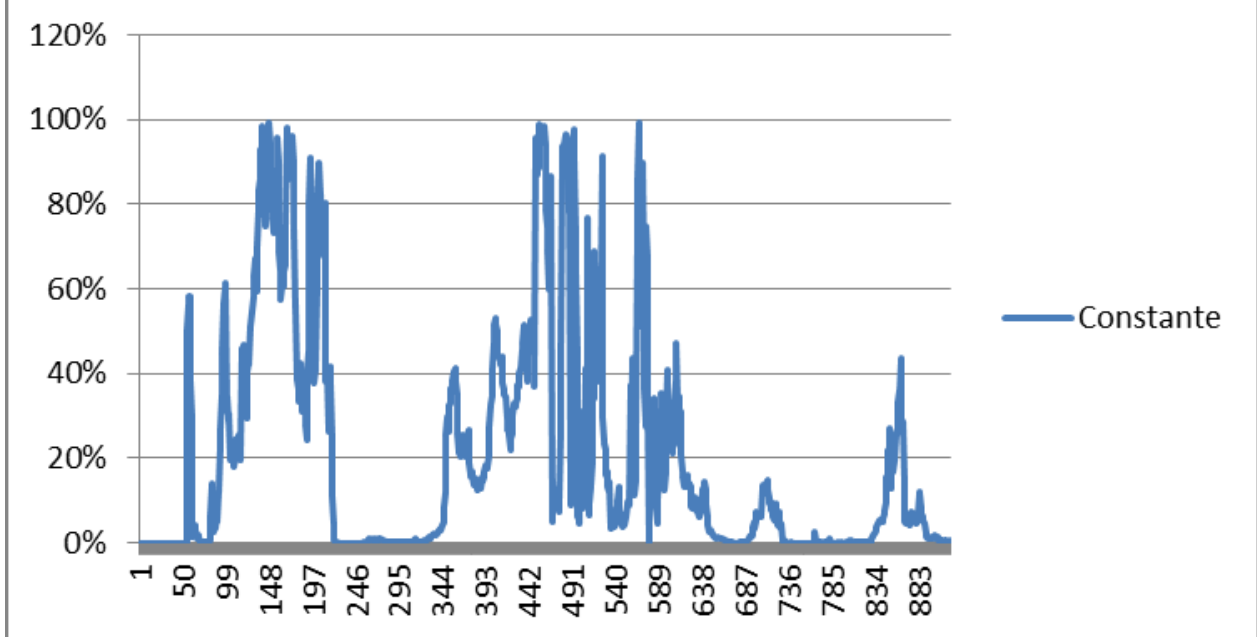

Figura 26: P-value da Constante na regressão com atraso de 5 dias 


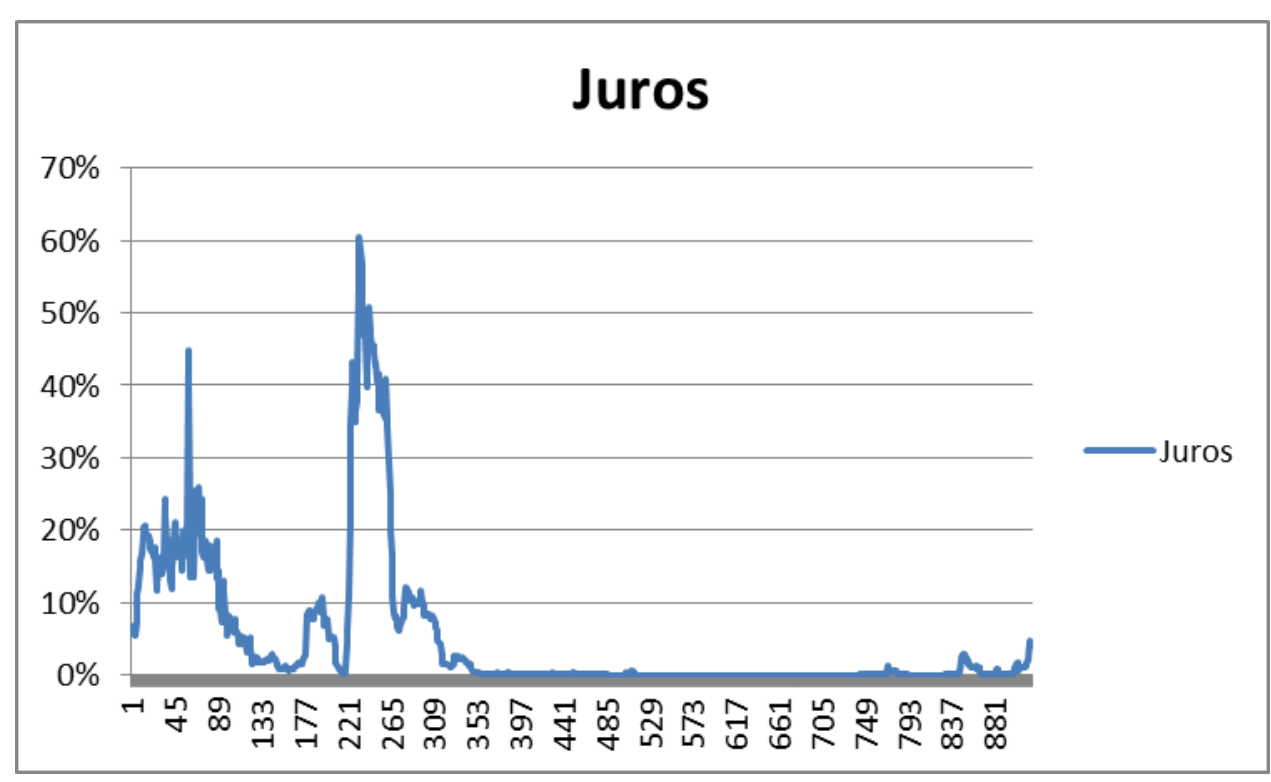

Figura 27: P-value do Fator de Juros na regressão com atraso de 5 dias

\section{Bonds}

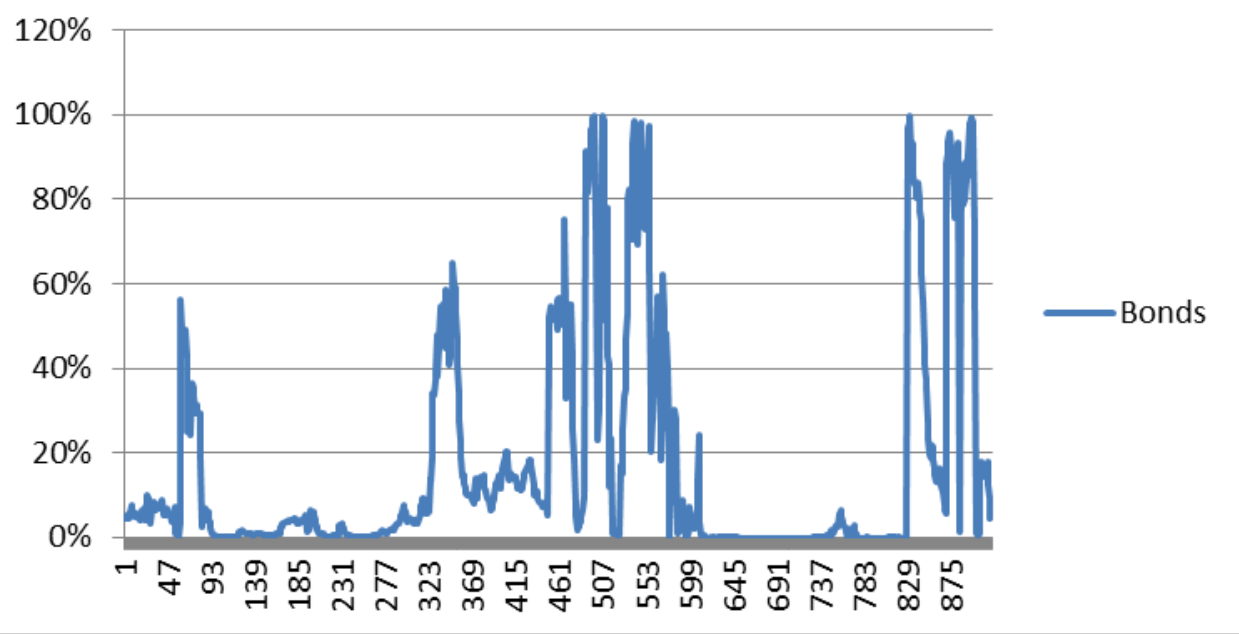

Figura 28: P-value do Fator de Bonds na regressão com atraso de 5 dias 


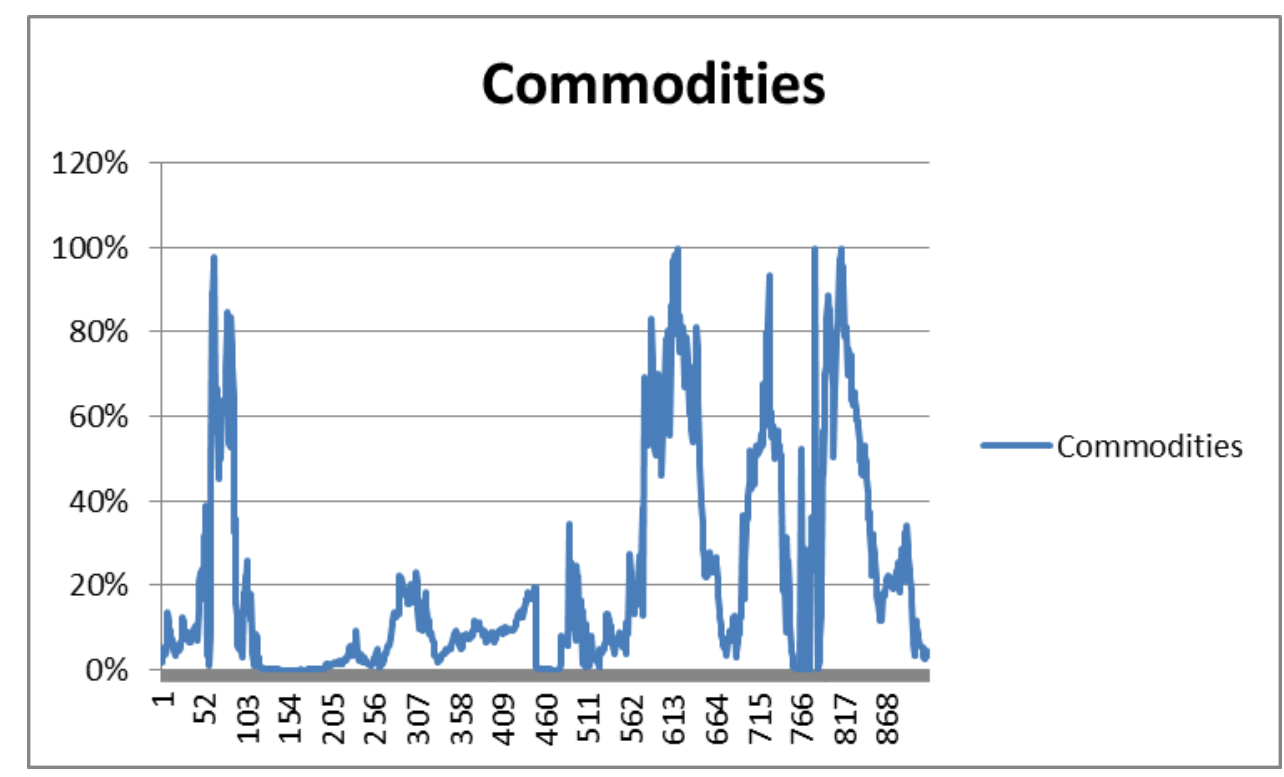

Figura 29: P-value do Fator de Commodities na regressão com atraso de 5 dias

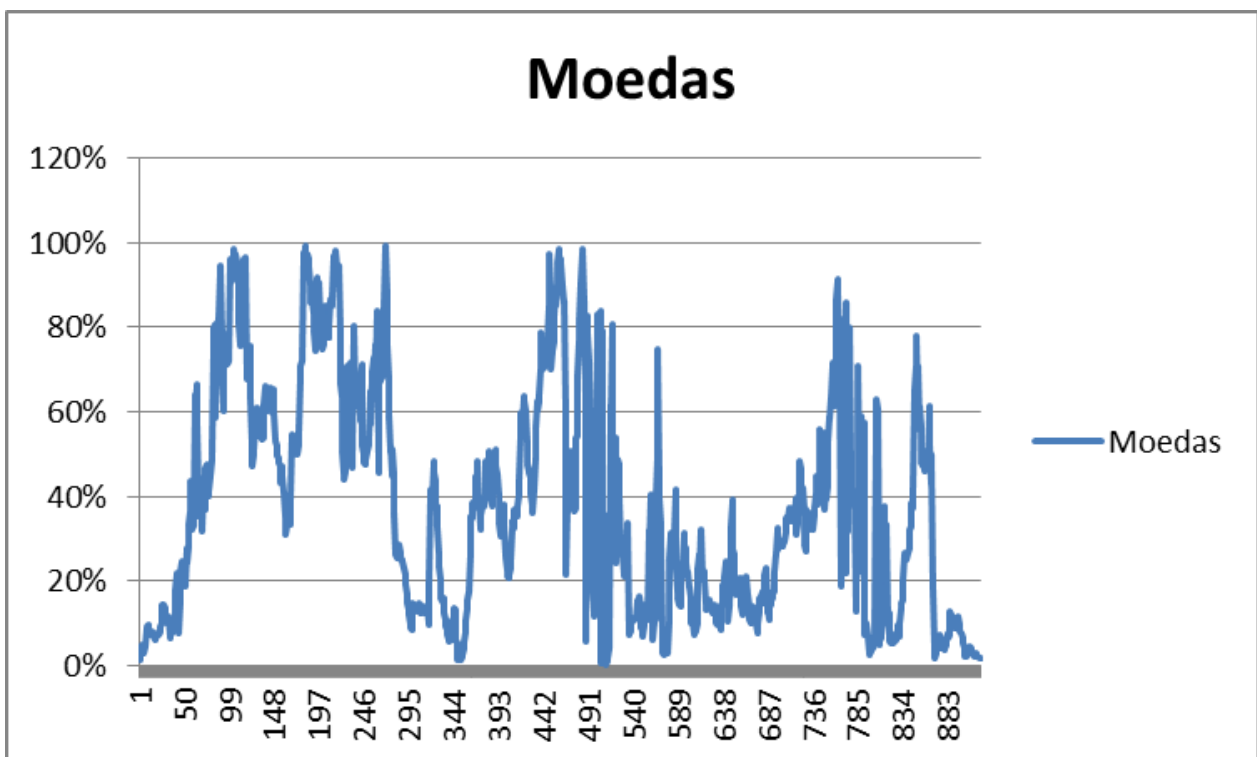

Figura 30: P-value do Fator de Moedas na regressão com atraso de 5 dias 


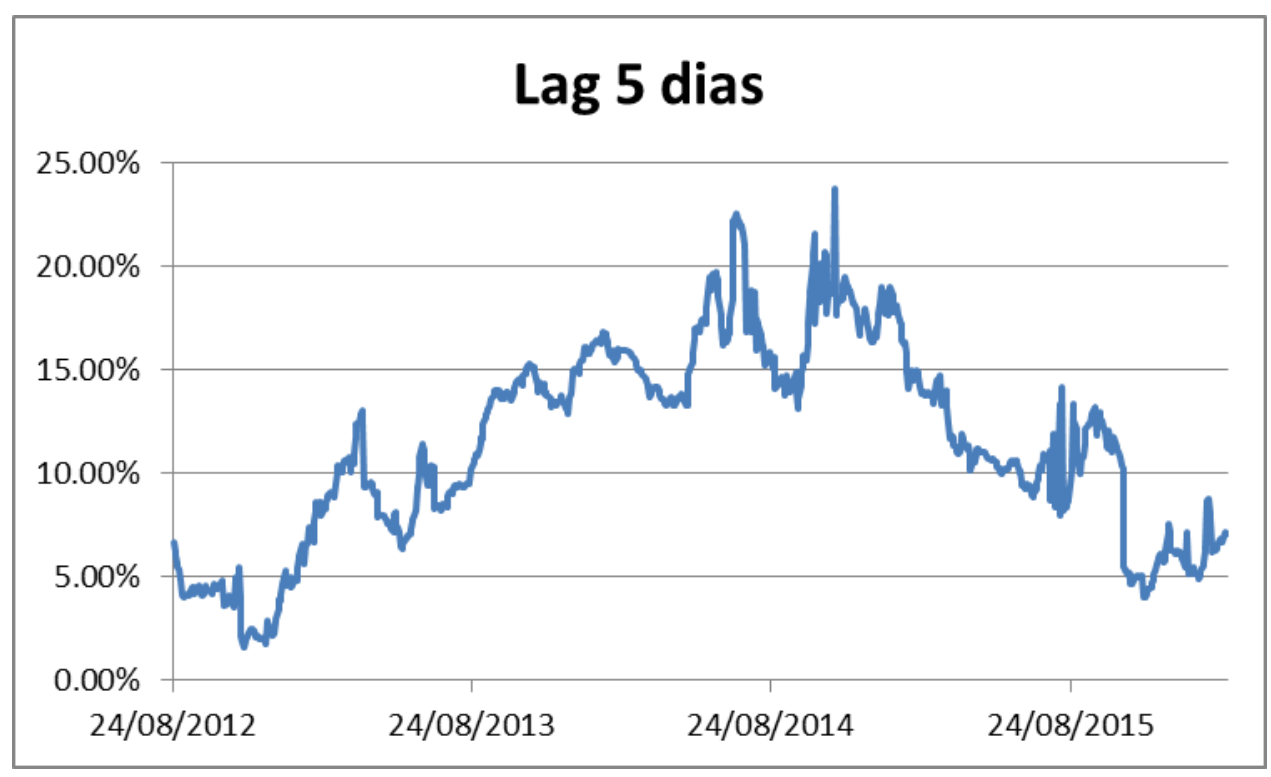

Figura 31: R Quadrado das regressões com atraso de 5 dias

\section{Lag 5 dias}

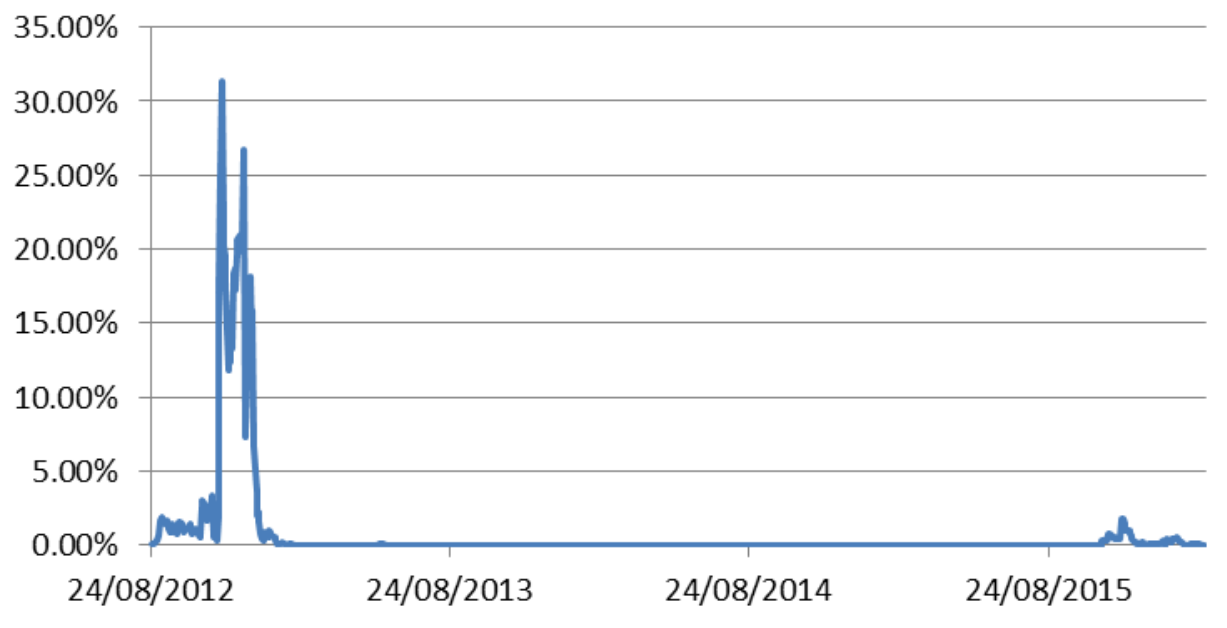

Figura 32: P-value das regressões com atraso de 5 dias 


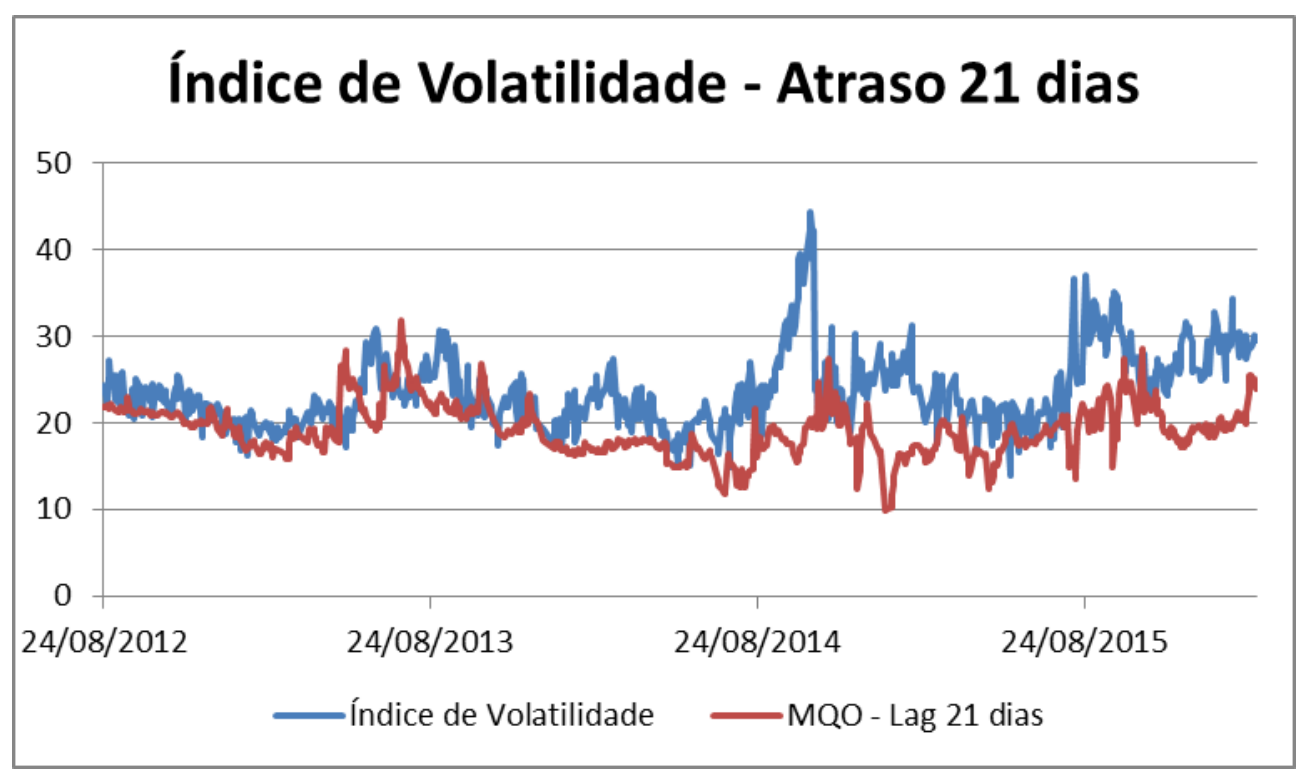

Figura 33: Regressão usando fatores com atraso de 21 dias

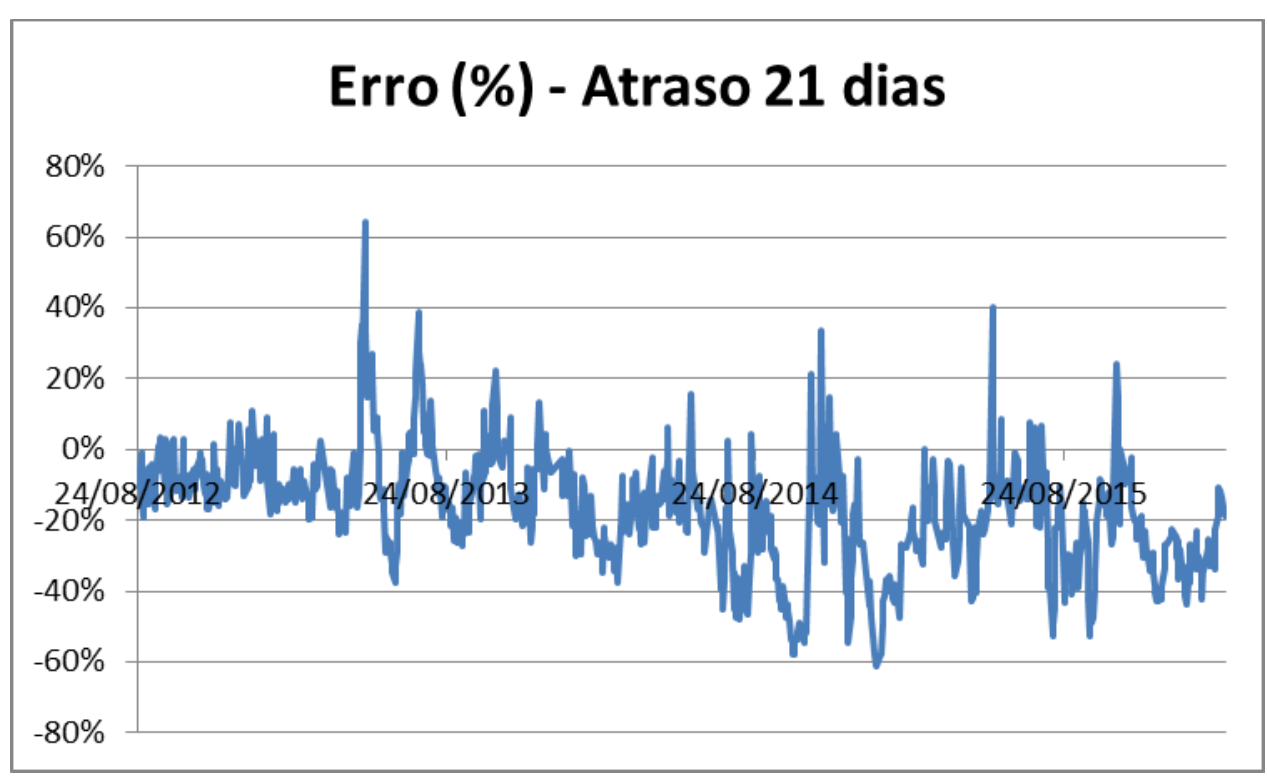

Figura 34: Erros da regressão do índice de ações - Lag 21 dias 


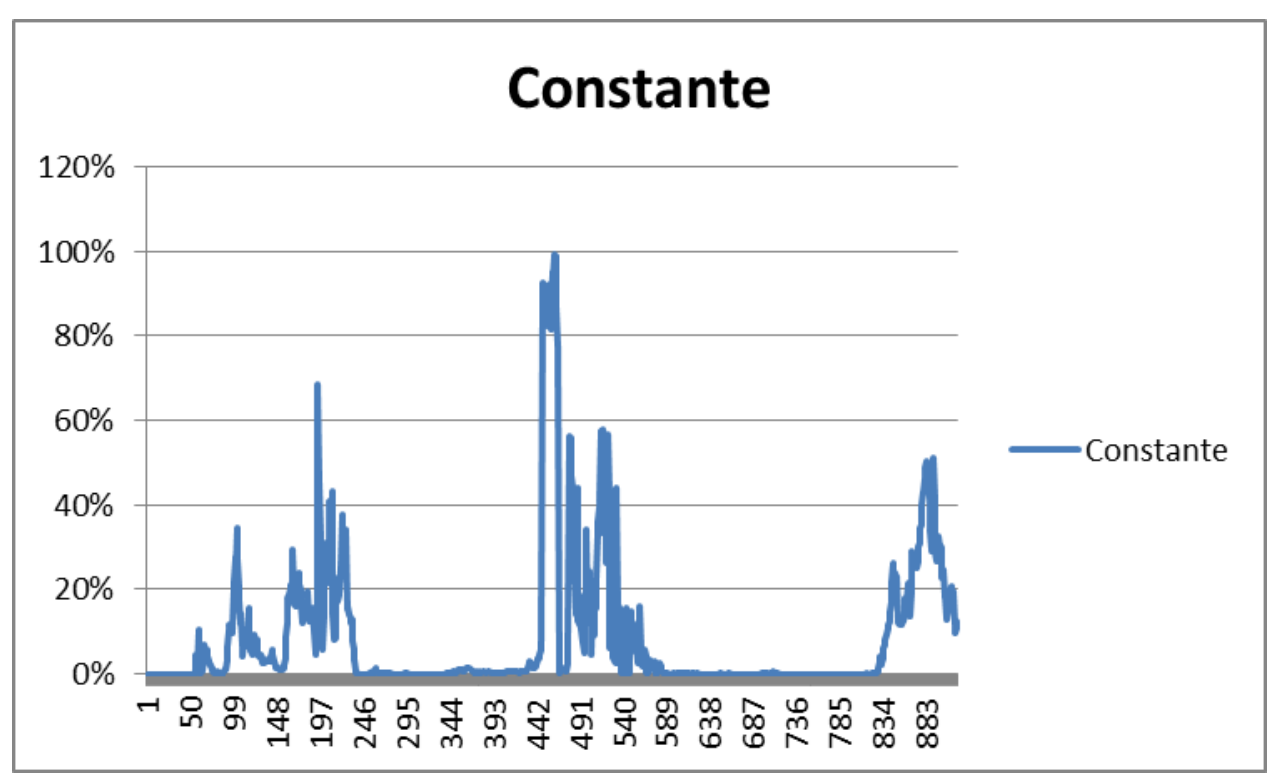

Figura 35: P-value da Constante na regressão com atraso de 21 dias

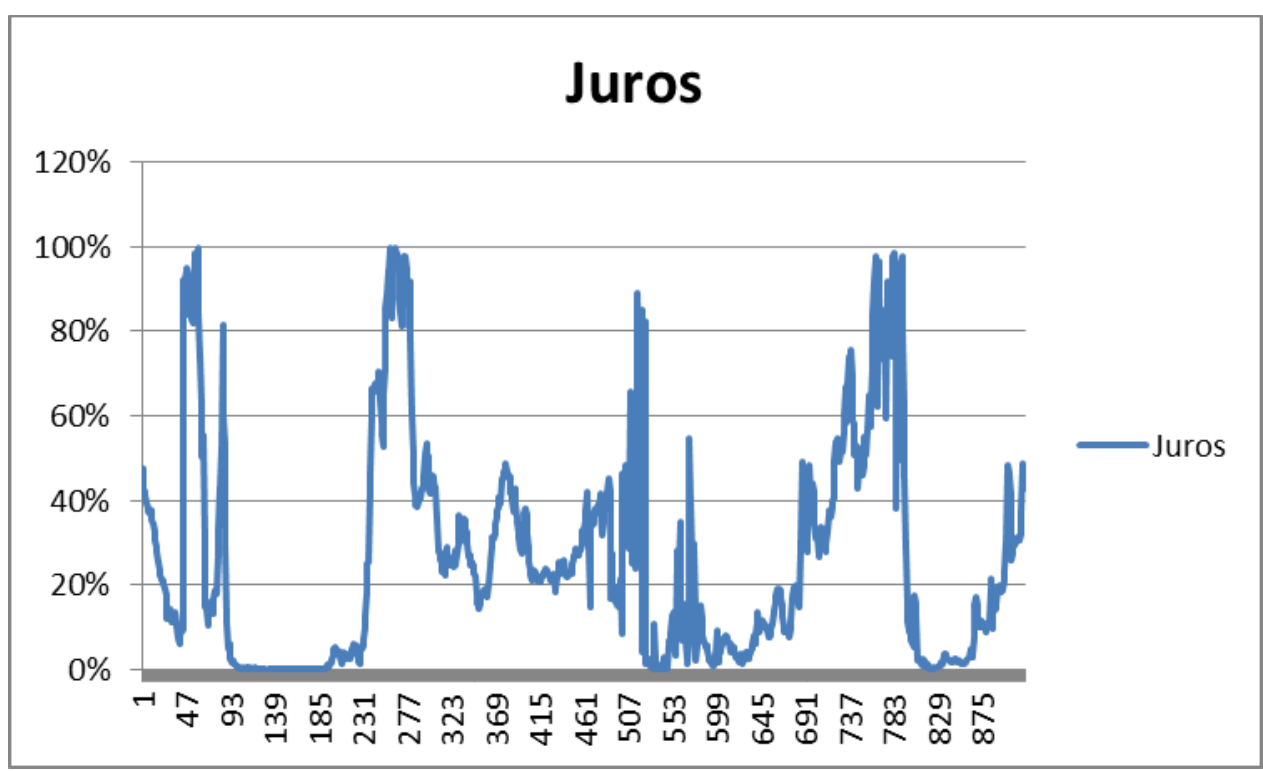

Figura 36: P-value do Fator de Juros na regressão com atraso de 21 dias 


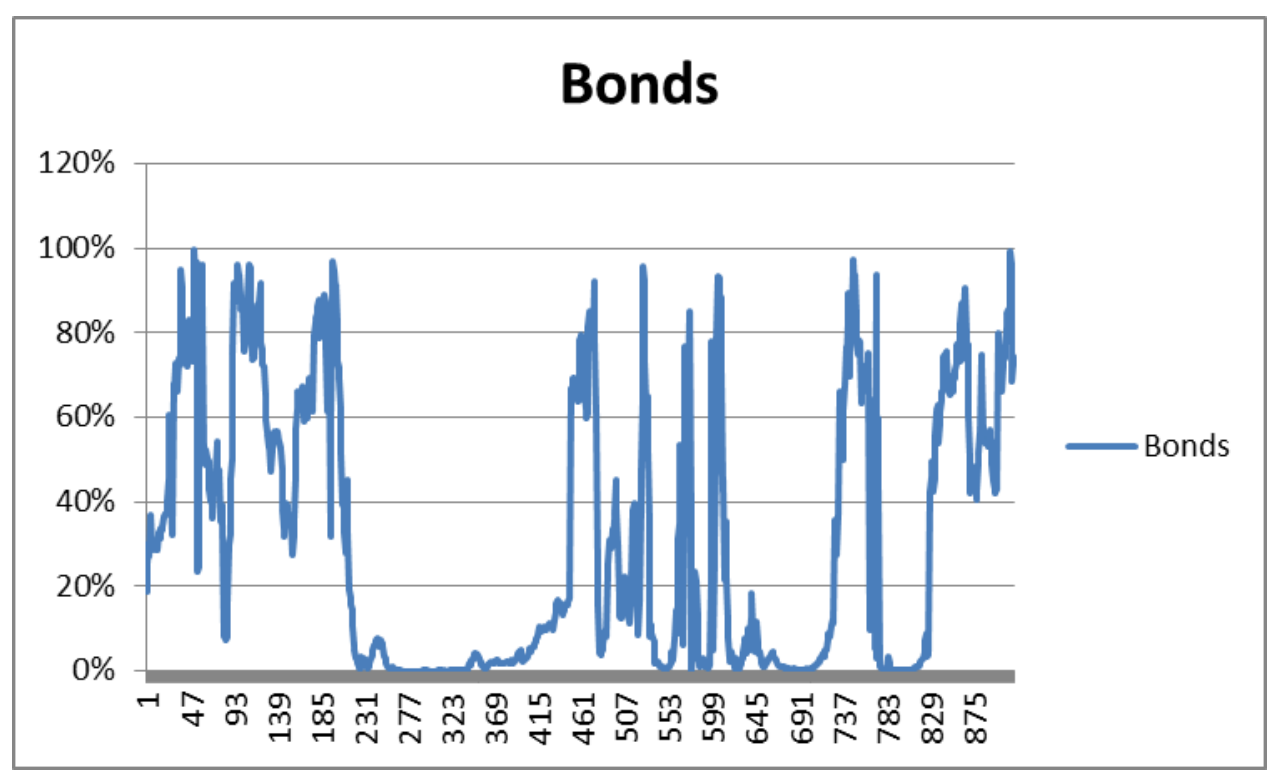

Figura 37: P-value do Fator de Bonds na regressão com atraso de 21 dias

\section{Commodities}

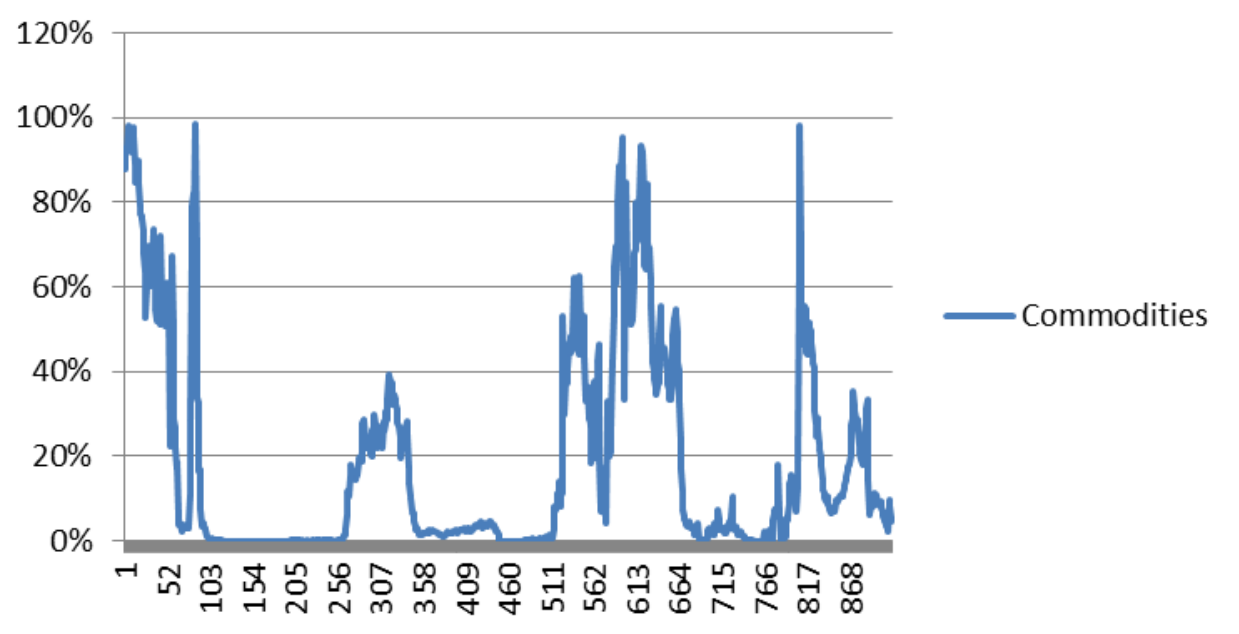

Figura 38: P-value do Fator de Commodities na regressão com atraso de 21 dias 


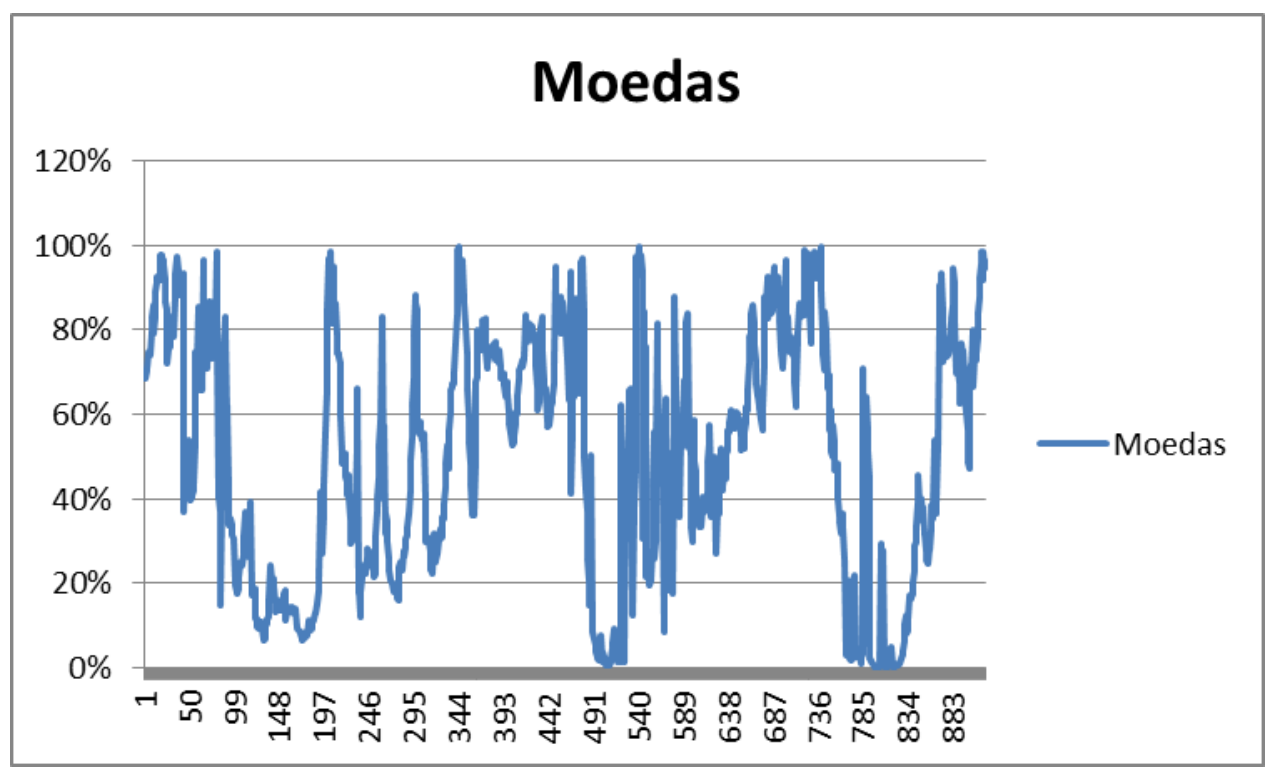

Figura 39: P-value do Fator de Moedas na regressão com atraso de 21 dias

\section{Lag 21 dias}

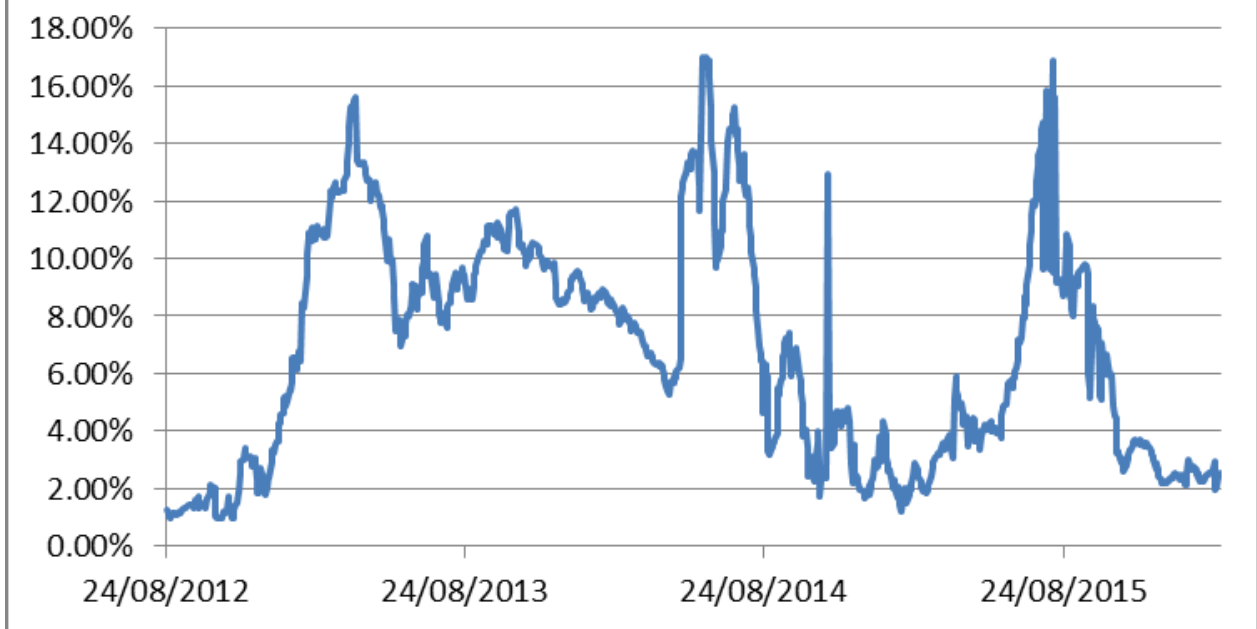

Figura 40: R Quadrado das regressões com atraso de 21 dias 


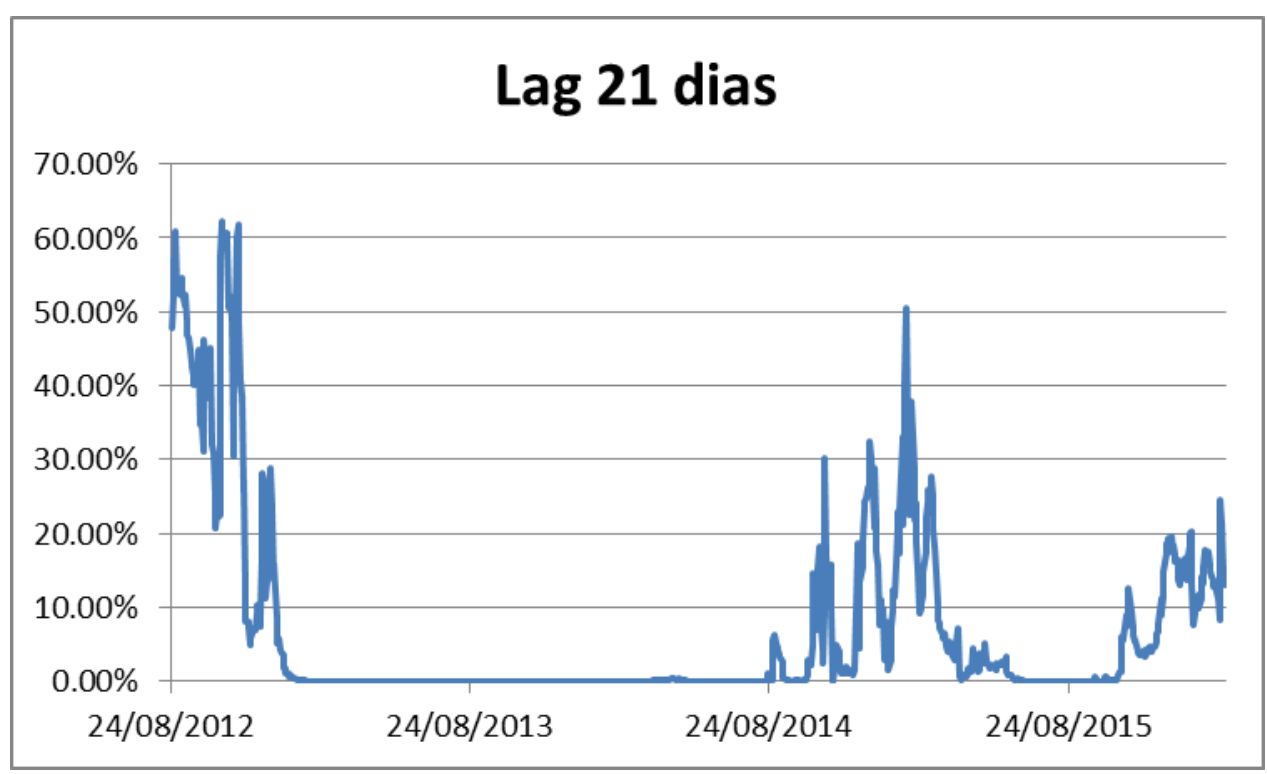

Figura 41: P-value das regressões com atraso de 21 dias

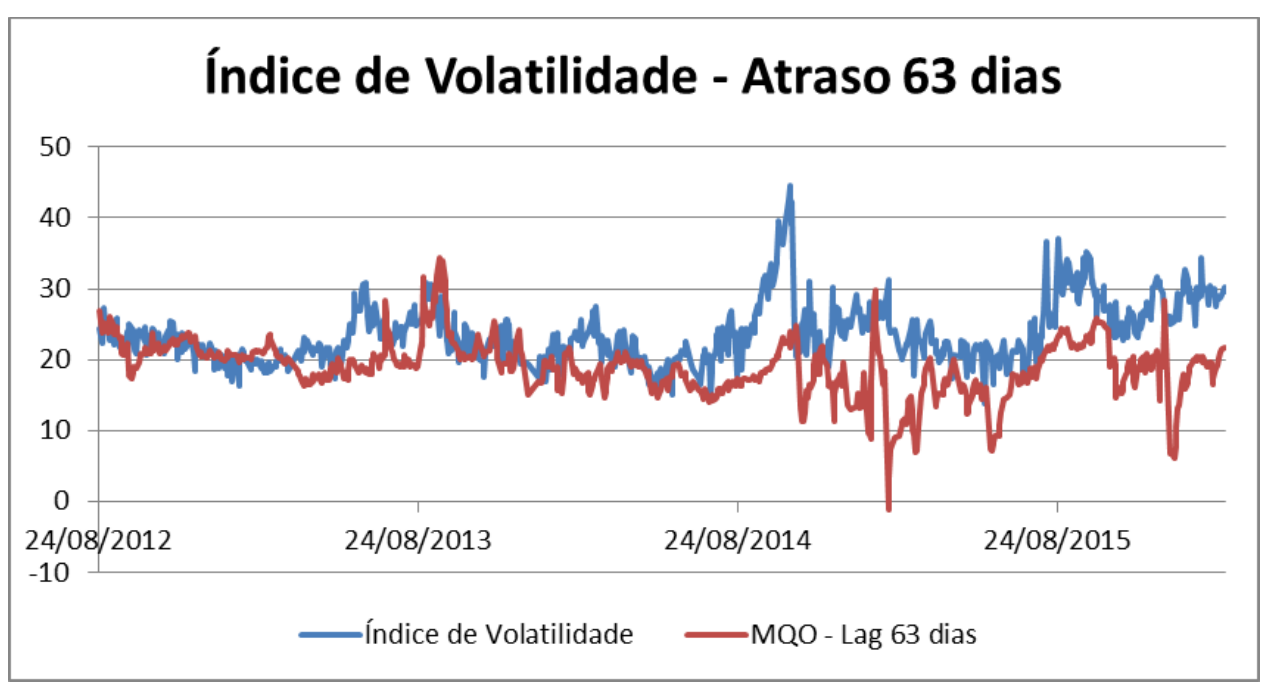

Figura 42: Regressão usando fatores com atraso de 63 dias 


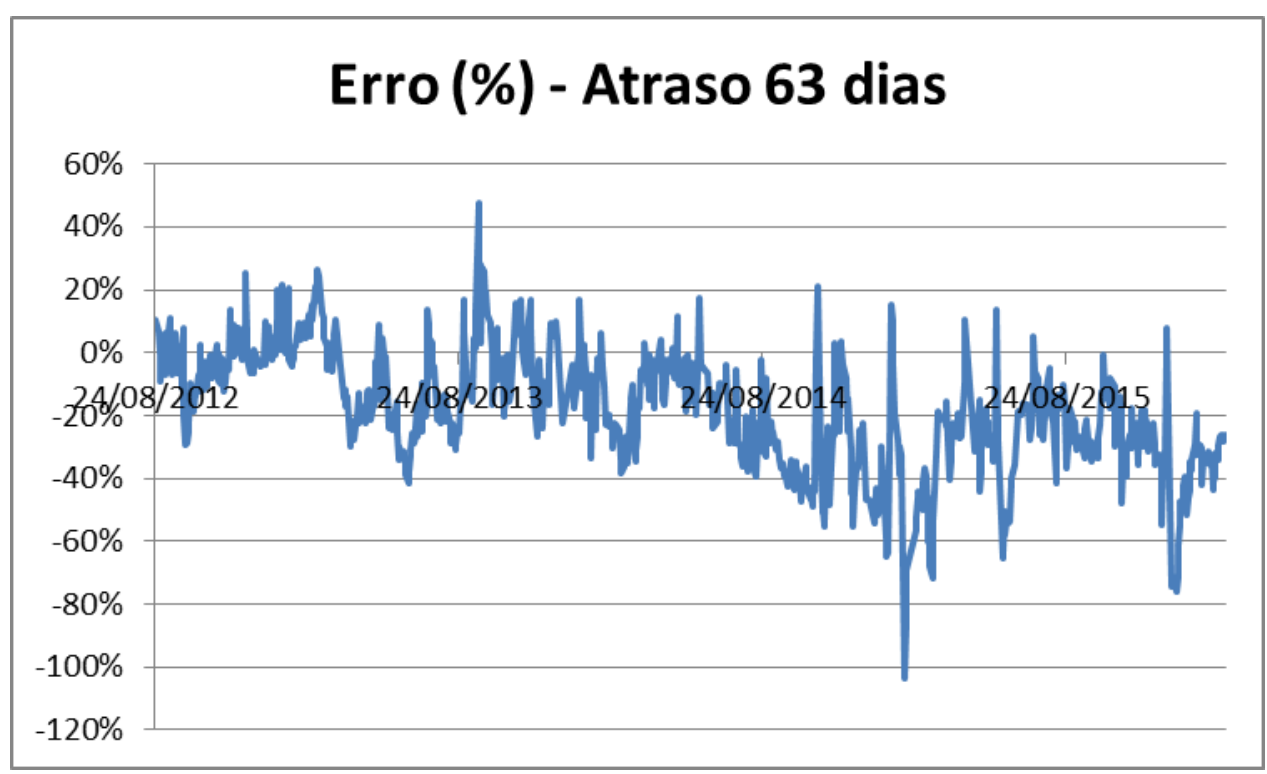

Figura 43: Erros da regressão do índice de ações - Lag 63 dias

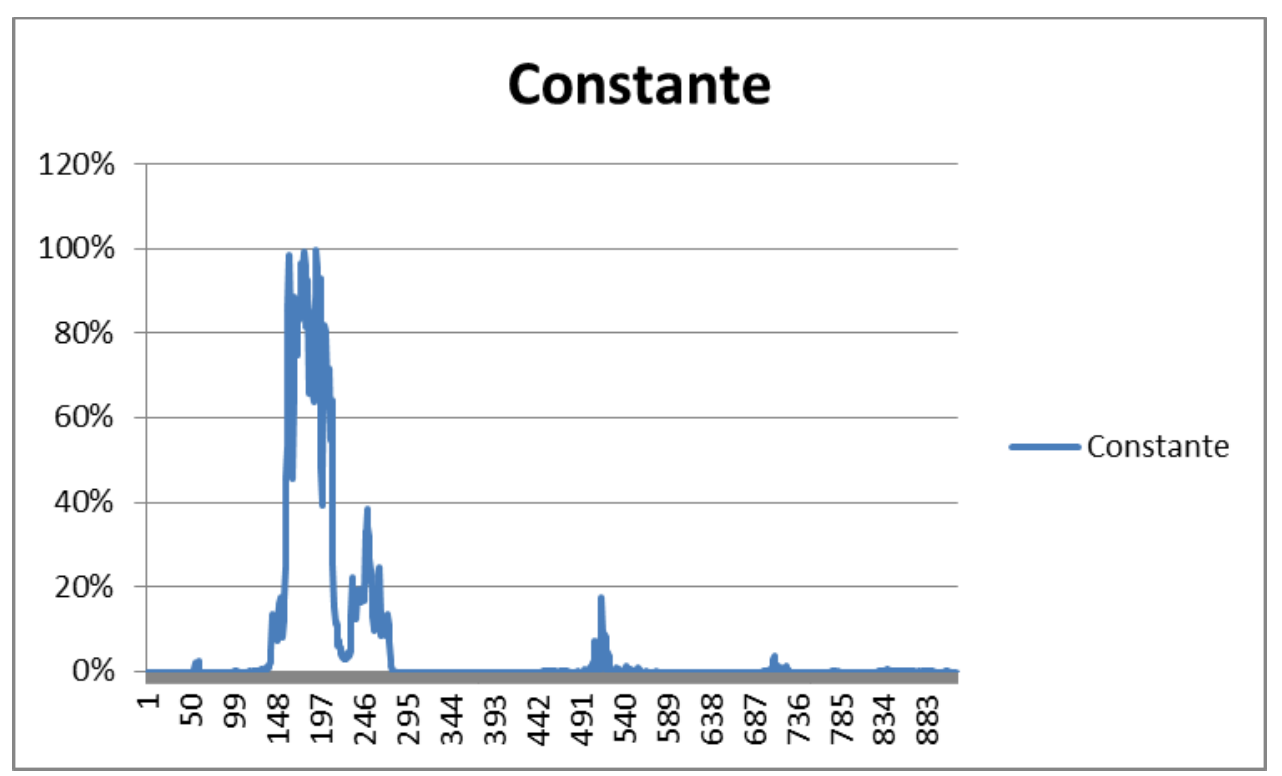

Figura 44: P-value da Constante na regressão com atraso de 63 dias 


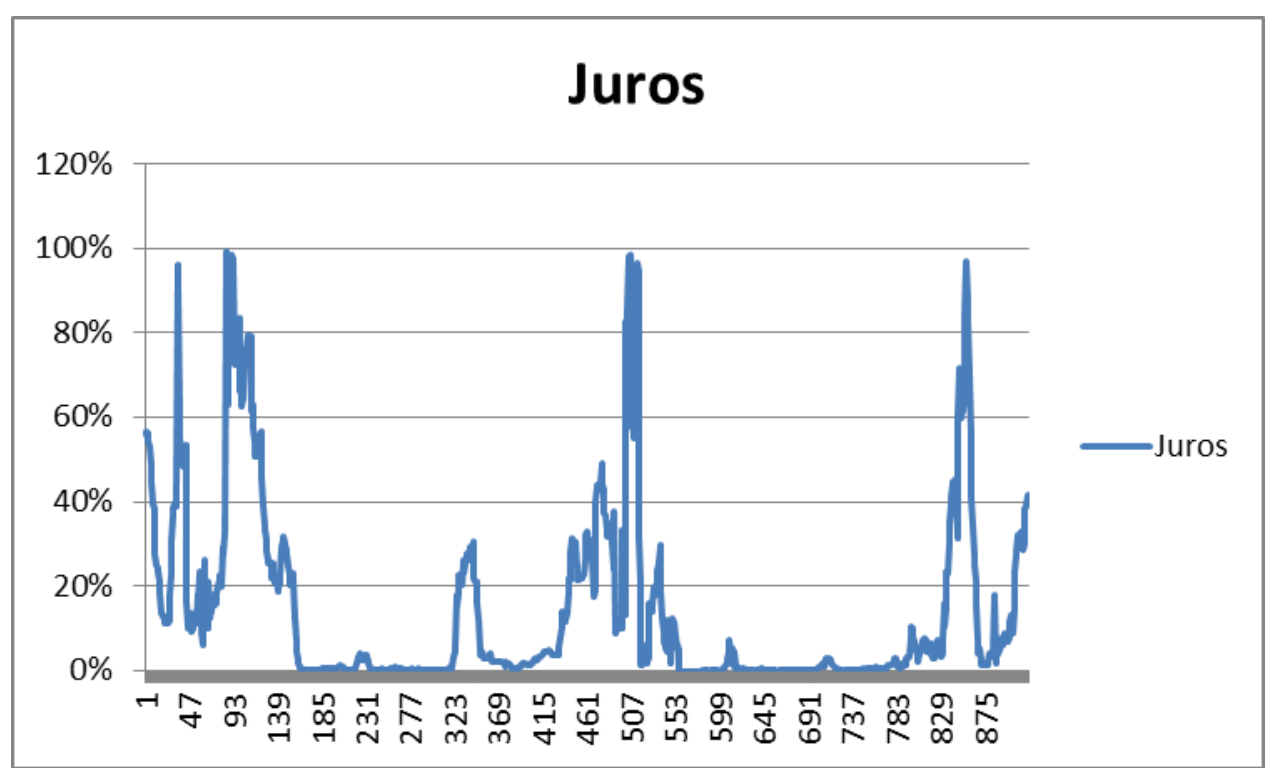

Figura 45: P-value do Fator de Juros na regressão com atraso de 63 dias

\section{Bonds}

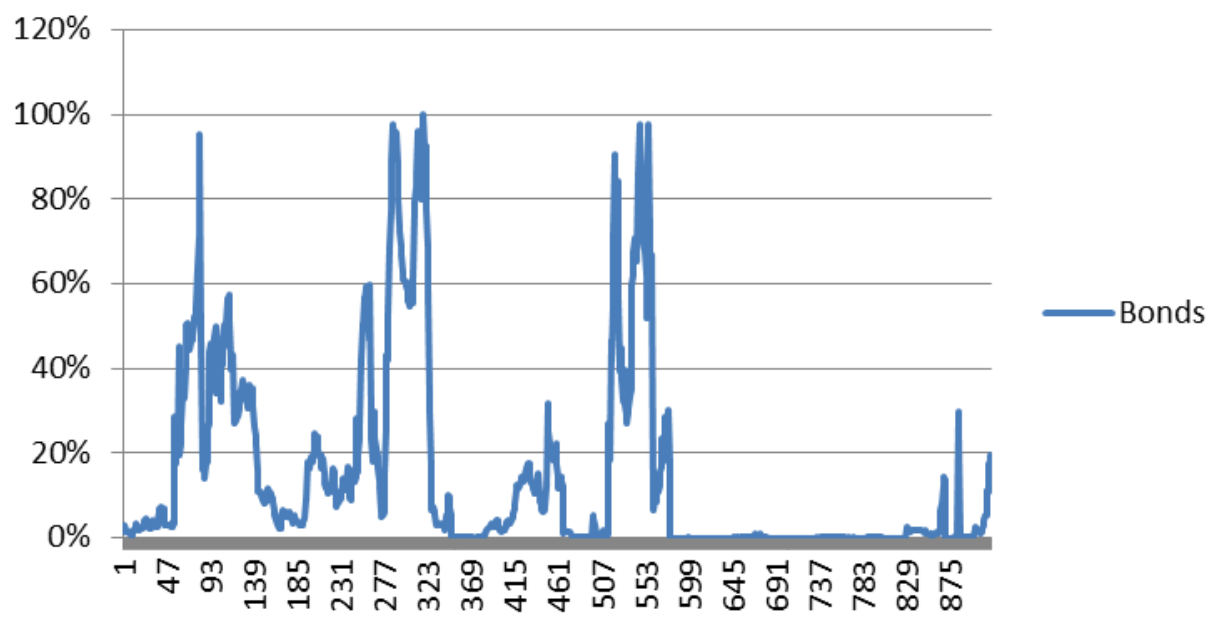

Figura 46: P-value do Fator de Bonds na regressão com atraso de 63 dias 


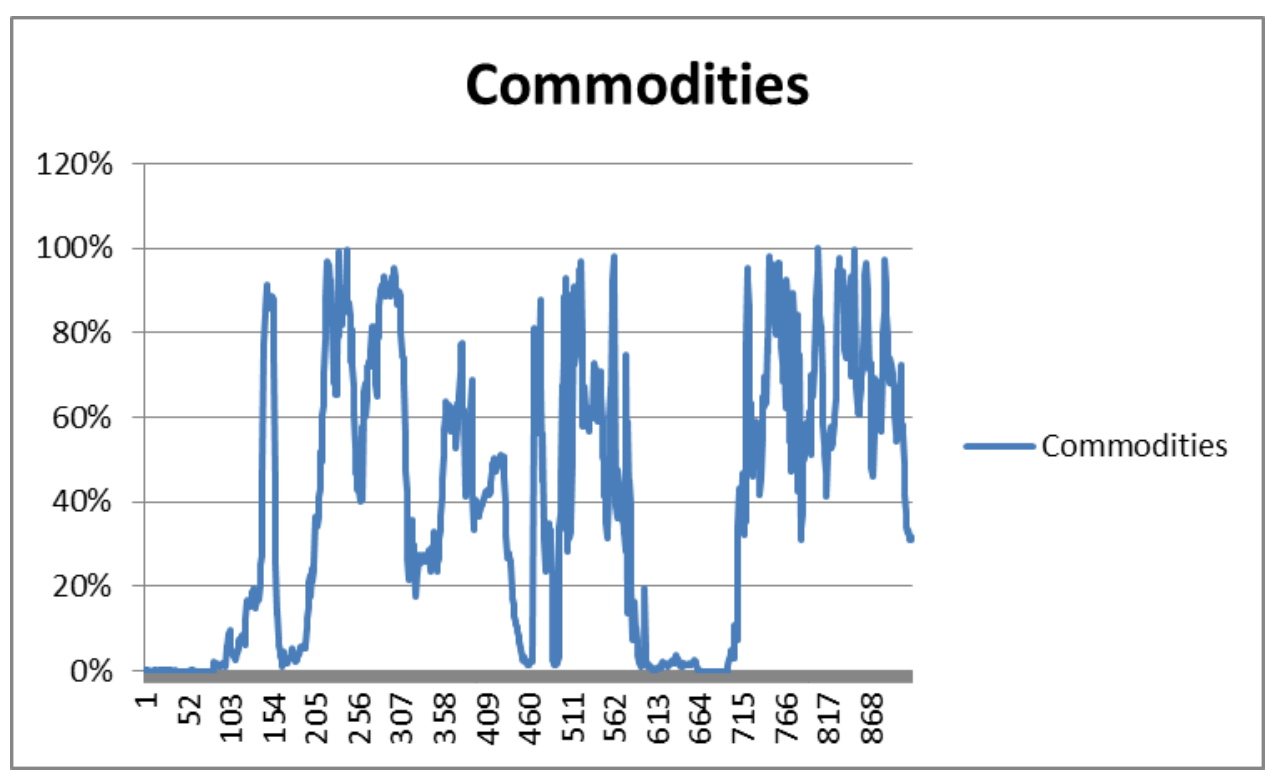

Figura 47: P-value do Fator de Commodities na regressão com atraso de 63 dias

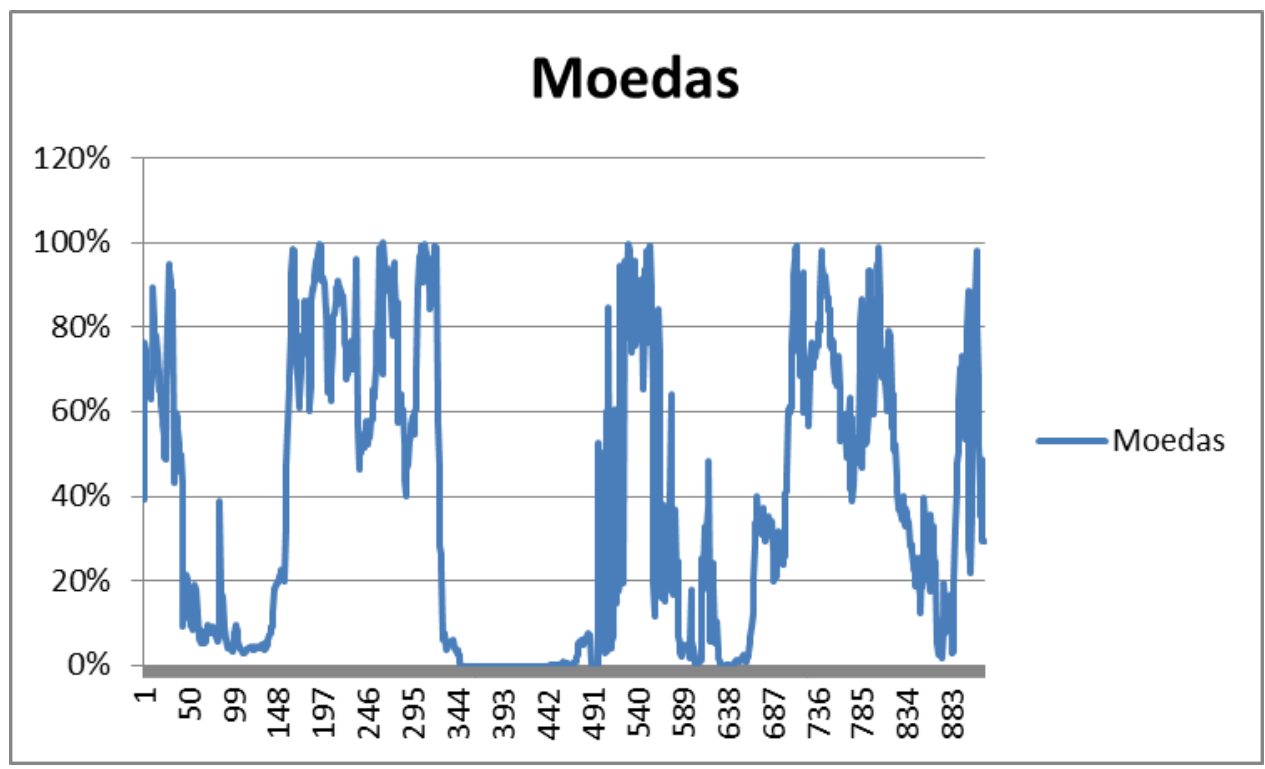

Figura 48: P-value do Fator de Moedas na regressão com atraso de 63 dias 


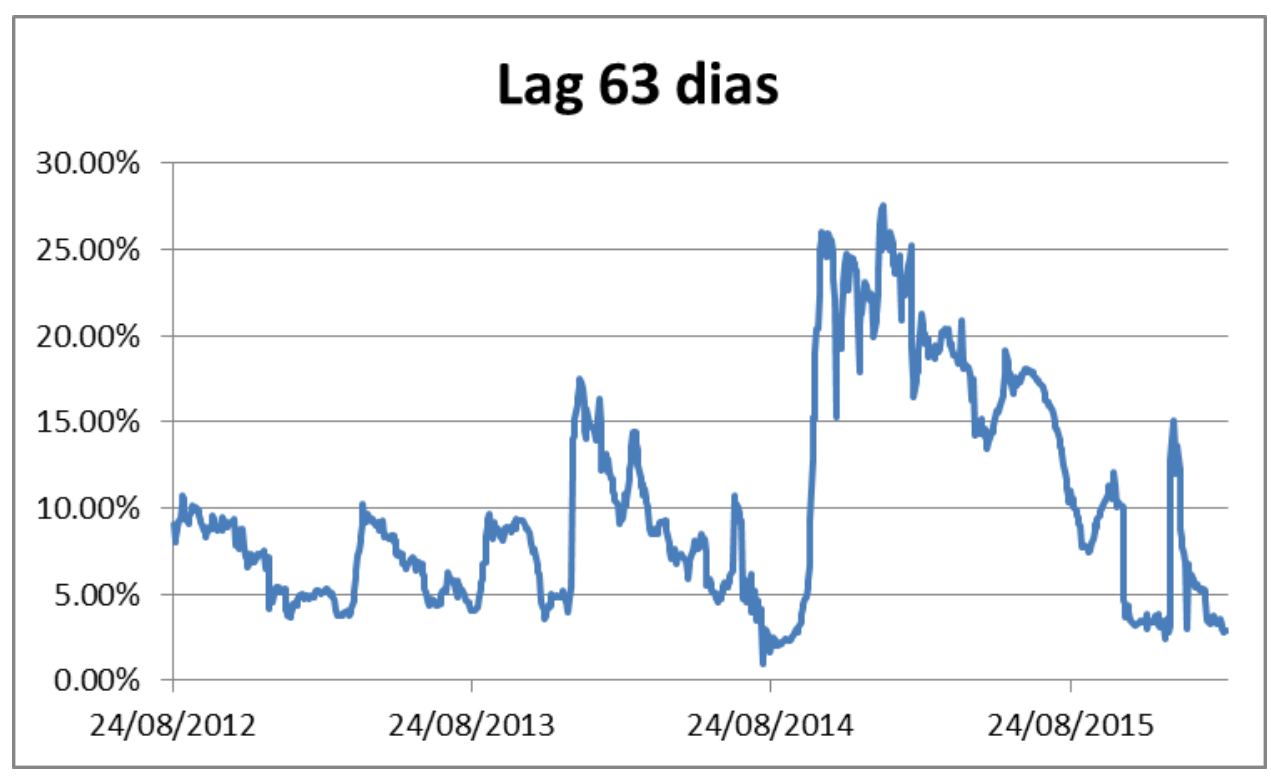

Figura 49: R Quadrado das regressões com atraso de 63 dias

\section{Lag 63 dias}

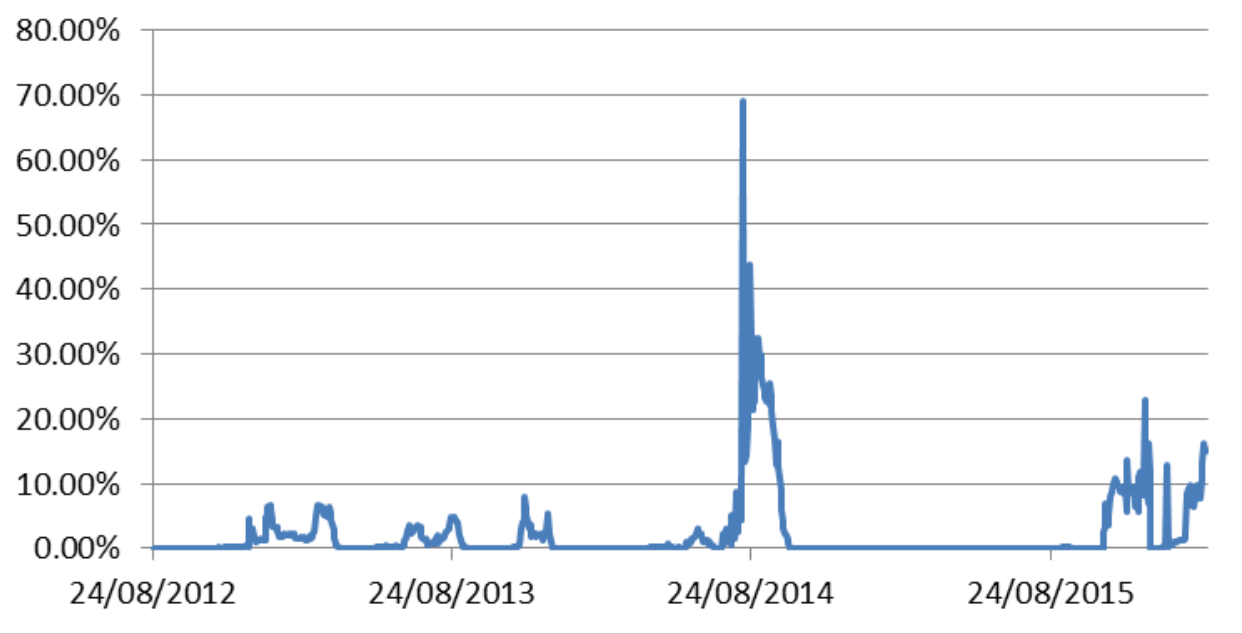

Figura 50: P-value das regressões com atraso de 63 dias 


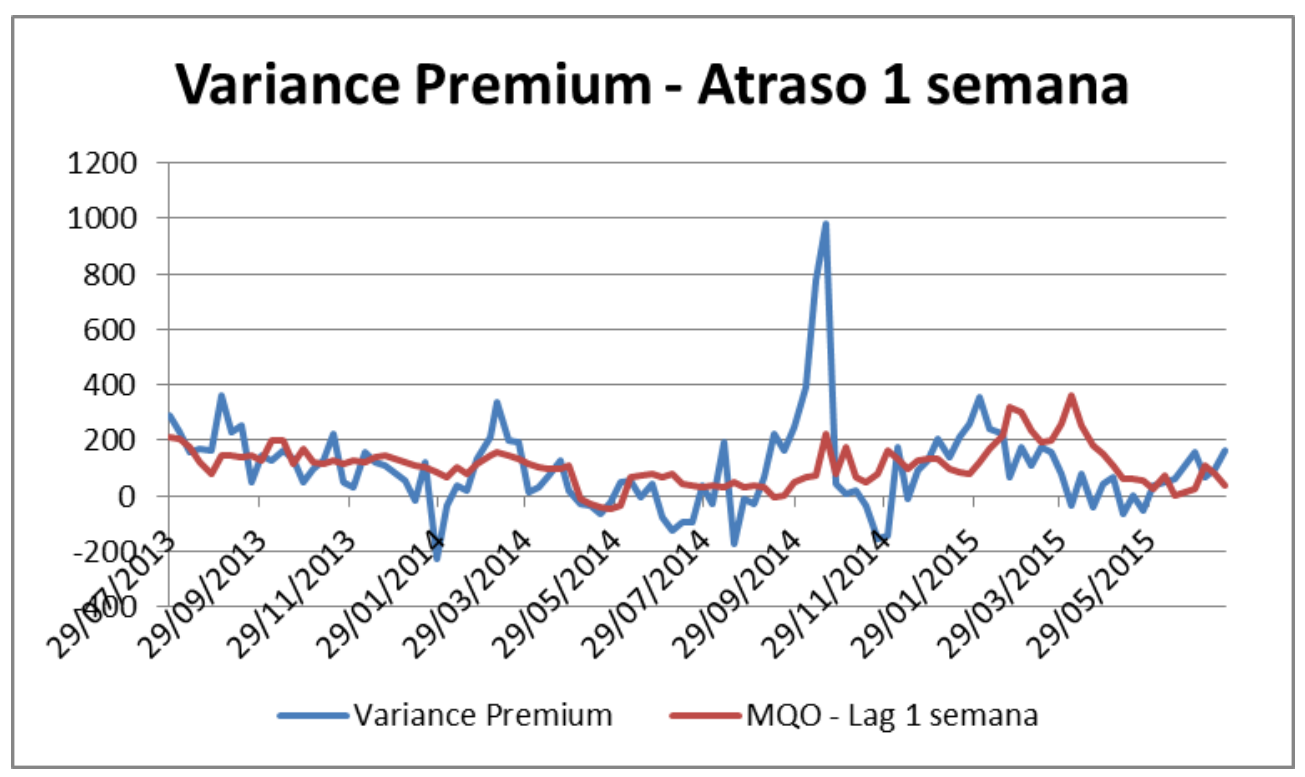

Figura 51: Regressão usando fatores com atraso de 1 semana

\section{Erro (\%) - Atraso 1 semana}

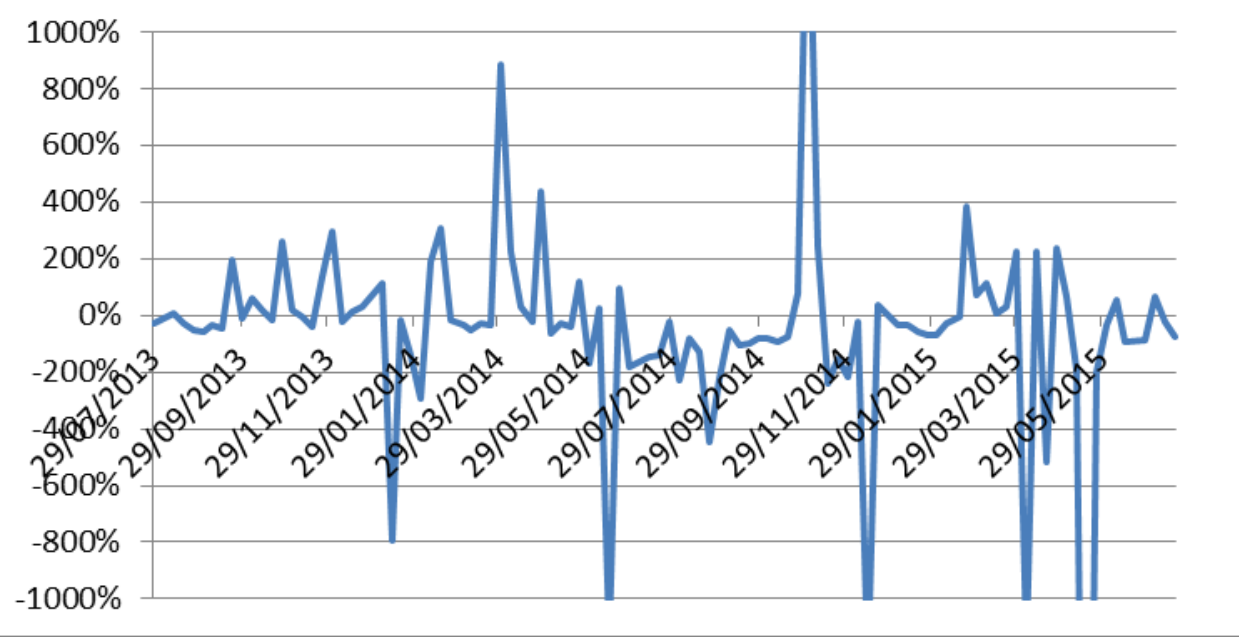

Figura 52: Erros da regressão do índice de ações - Lag 1 semana 


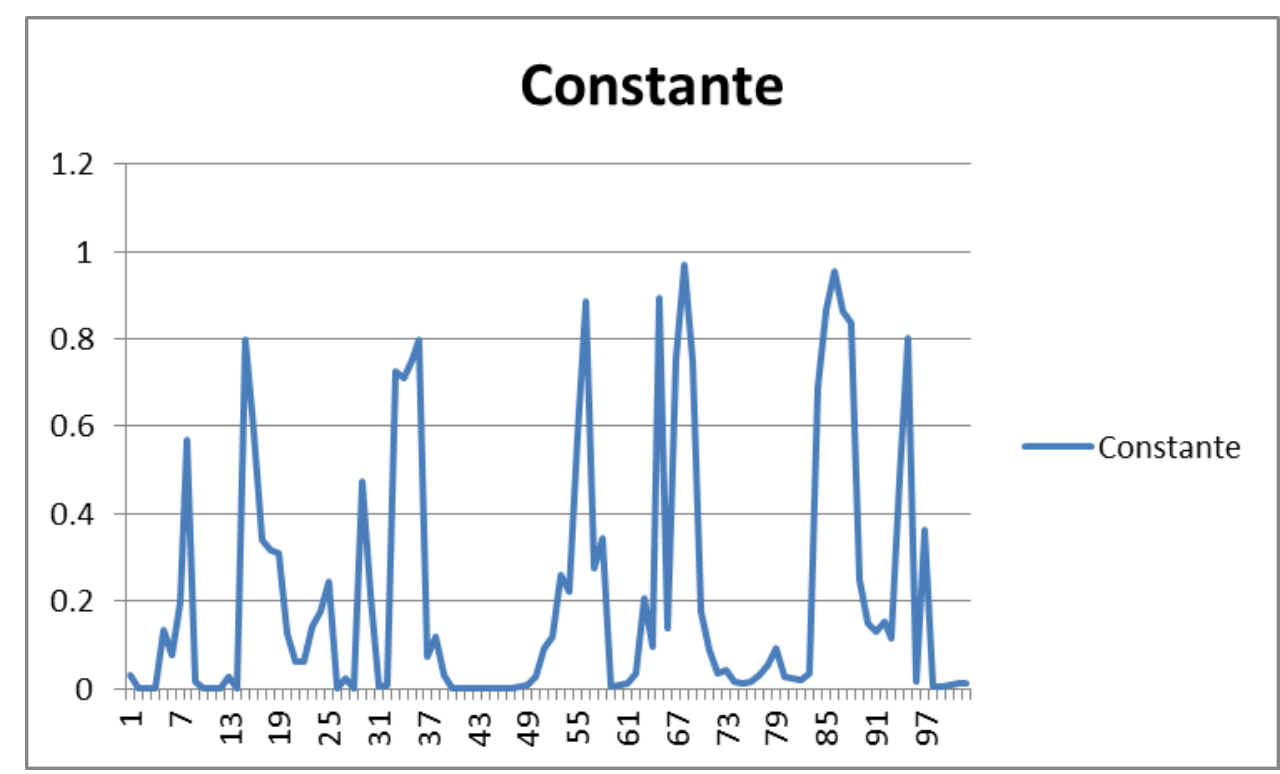

Figura 53: P-value da Constante na regressão com atraso de 1 semana

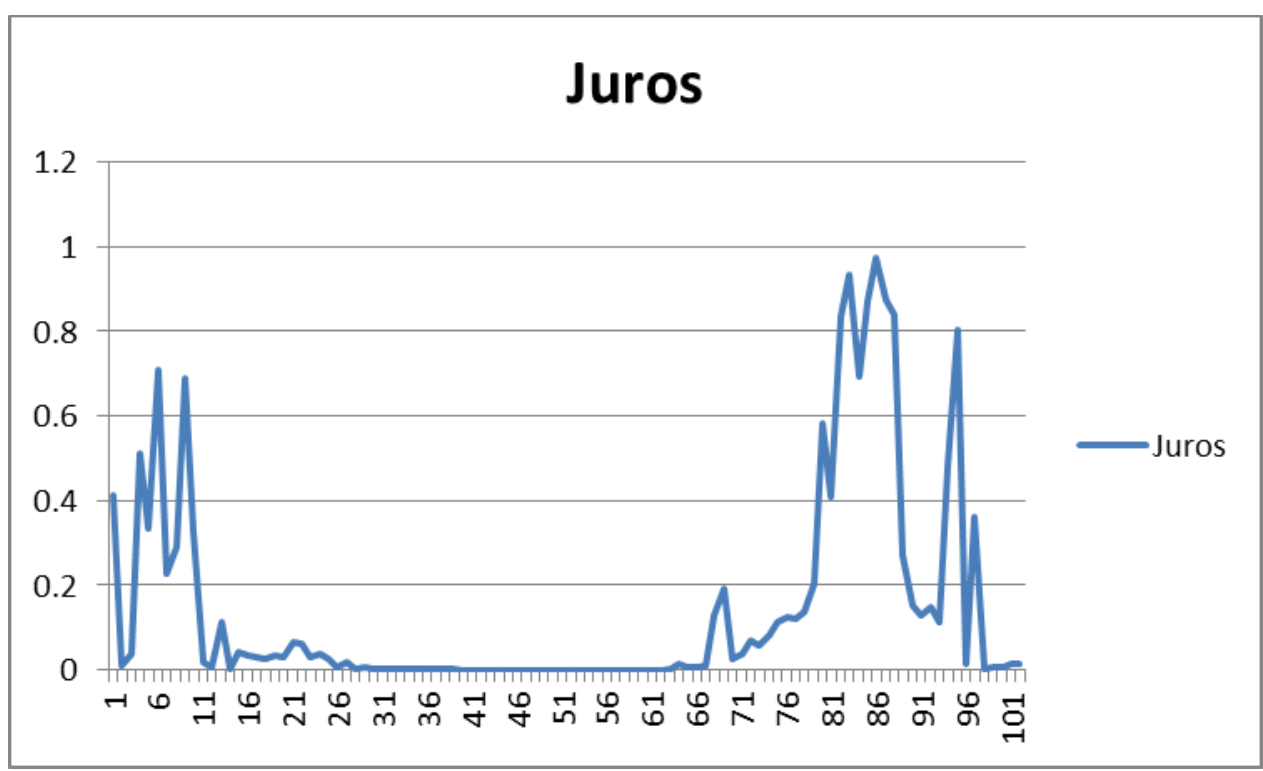

Figura 54: P-value do Fator de Juros na regressão com atraso de 1 semana 


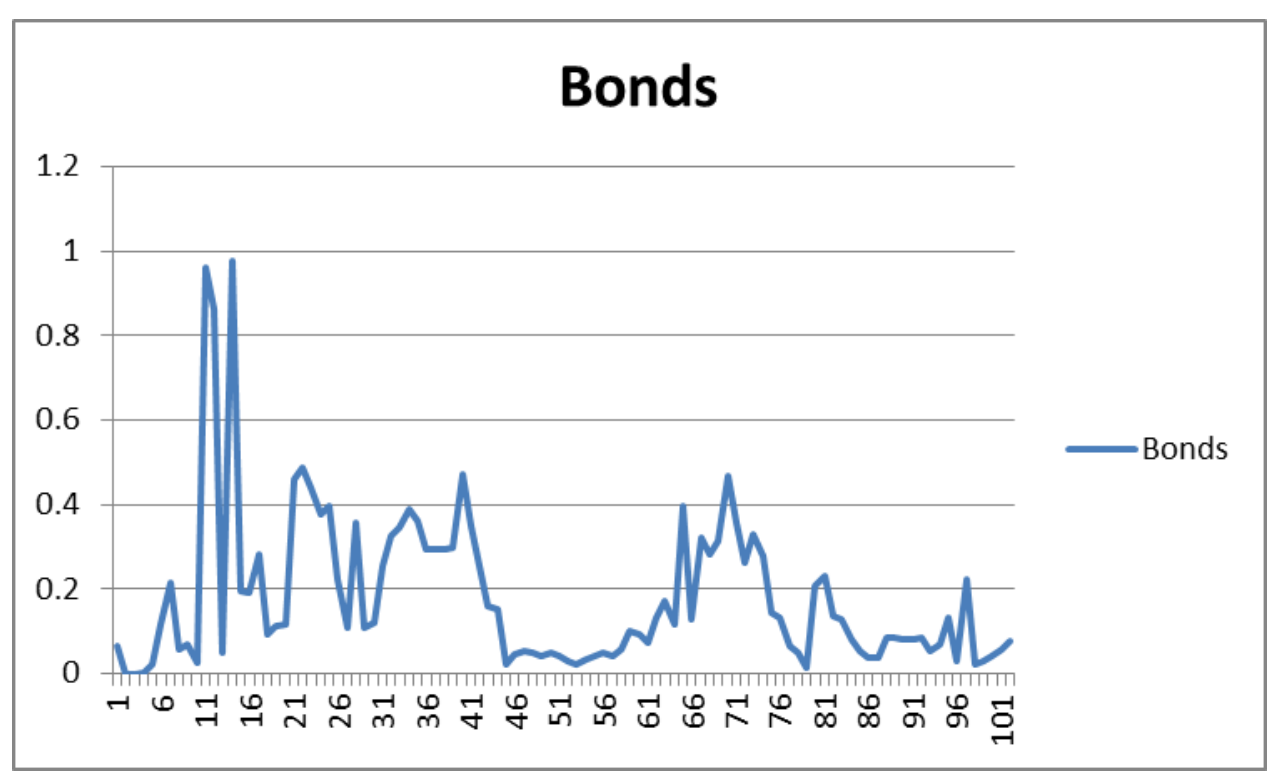

Figura 55: P-value do Fator de Bonds na regressão com atraso de 1 semana

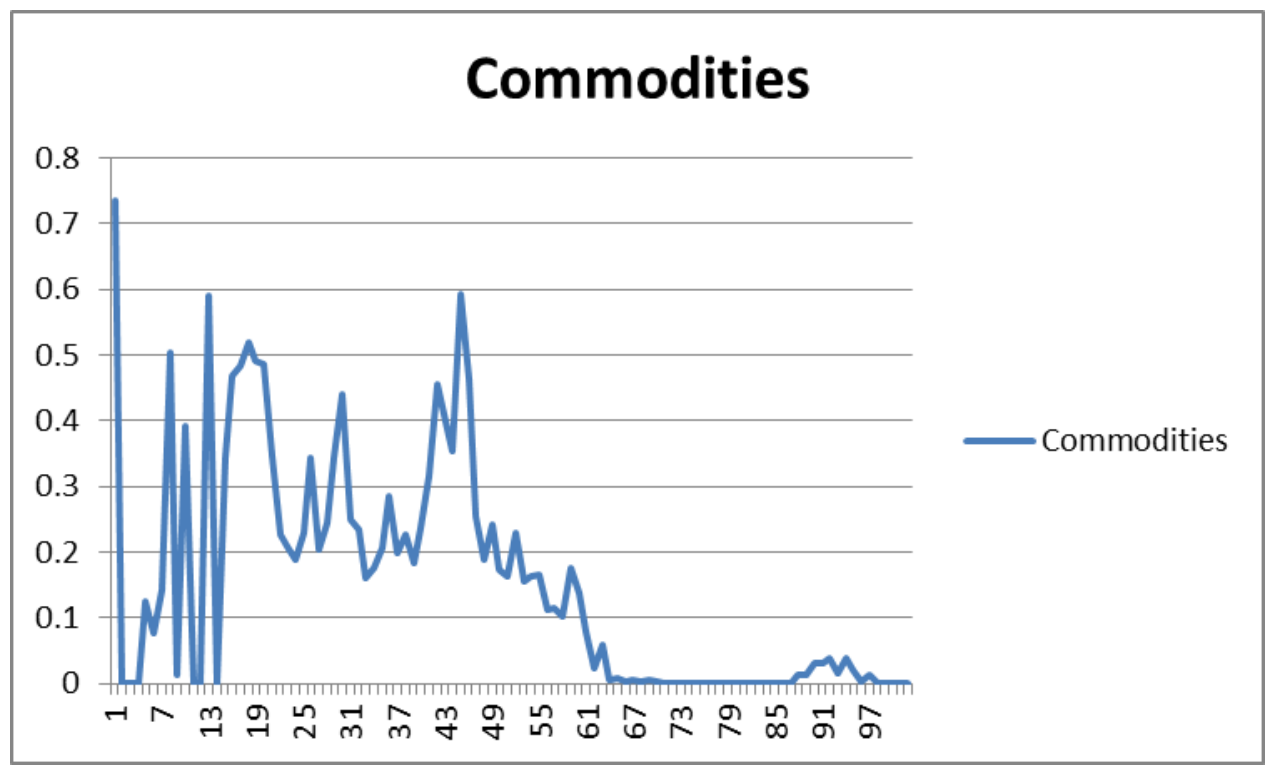

Figura 56: P-value do Fator de Commodities na regressão com atraso de 1 semana 


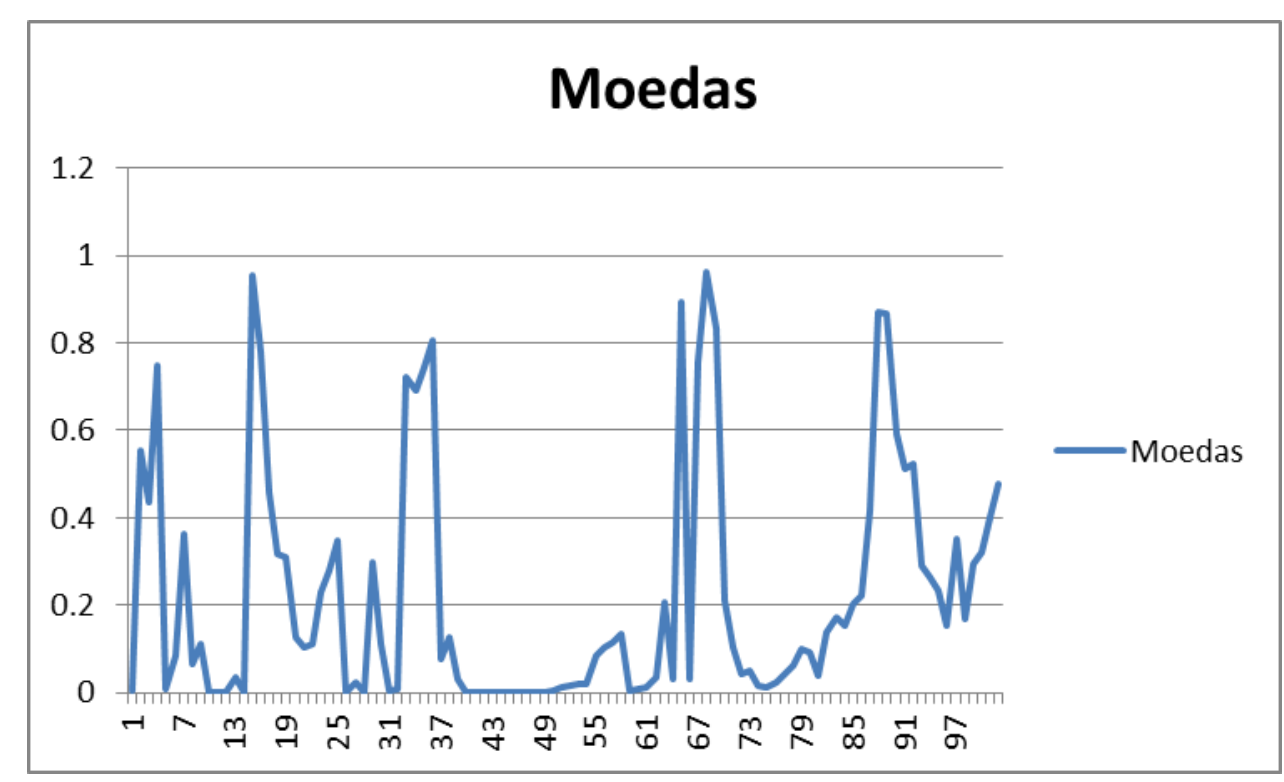

Figura 57: P-value do Fator de Moedas na regressão com atraso de 1 semana

\section{Lag 1 semana}

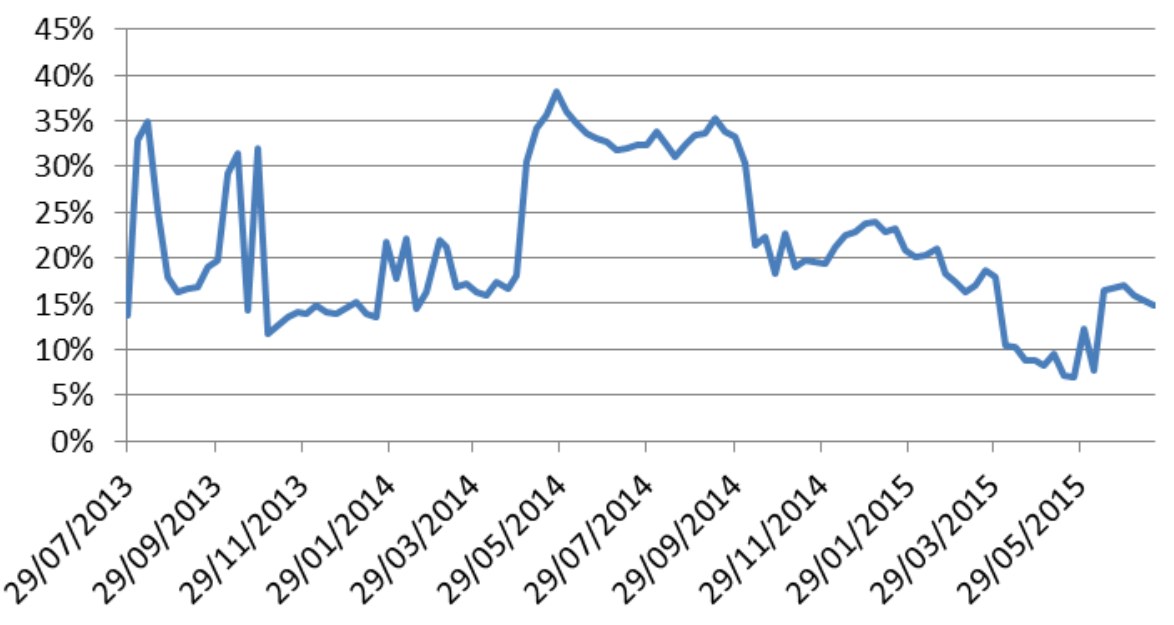

Figura 58: R Quadrado das regressões com atraso de 1 semana 


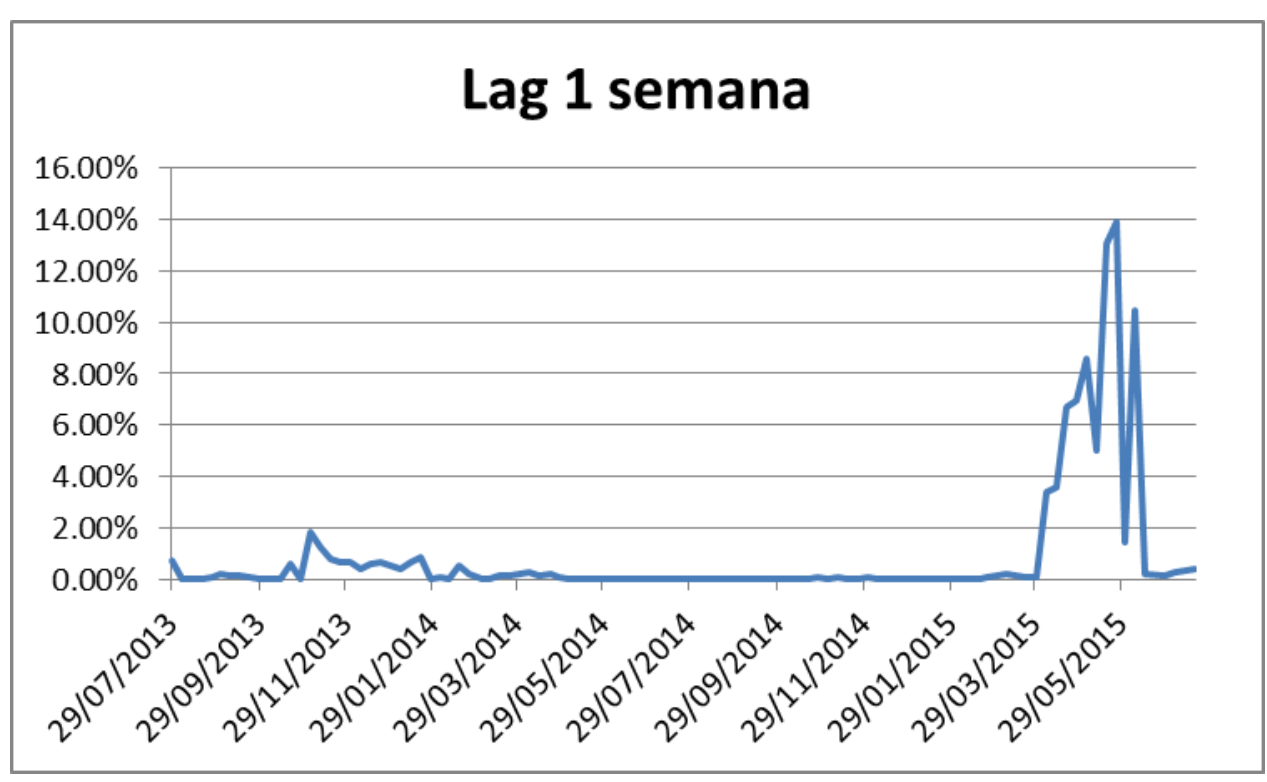

Figura 59: P-value das regressões com atraso de 1 semana

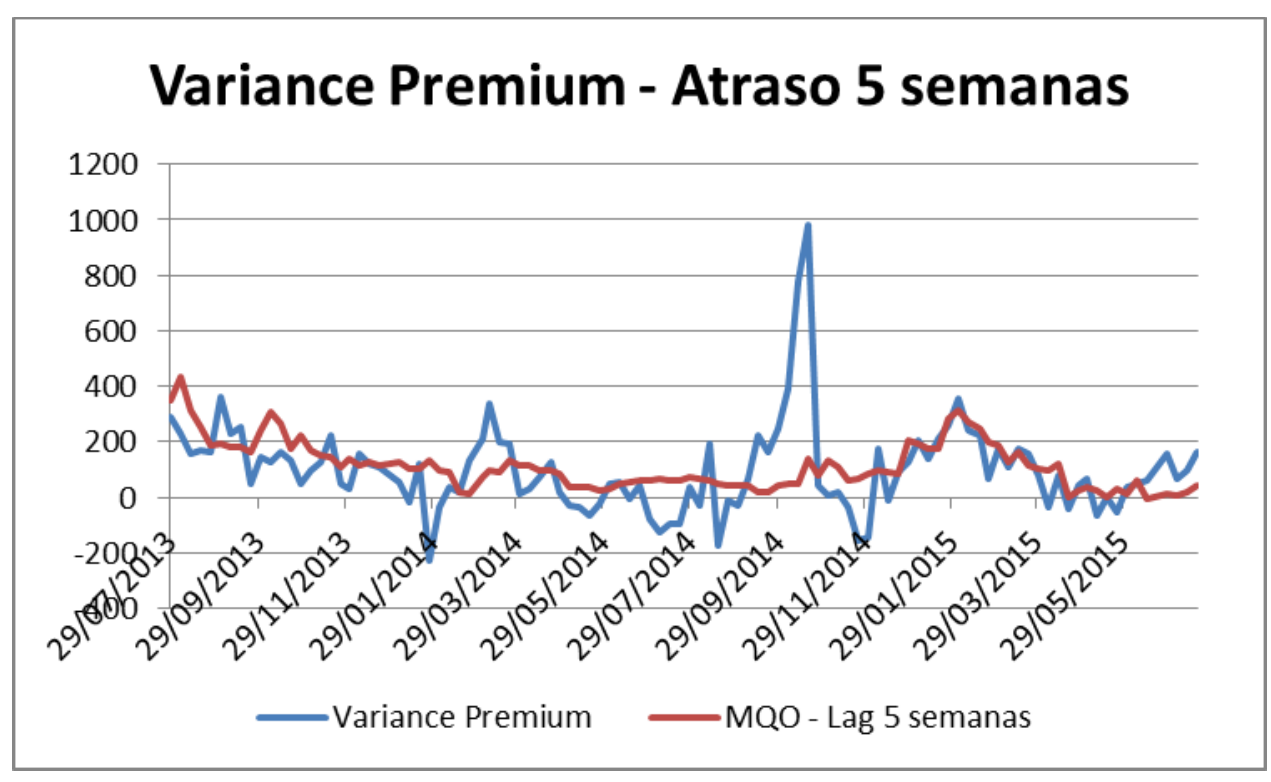

Figura 60: Regressão usando fatores com atraso de 5 semanas 


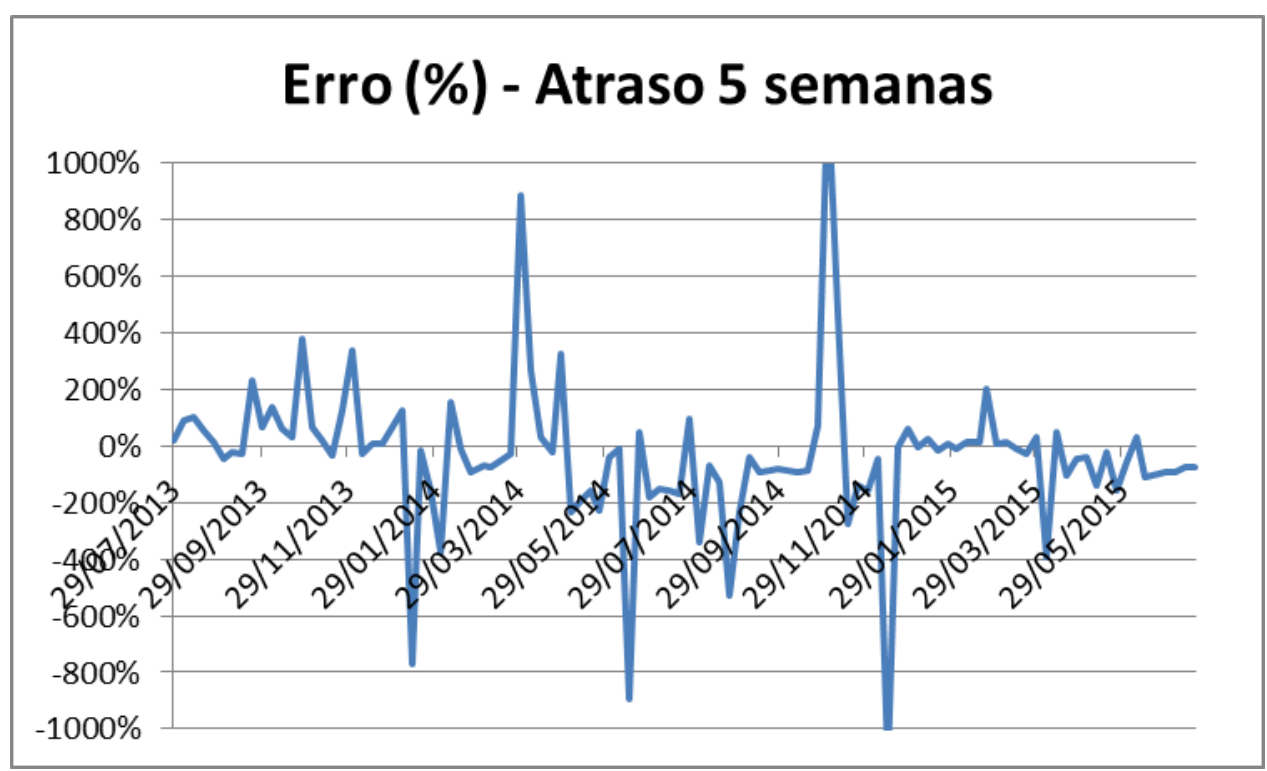

Figura 61: Erros da regressão do índice de ações - Lag 5 semana

\section{Constante}

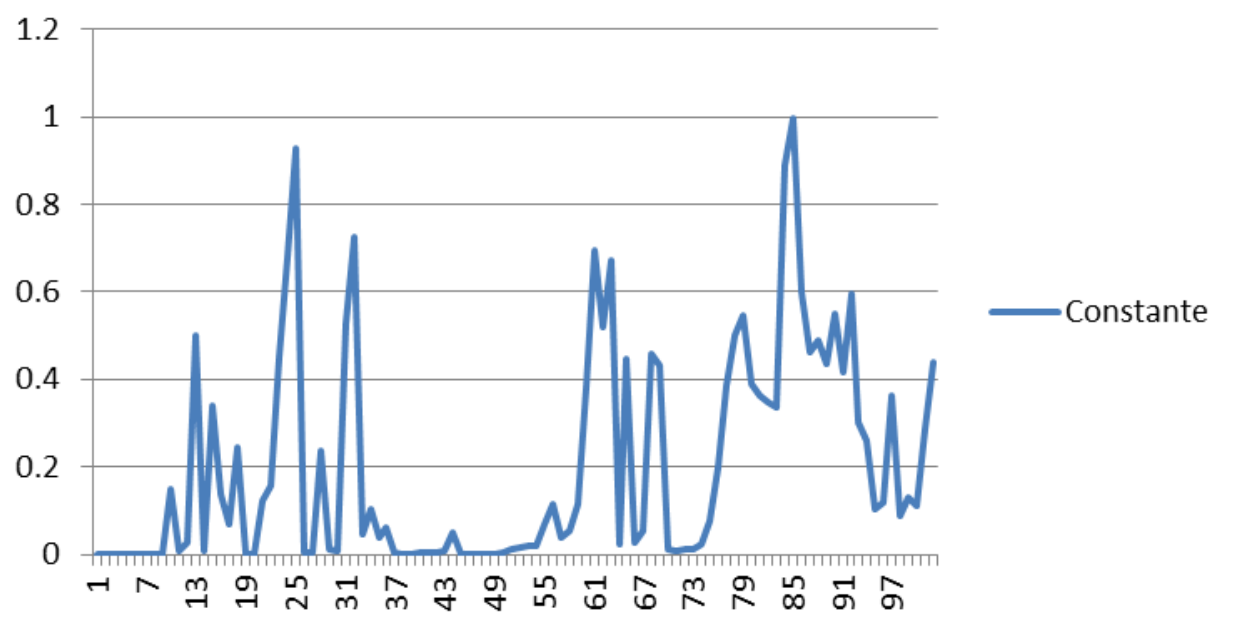

Figura 62: P-value da Constante na regressão com atraso de 5 semanas 


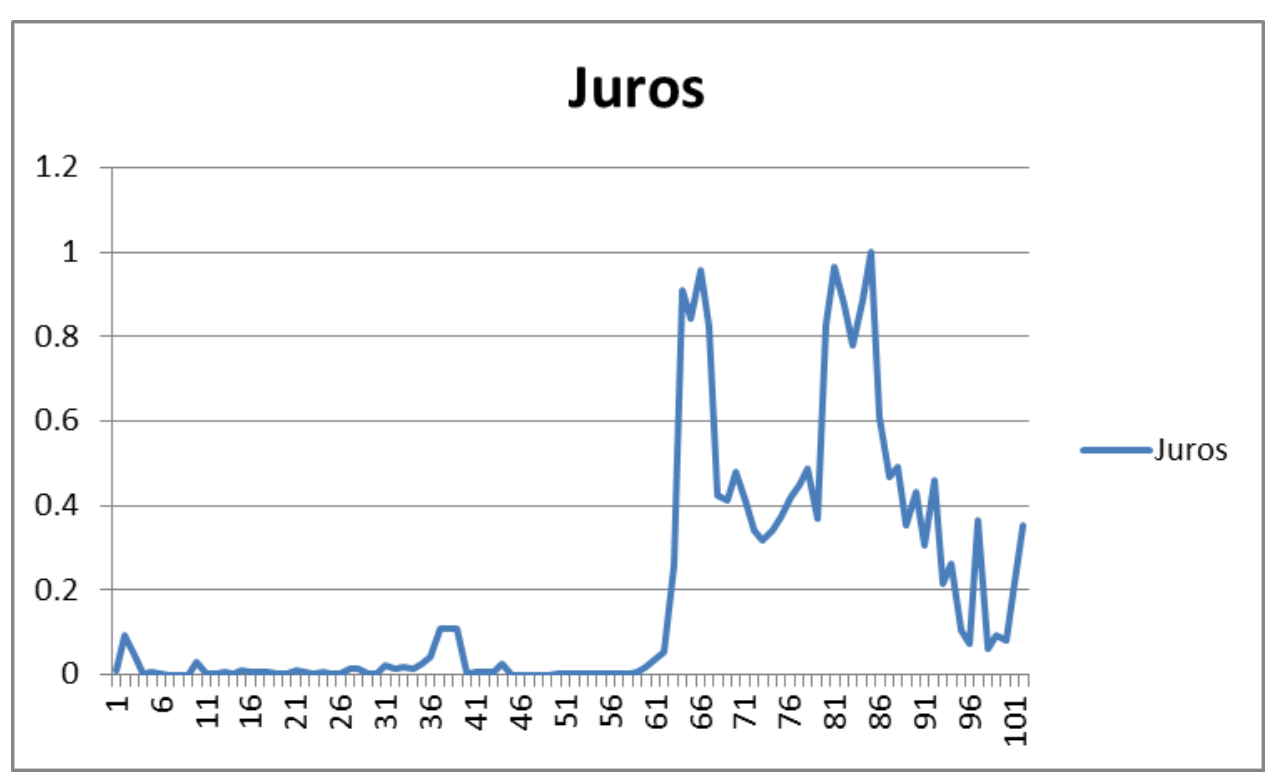

Figura 63: P-value do Fator de Juros na regressão com atraso de 5 semanas

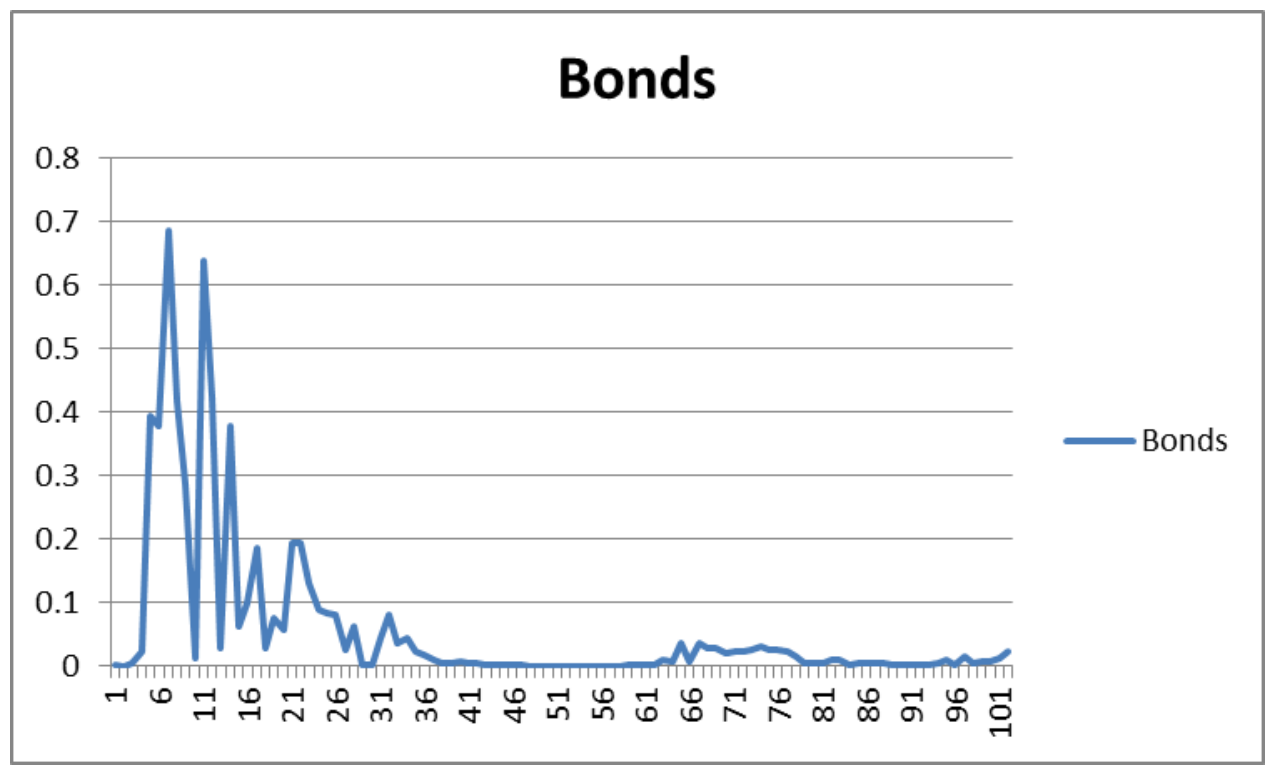

Figura 64: P-value do Fator de Bonds na regressão com atraso de 5 semanas 


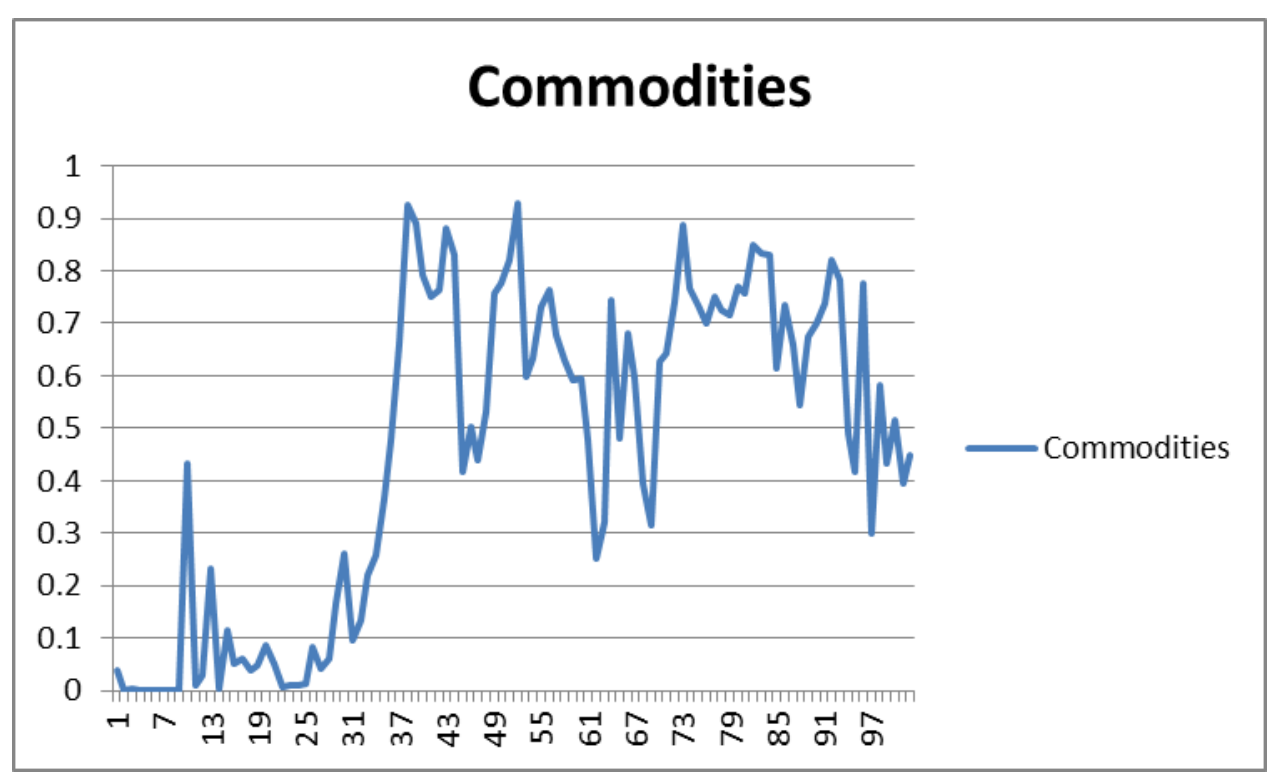

Figura 65: P-value do Fator de Commodities na regressão com atraso de 5 semanas

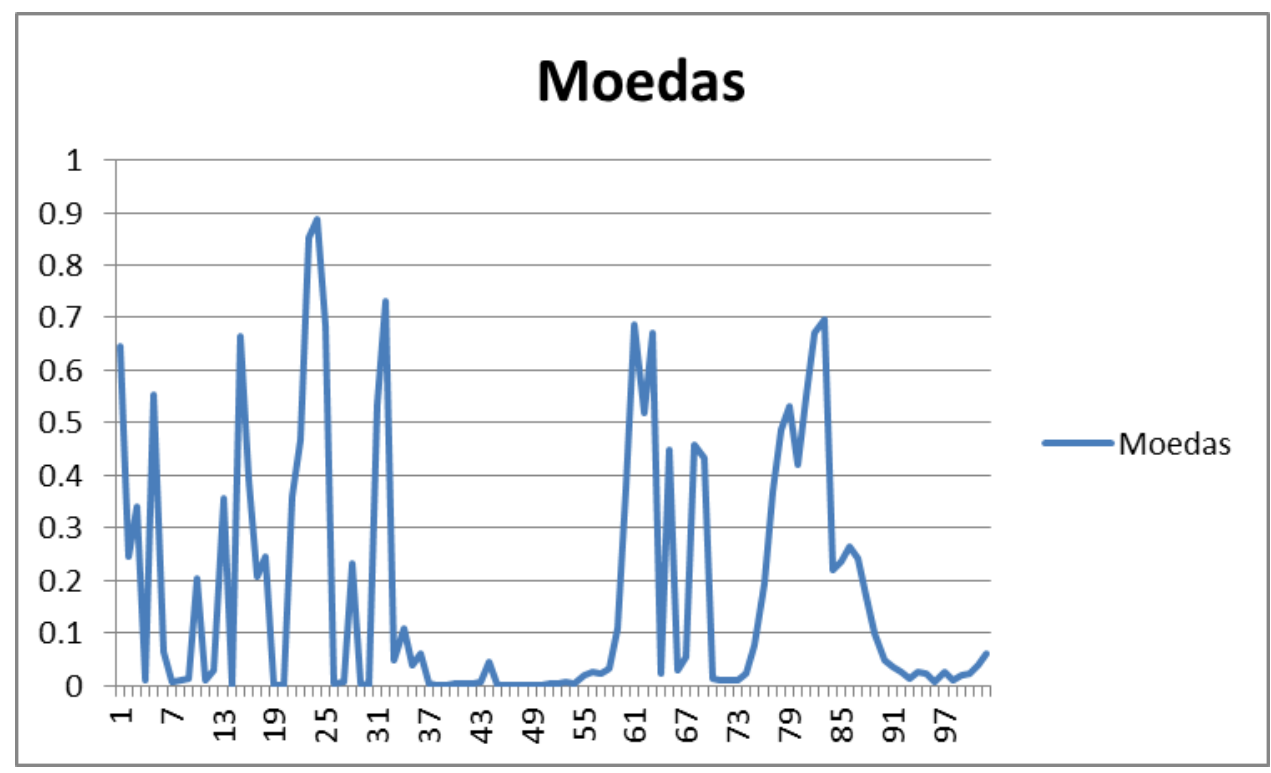

Figura 66: P-value do Fator de Moedas na regressão com atraso de 5 semanas 


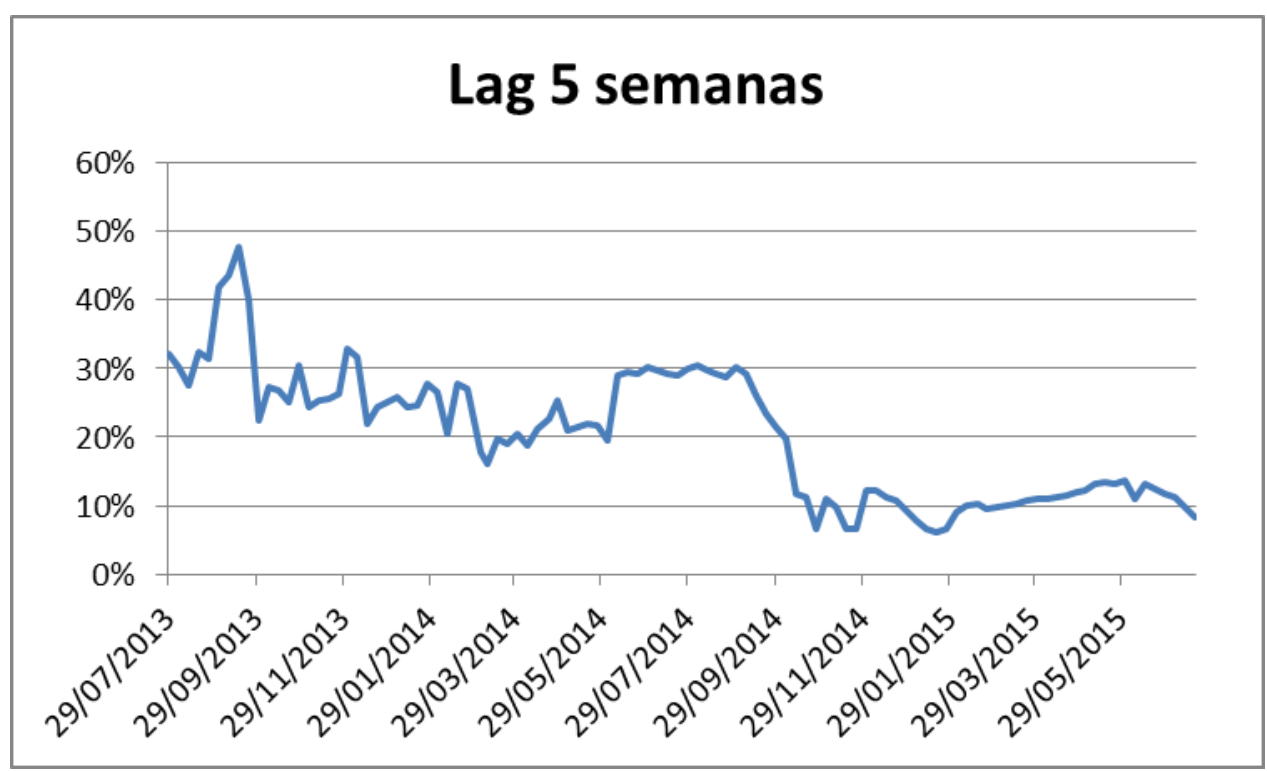

Figura 67: R Quadrado das regressões com atraso de 5 semanas

\section{Lag 5 semanas}

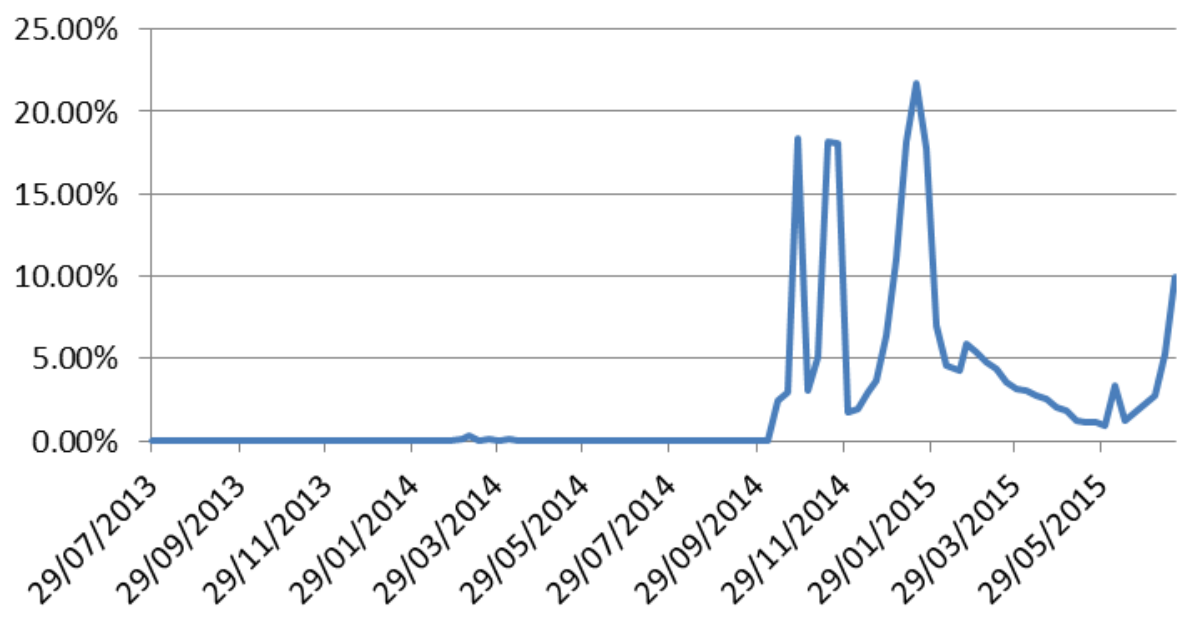

Figura 68: P-value das regressões com atraso de 5 semanas 


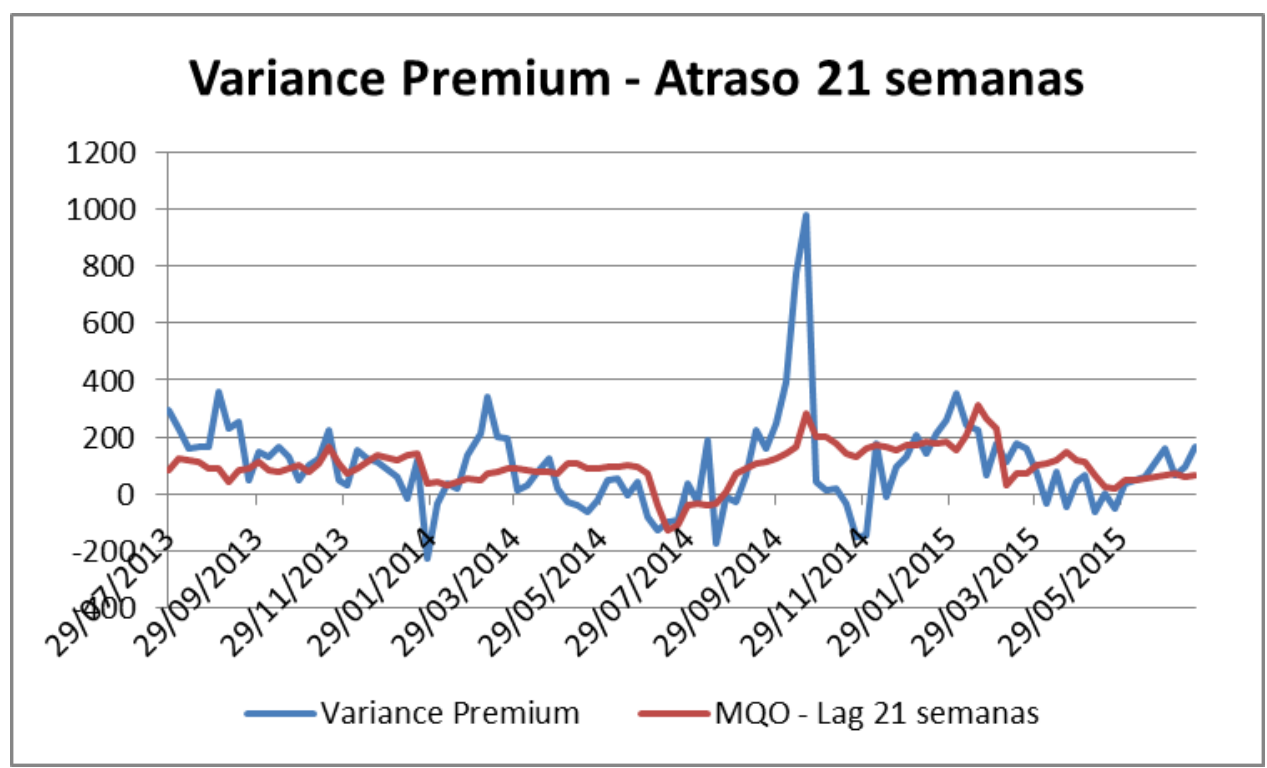

Figura 69: Regressão usando fatores com atraso de 21 semanas

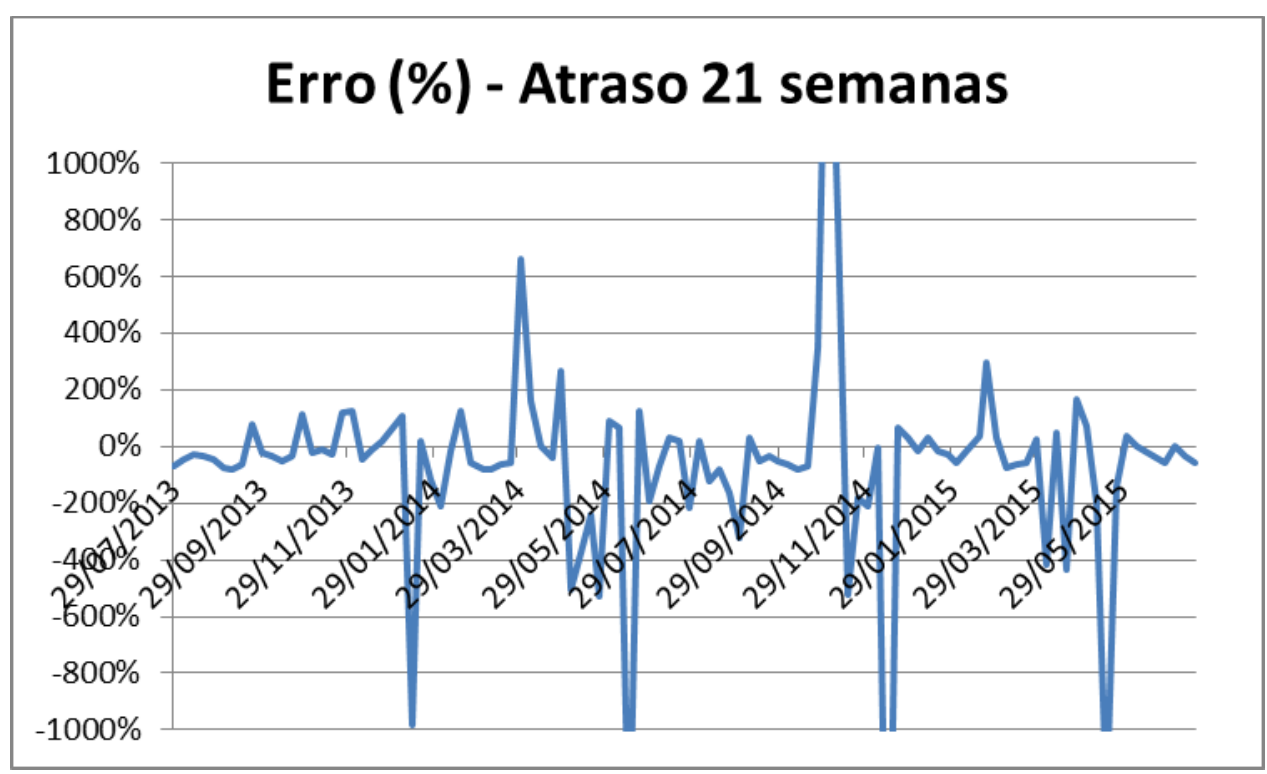

Figura 70: Erros da regressão do índice de ações - Lag 21 semanas 


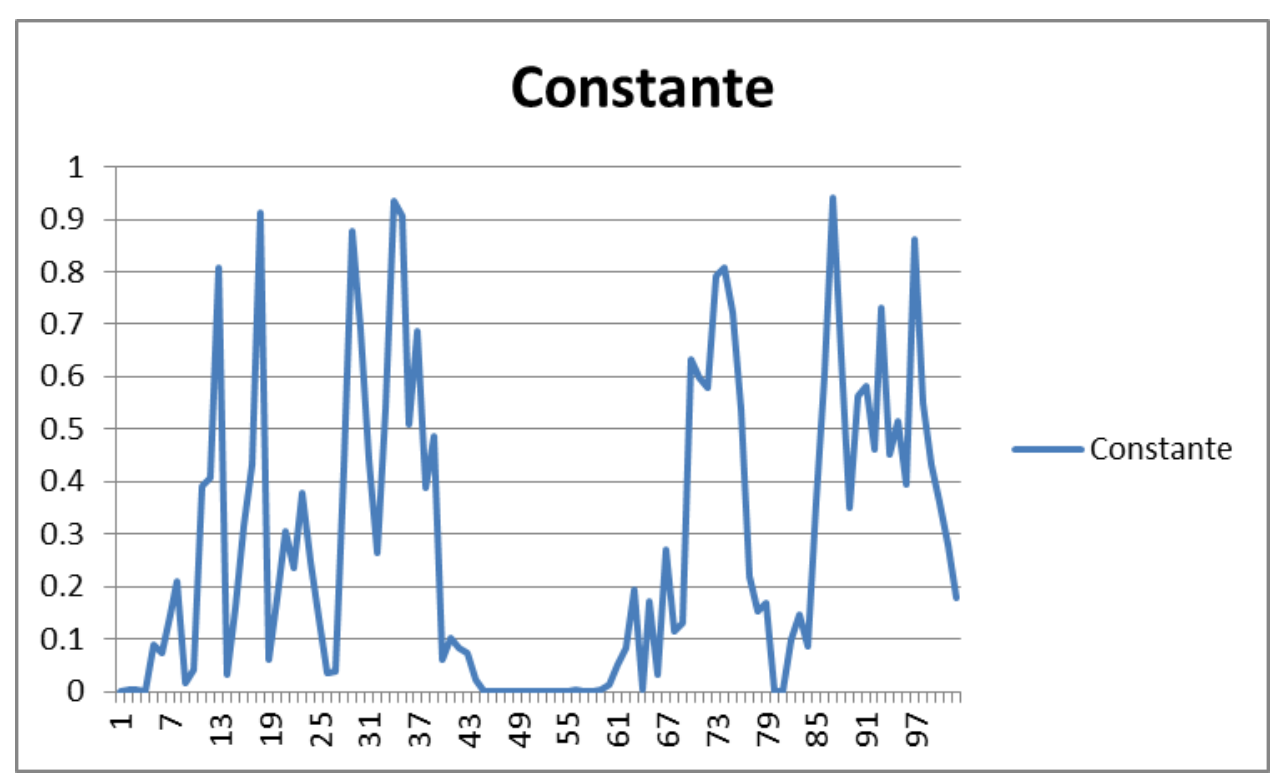

Figura 71: P-value da Constante na regressão com atraso de 21 semanas

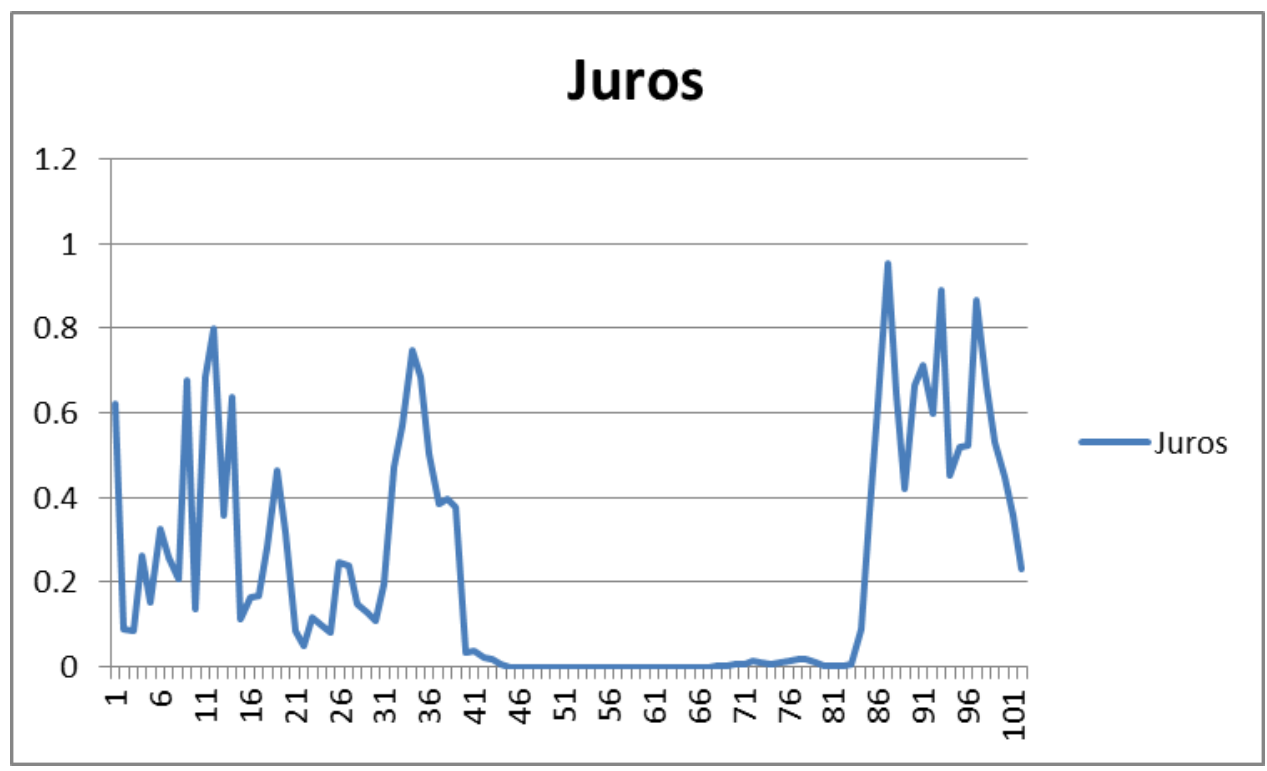

Figura 72: P-value do Fator de Juros na regressão com atraso de 21 semanas 


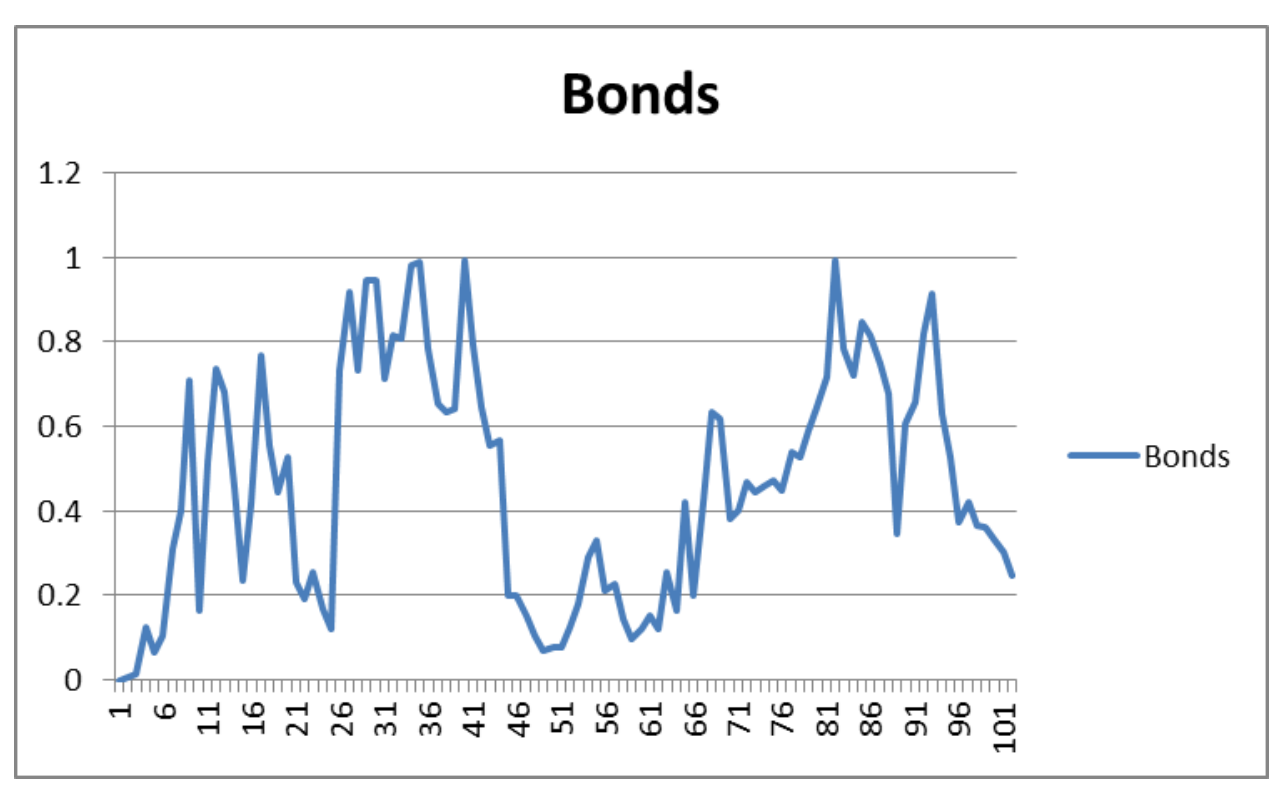

Figura 73: P-value do Fator de Bonds na regressão com atraso de 21 semanas

\section{Commodities}

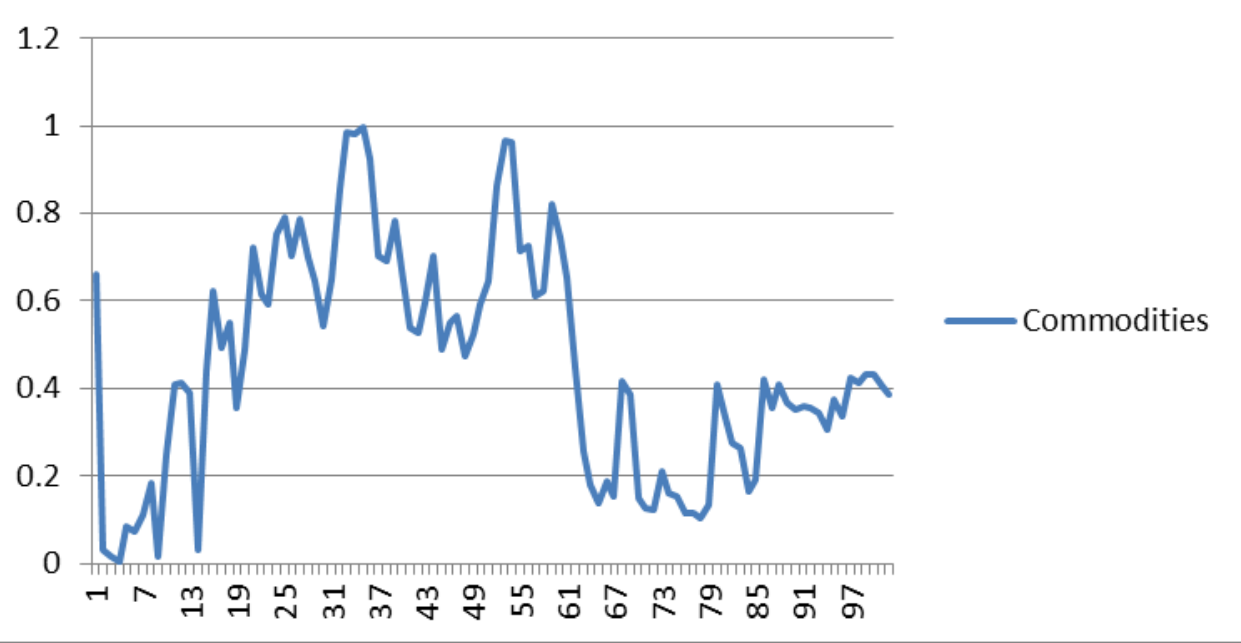

Figura 74: P-value do Fator de Commodities na regressão com atraso de 21 semanas 


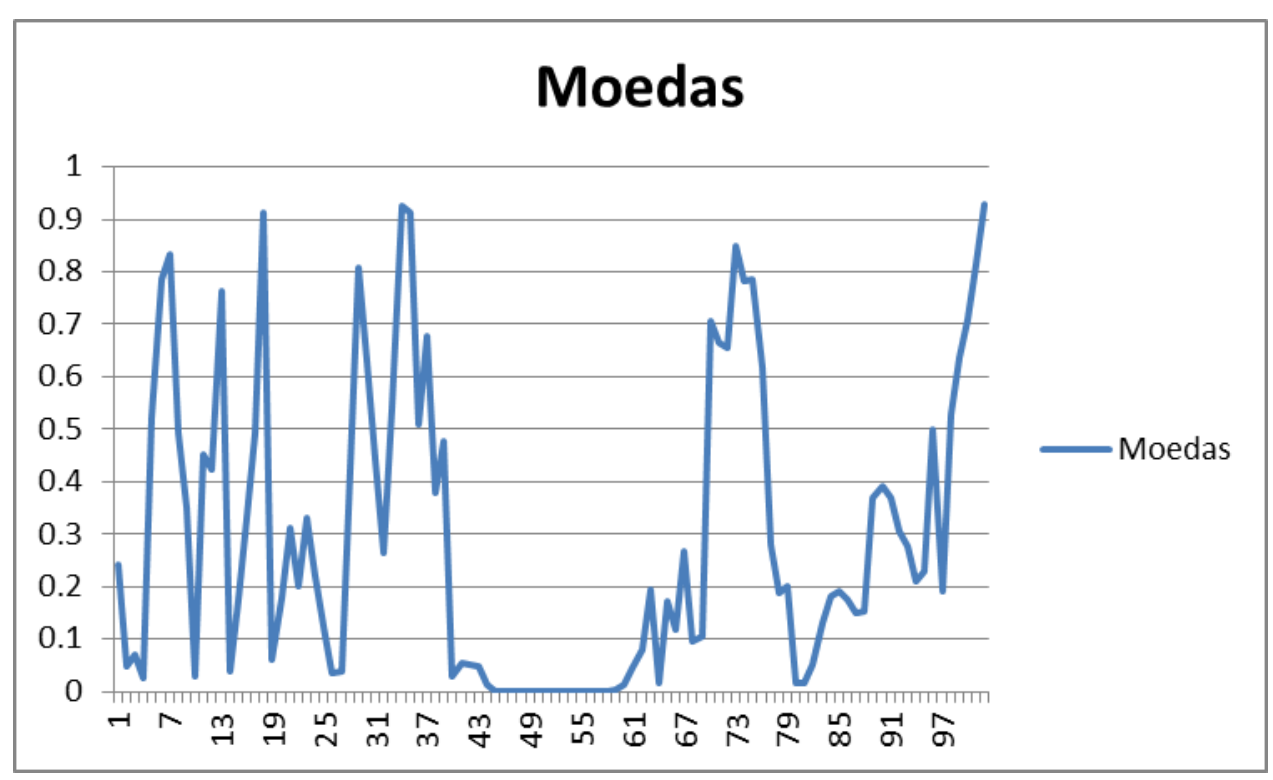

Figura 75: P-value do Fator de Moedas na regressão com atraso de 21 semanas

\section{Lag 21 semanas}

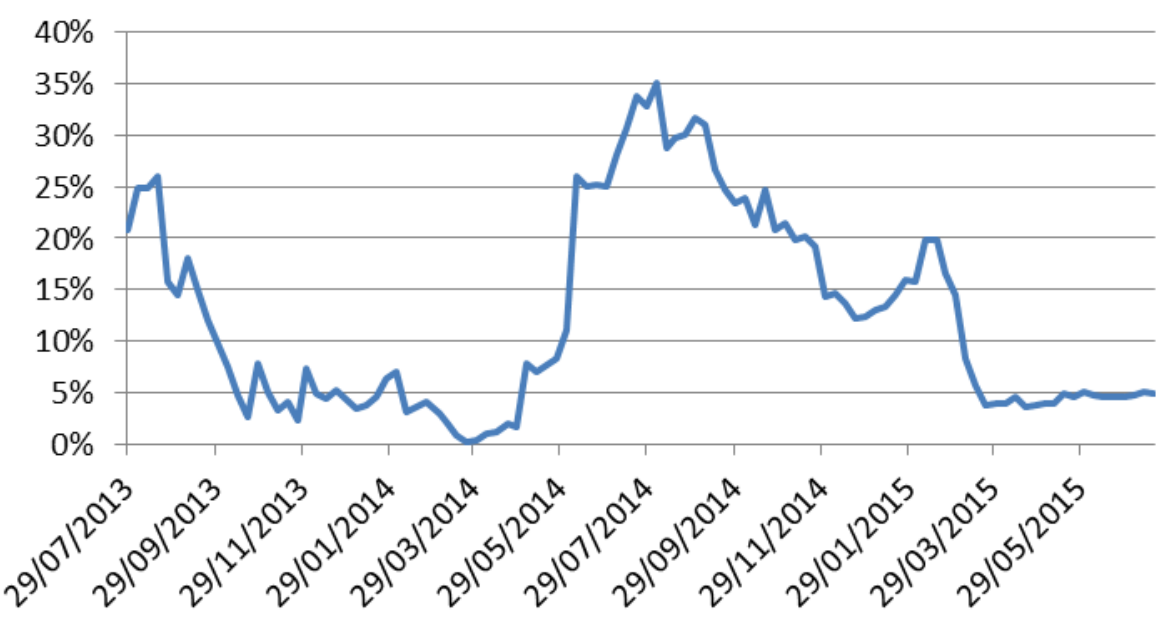

Figura 76: R Quadrado das regressões com atraso de 21 semanas 


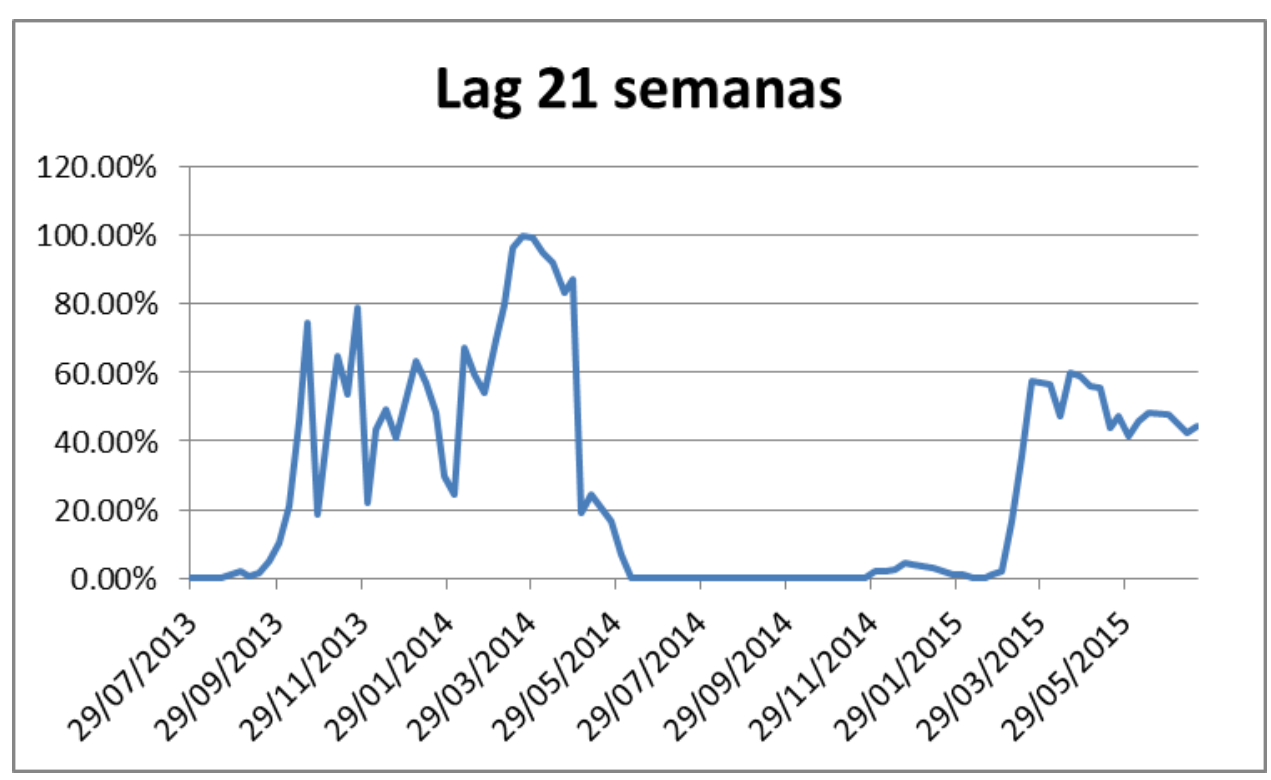

Figura 77: P-value das regressões com atraso de 21 semanas

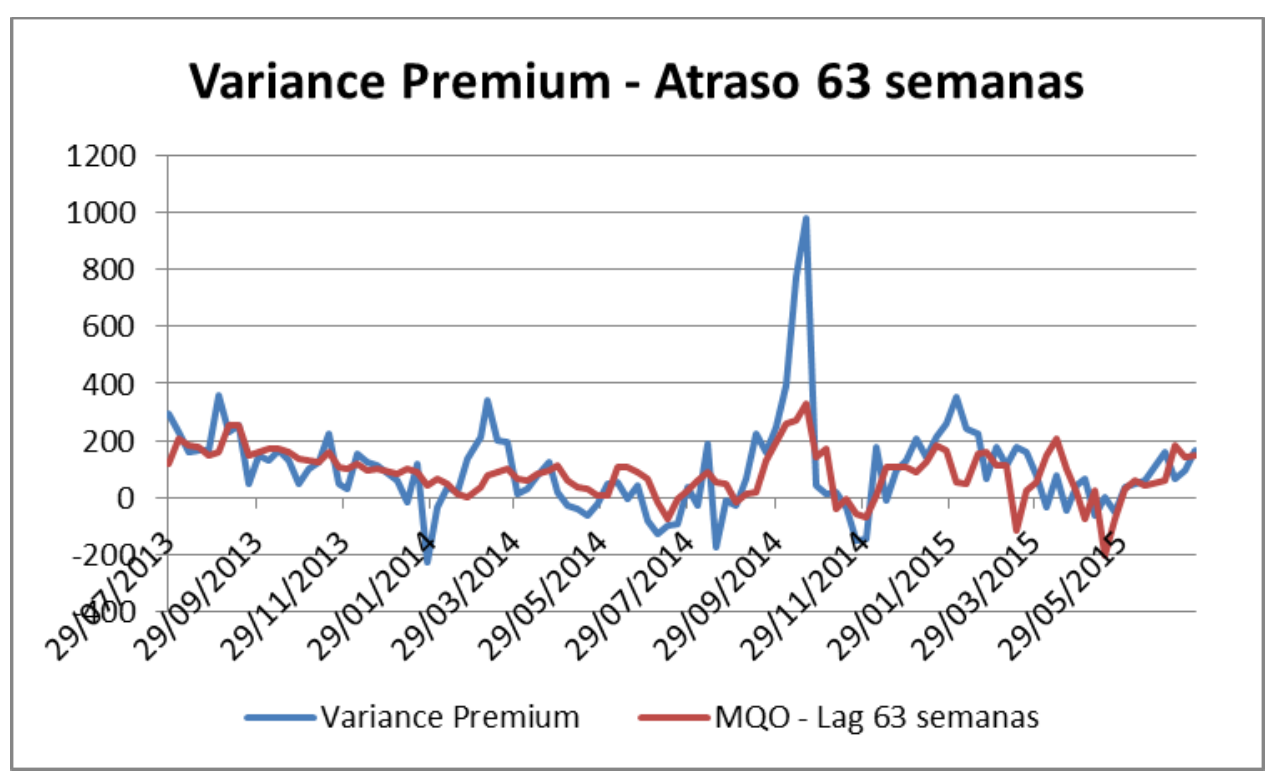

Figura 78: Regressão usando fatores com atraso de 63 semanas 


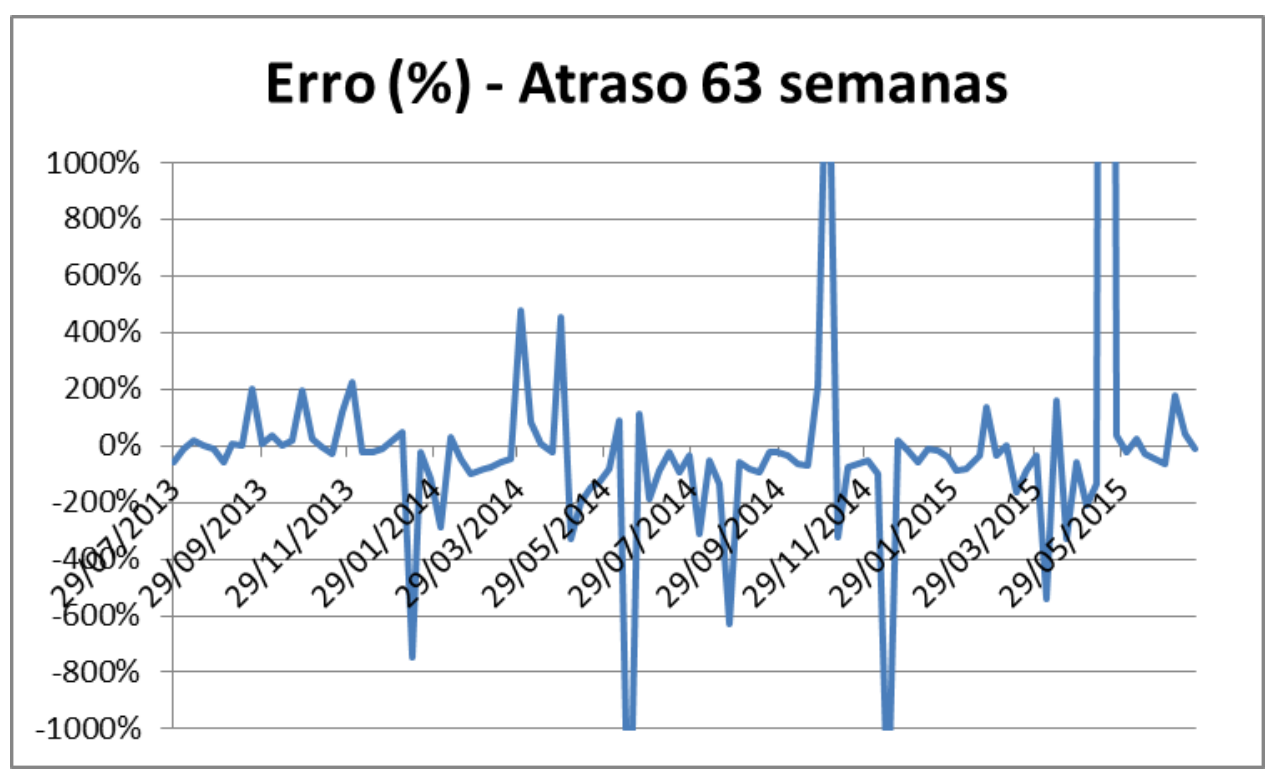

Figura 79: Erros da regressão do índice de ações - Lag 63 semanas

\section{Constante}

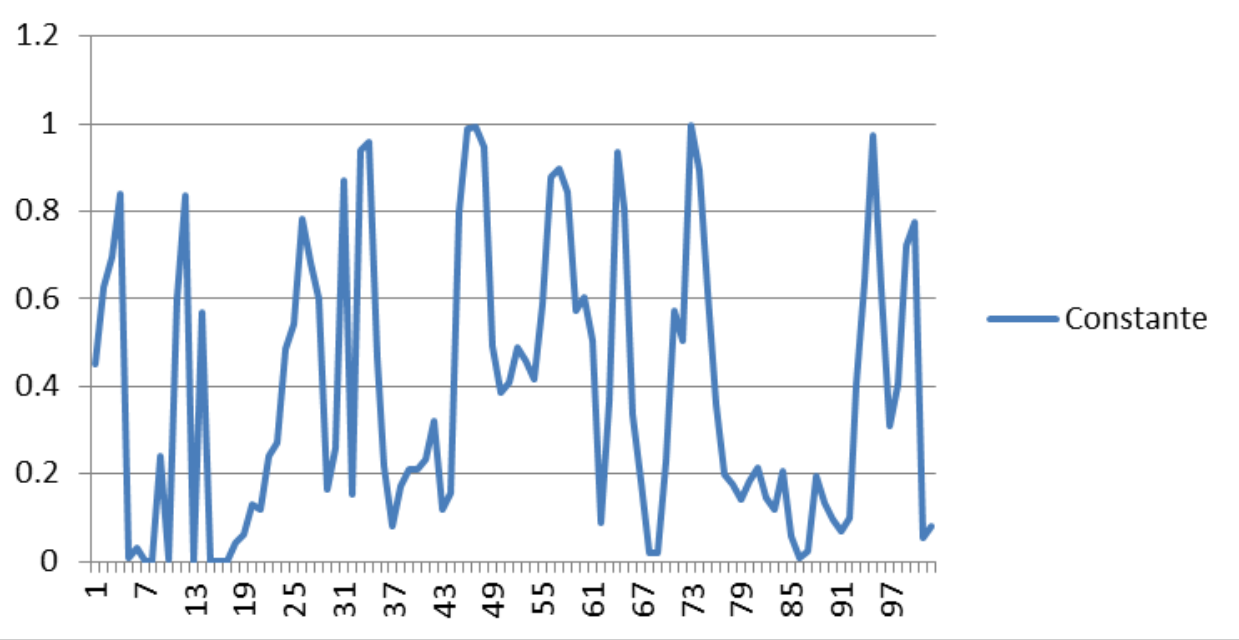

Figura 80: P-value da Constante na regressão com atraso de 63 semanas 


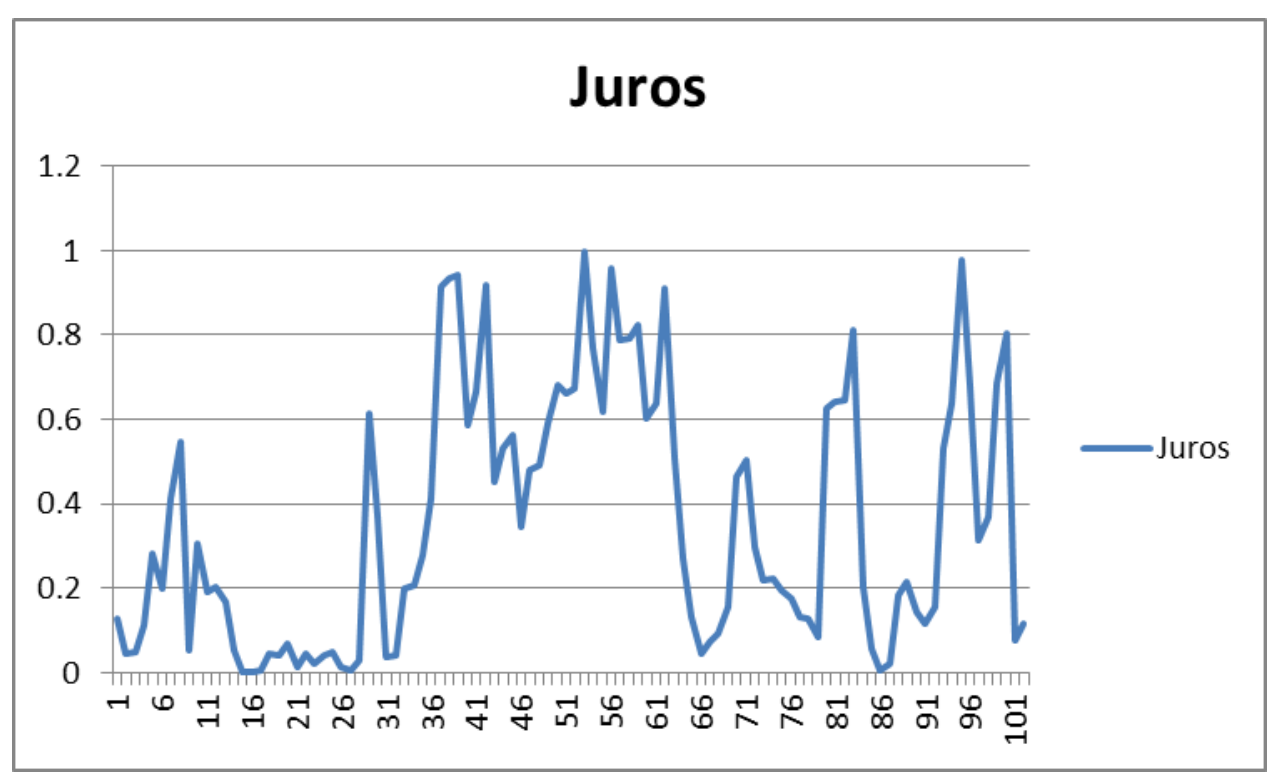

Figura 81: P-value do Fator de Juros na regressão com atraso de 63 semanas

\section{Bonds}

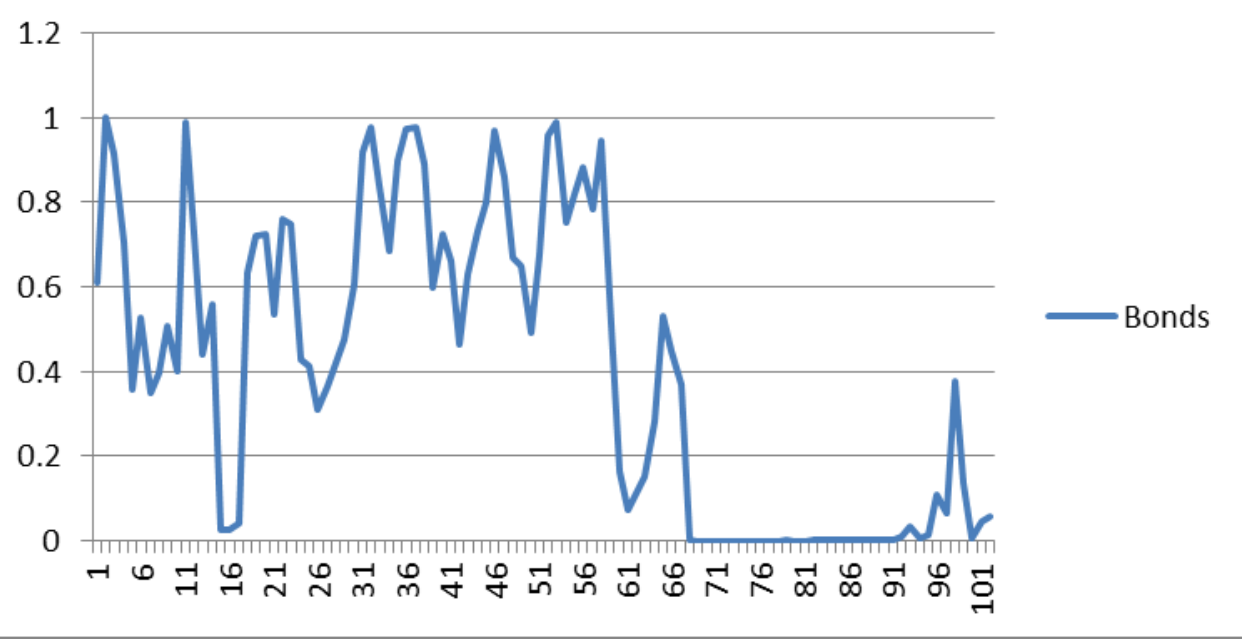

Figura 82: P-value do Fator de Bonds na regressão com atraso de 63 semanas 


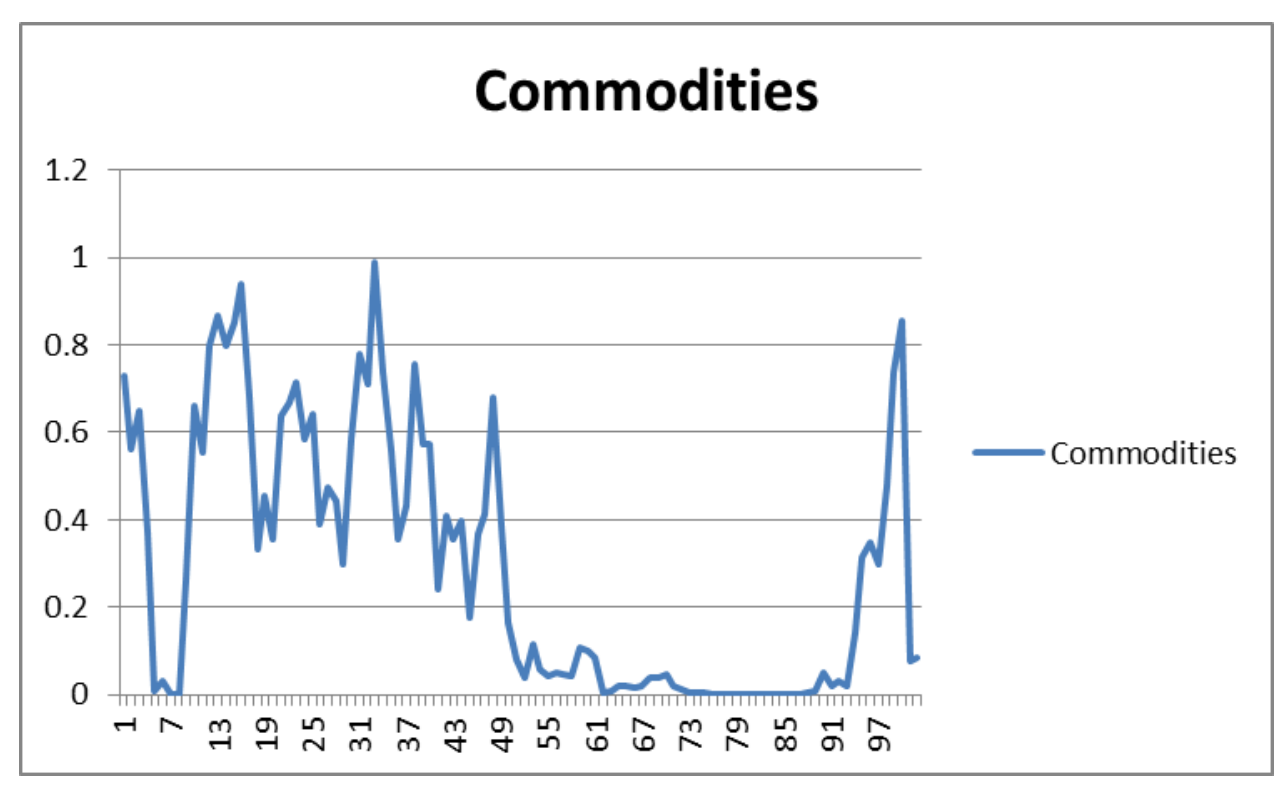

Figura 83: P-value do Fator de Commodities na regressão com atraso de 63 semanas

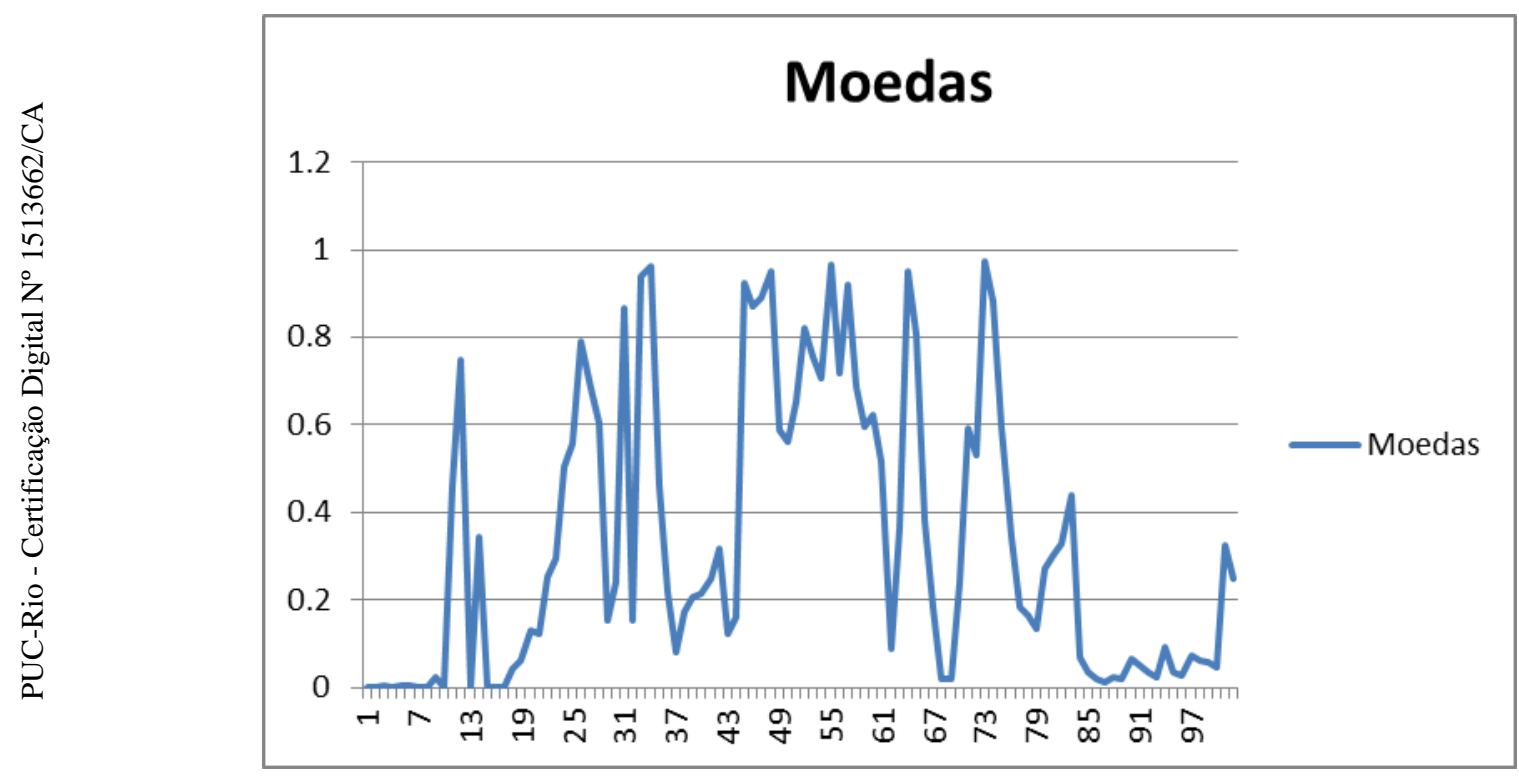

Figura 84: P-value do Fator de Moedas na regressão com atraso de 63 semanas 


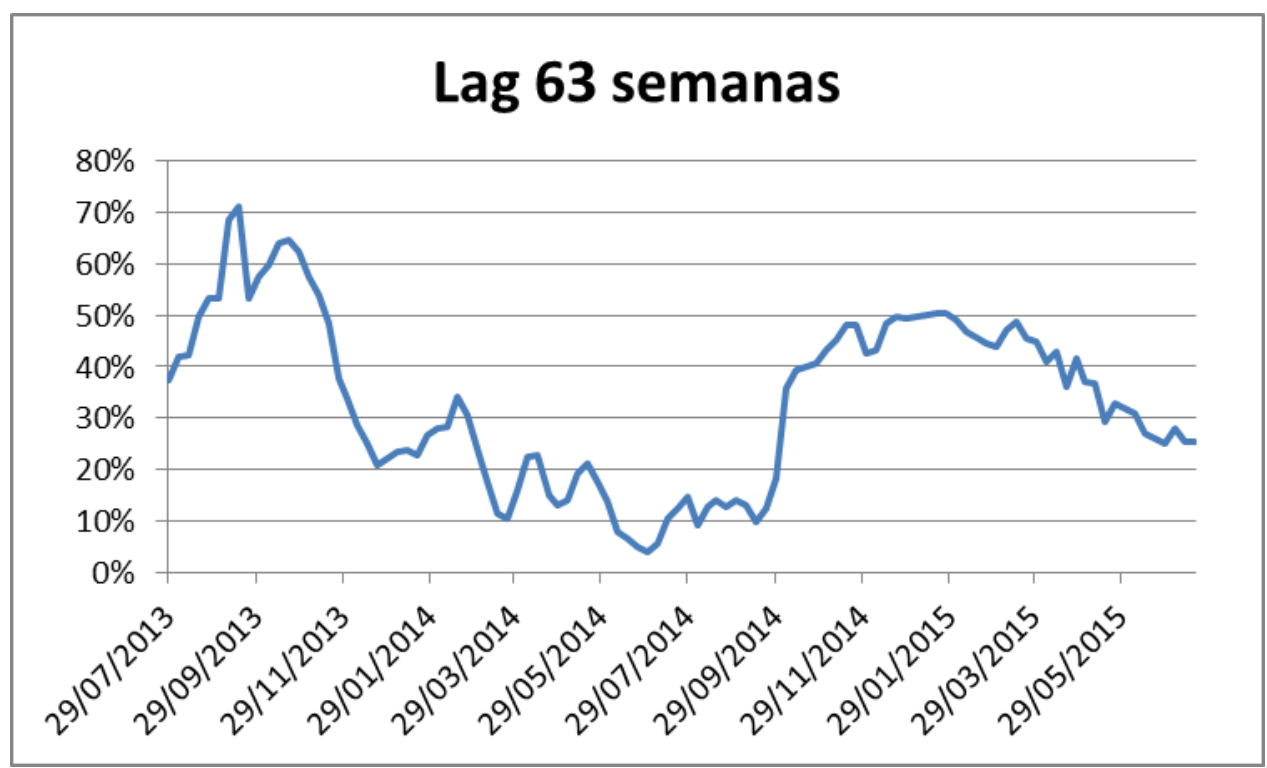

Figura 85: R Quadrado das regressões com atraso de 63 semanas

\section{Lag 63 semanas}

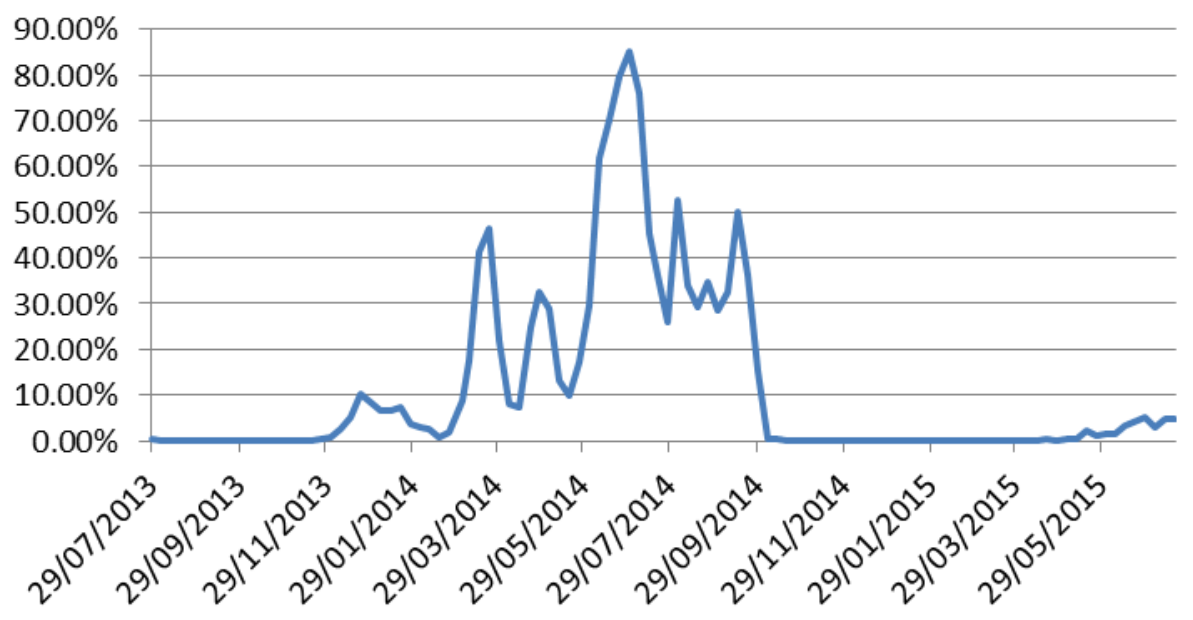

Figura 86: P-value das regressões com atraso de 63 semanas 